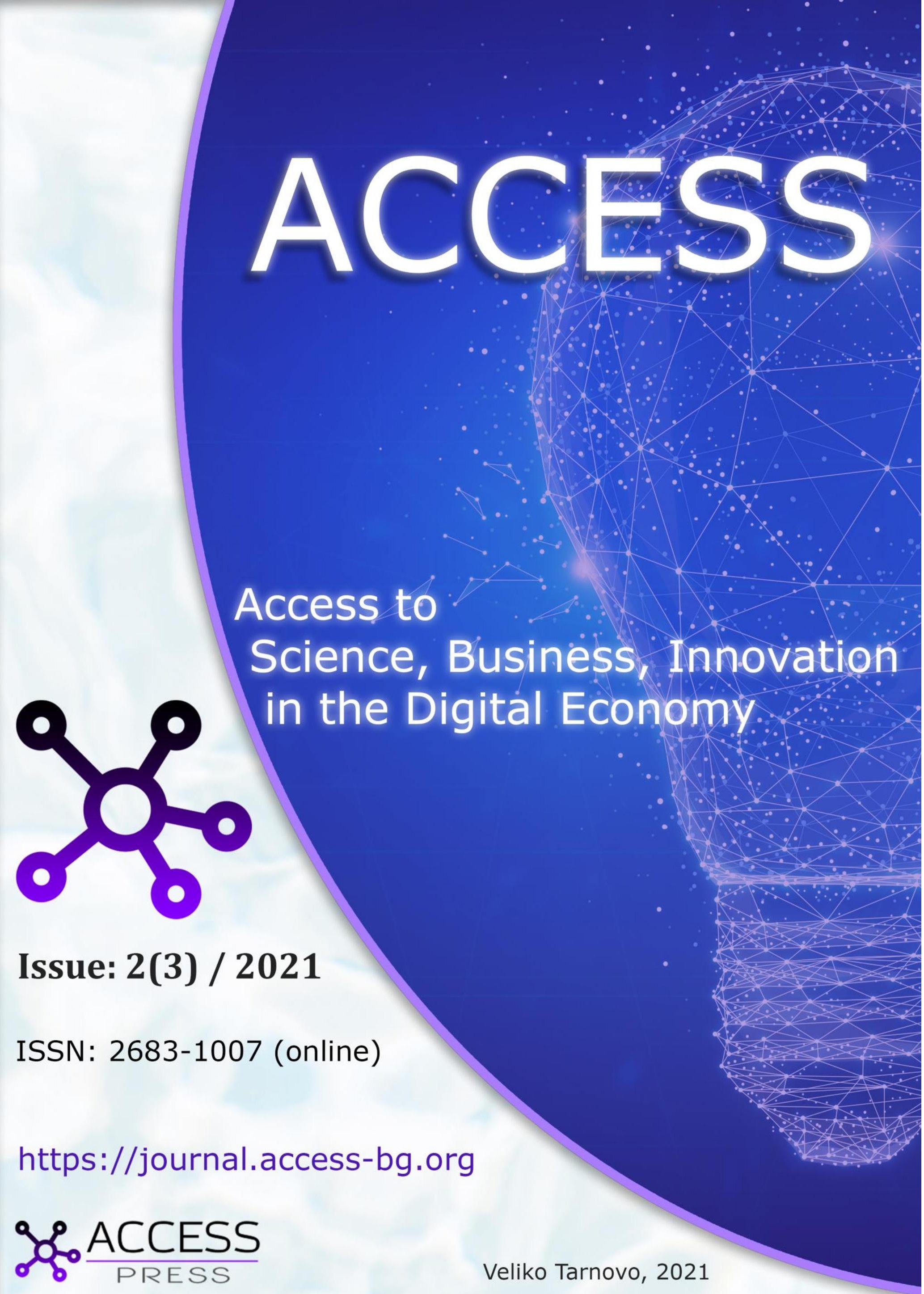




\section{ACCESS Journal:}

Access to science, business, innovation in the digital economy

ISSN 2683-1007 (online)

http://journal.access-bg.org
2021, Volume 2, Issue 3, September http://doi.org/10.46656/access.2021.2.3

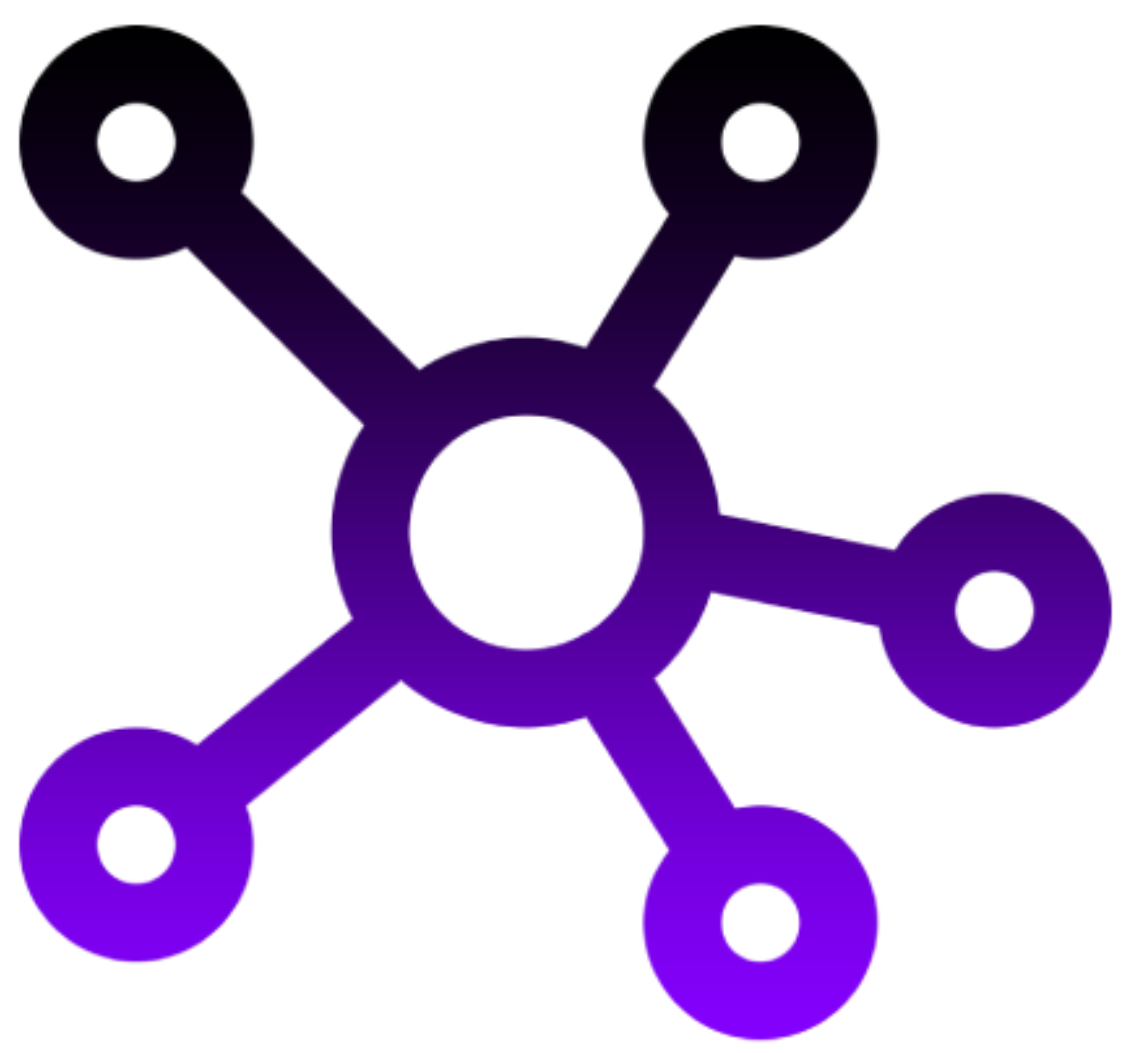

\section{Publisher:}

Publishing House "ACCESS PRESS" , Bulgaria, 2021

32 Aleksandar Burmov Str., 5000 Veliko Tarnovo, Bulgaria Email: office@access-bg.org

https://access-bg.org

ACCESS JOURNAL 
ACCESS: Access to science, business, innovation in digital economy is a peerreviewed international scientific journal, which publishes original research papers and case studies.

The Journal is designed for publishing articles includes but is not limited to the following fields of research:

Challenges of economic development of society

Innovation of the economy and enterprises, start-up activities

Risk, risk management, risk financing instruments

Finance and financial markets

Market mechanisms of entrepreneurship development

Technological Changes Management and Economic Development Management Innovation management

Management of the national and international economy

Regional competitiveness through investment efficiency

Business, Strategy and Investional Management

Management Science and Information Systems

Educational Management Challenges in Digital Environment

Global Management of Social Issues in Digital Economy

Sustainable social and economical environment of business development

Sustainable enterprise; State sustainability

Innovation on Implementation and Protection of Human Rights in Digital Environment

Innovation and technologies on the Intellectual Property rights in Digital Environment

Information, innovation and nonlinear modeling technologies, forecasting and management of processes and systems;

Cognitive modeling and management decision making in poorly structured systems. (Fuzzy cognitive modeling)

Artificial intelligence systems and technologies.

Robotics; Digital Economy.

INDUSTRY 4.O.; Industrial Internet of Things( "IoT" for I). 
Access Journal is included in The National Reference List

National centre for information and documentation
(NRL) of contemporary Bulgarian scientific publications with scientific review, maintained by the Minister of Education and Science through the National Center for Information and Documentation, Ref №: 3818

All papers published in the ACCESS Journal: Access to science, business, innovation in digital economy are listed, indexed and abstracted in:

BASE, CiteFactor, Crossref, Google Scholar, EconPapers/RePEc (Research Papers in Economics), ESJl, EuroPub, eLybrary, Index Copernicus International, InfobaseIndex, Polska Bibliografia Naukowa - portal of the Polish, Ministry of Science and Higher Education, ResearchBib, Scholar Steer, Scilit

\section{https://doi.org/10.46656/access}

ACCESS:Access to science, business, innovation in digital economy, 2021, 2(3)

Printout: 3 issues per year. Issue 1 (January); Issue 2 (May); Issue 3 (September).

Please, send your comments and opinions at: editors@access-bg.org

EDITORIAL CORRESPONDENCE including manuscripts and submissions:

\section{Prof. DSc. Mariana Petrova}

e-mail: submissions@access-bg.org or m.petrova@access-bg.org

This is an open access journal and all published articles are licensed under a Creative Commons Attribution 4.0 International License 


\section{EDITORS-IN-CHIEF:}

Mariana Petrova, St.Cyril and St.Methodius University of Veliko Tarnovo, Bulgaria e-mail: m.petrova@ 1 ts.uni-vt.bg

\section{EDITORIAL BOARD MEMBERS:}

Ludmila ALEKSEJEVA, Daugavpils University

Daugavpils LV

Alina BADULESCU, University of Oradea

Oradea $\quad$ RO

Iurie CARAUS, University of Montreal

Montreal CA

Manoj Kumar CHAUDHARY, Tribhuvan University

Kathmandu NP

Francesca DI VIRGILIO, University of Molise

Campobasso IT

Deniss DYAKONS, ISMA University

Riga

LV

Liudmyla DOROKHOVA, National University of Pharmacy

Kharkiv UA

Badri GECHBAIA, Batumi Shota Rustaveli State University

Batumi GE

Viktor KOVAL, Odessa Institute of Trade and Economics of Kyiv National

Odessa

University of Trade and Economics

Nayden NENKOV, Konstantin Preslavsky University of Shumen

Shumen $\quad$ BG

Yashar SALAMZADEH, Universiti Sains Malaysia

Penang MY

Jan-Urban SANDAL, Fil. Dr. Jan-U. Sandal Institute

Oslo

NO

Ludmila STEMPLEWSKA, Vistula University, Vistula Academy of Finance and

Warsaw

PL

Business in Warsaw

Olena SUSHCHENKO, Simon Kuznets Kharkiv National University of Economics

Kharkiv

UA

Gonca TELLI, Dogus University

Istanbul

TR

Nguyen Van TRU, Information business software consultancy (IBC)

Singapore

SG

Ho Chi Minh

$\mathrm{VN}$

Talgat UTEUBAYEV, L.N. Gumilyov Eurasian National University

Nur-Sultan

$\mathrm{KZ}$

Radostin VAZOV, VUZF University (Higher School of Insurance and Finance)

Sofia

BG

Ludmila ZAKONNOVA, T.F. Gorbachev Kuzbass State Technical University

Kemerovo

RU

\section{SCIENTIFIC COUNCIL}

\section{Sultan RAMAZANOV}

Chairman of the Scientific Council

Ryszard PUKALA

Co-Chairman of the Scientific Council

Yuriy DYACHENKO

Ketevan GOLETIANI

Janis GRASIS

Nurlan KURMANOV

Karim NAAMA

Evgeny ZHERNOV
Vadym Hetman Kyiv National Economics University, Kyiv

UA

Bronislaw Markiewicz State Higher School of Technology and Economics, Jaroslaw (PWSTE)

Volodymyr Dahl East Ukrainian National University,

Severodonetsk

Batumi Navigation Teaching University

Riga Stradins University, Riga

L.N. Gumilyov Eurasian National University, Nur-Sultan

St. Cyril and St. Methodius University of Veliko Tarnovo

T.F. Gorbachev Kuzbass State Technical University, Kemerovo
GE

LV

$\mathrm{KZ}$

BG

PL

UA

RU 
ACCESS: Access to science, business, innovation in digital economy, ISSN 2683-1007 (online)

Volume 2, Issue 3, September 2021

\section{CONTENTS}

\section{ARTICLES}

Evgeny ZHERNOV, Pavel STRELNIKOV

STORYTELLING AND SPEECH ACT THEORY IN KNOWLEDGE

MANAGEMENT: THE POTENTIAL OF SYNTHESIS

Andrii ROSKLADKA, Roman BAIEV

DIGITALIZATION OF DATA ANALYSIS TOOLS AS THE KEY FOR SUCCESS IN THE ONLINE

TRADING MARKETS

Olena LIASHENKO, Tetyana KRAVETS, Matvii PROKOPENKO

CONSUMER BEHAVIOR CLUSTERING OF FOOD RETAIL CHAINS BY MACHINE LEARNING

ALGORITHMS

Irada DZHALLADOVA, Oleg KAMINSKY, Oleksandr LUTYJ

THE IMPACT OF THE CONSEQUENCES OF THE COVID-19 PANDEMIC ON THE SOCIAL SECURITY OF UKRAINE

Stanislav PERMINOV

TRENDS IN THE DEVELOPMENT OF REGIONAL TRUST MANAGEMENT MARKETS

Galyna CHORNOUS, Yana FARENIUK

MARKETING MIX MODELING FOR PHARMACEUTICAL COMPANIES ON THE BASIS OF DATA SCIENCE TECHNOLOGIES

Nadiia GRAZHEVSKA, Tetiana GAIDAI, Alla MOSTEPANIUK, Andrii ZAVAZHENKO

INSTITUTIONAL DYSFUNCTIONS AS A FACTOR OF CONVERGENT-DIVERGENT INSTITUTIONAL DEVELOPMENT OF POST-SOCIALIST COUNTRIES

\section{REVIEWS, ANNOTATIONS, SCIENTIFIC and ACADEMIC SPEECHES}

Jan-Urban SANDAL

WHAT IS INDEPENDENCE AND HOW TO USE IT? 


\title{
STORYTELLING AND SPEECH ACT THEORY IN KNOWLEDGE MANAGEMENT: THE POTENTIAL OF SYNTHESIS
}

\author{
Evgeny Zhernov1*, Pavel Strelnikov² \\ ${ }^{1,2}$ T.F. Gorbachev Kuzbass State Technical University, Kemerovo, the Russian Federation \\ e-mails: ${ }^{1}$ zhee.eti@kuzstu.ru, ${ }^{2}$ strelnikovpa@kuzstu.ru
}

Received: 19 May 2021 Accepted: 20 June 2021 Online Published: 07 August 2021

\begin{abstract}
The problem of converting the implicit knowledge of employees into explicit knowledge of a business entity (a firm) is considered from the perspective of a combination of knowledge management theory in so far as it relate to storytelling and speech act theory. The purpose of the work is to determine the possibility and areas of application of the concept of performativity and speech act theory in knowledge management for its humanization and socialization. The object of the research is converting implicit non-formalized knowledge into explicit formalized one and explicit knowledge into implicit one as a sphere of application of speech act theory in knowledge management. The subject of the research is socio-economic and managerial relations in this area, transformed by performativity. The scientific novelty of the research lies in the identification and application of the relationship in the form of storytelling of knowledge management theory and speech act theory to develop measures for improving the efficiency of the knowledge-based firm's activities. The practical significance of the study lies in the fact that its results can be used by knowledge managers to improve the efficiency of the mechanism for converting implicit knowledge into explicit one and vice versa.
\end{abstract}

Keywords: knowledge management, humanization, socialization, John Langshaw Austin, performativity, performatives, Michael Polanyi, implicit knowledge, formalized knowledge, stories, firm.

JEL classification: D83, D91, J24, M54

Citation:

Zhernov, E., Strelnikov, P. (2021). Storytelling and speech act theory in knowledge management: the potential of synthesis. Access to science, business, innovation in digital economy, ACCESS Press, 2(3): 211-221. https://doi.org/10.46656/access.2021.2.3(1)

\section{INTRODUCTION}

Converting non-formalized knowledge into formalized one and the reverse process - converting formalized knowledge into non-formalized one continues to be an urgent problem in knowledge management. Moreover, the first process is, in a way, an end in itself for knowledge managers in a business entity (a firm). The main means of expressing knowledge in this continuous process of converting in both directions is language. The knowledge of an employee, expressed in professional language, is the object of knowledge management and storytelling as its tool.

According to M. Foucault's hypothesis, the image of a person in modern knowledge is outlined by three types of empirical objects: Life, Labor and Language (Foucault, 2001). Knowledge management pays much attention to language in storytelling, which is interpreted as a tool for transferring knowledge in the working

*Corresponding author, Evgeny Zhernov - zhee.eti@ kuzstu.ru 
environment. In production processes, it is especially important to adhere to the principle of "word - action", which forms the basis of performativity. The concept of performativity has not yet been included into knowledge management, although storytelling is actively used there. But, in our opinion, this concept should be used as a form of changing the status of knowledge from a description of a situation to an action, since a performative is an utterance equivalent to an action.

J. Austin's performativity thesis in combination with M. Polanyi's implicit knowledge theory are the prerequisites for a new approach to solving the problem of converting non-formalized knowledge into formalized one in knowledge management. It allows us to give due place to economic and management theories and techniques, which are increasingly actively shaping and structuring economic practices. However, they do not yet contribute to the humanization and socialization of a firm, which is most clearly seen in the example of converting implicit knowledge of employees into explicit knowledge of a firm.

Research hypothesis: reciprocal explicit and implicit knowledge conversion in a firm changes economic and managerial reality in the direction of socialization and humanization thanks to language - knowledge as a word, a word as an action.

The scientific novelty of the work lies in the application of the concept of performativity, which then developed into speech act theory, to the theory and practice of knowledge management in conjunction with M. Polanyi's implicit knowledge theory for the humanization and socialization of knowledge management.

The purpose of the work is to determine the potential of the synthesis of storytelling and speech act theory for the development of knowledge management in the direction of humanization and socialization, to use the potential of their symbiosis to increase the efficiency of the exchange of formalized knowledge and the transfer of non-formalized knowledge (skills) when improving competencies and mastering functions.

Tasks: 1) to find the possibility and area of application of the concept of performativity and speech act theory in knowledge management, 2) to determine the reciprocal conversion of formalized and nonformalized knowledge as an area of application of the concept of performativity and speech act theory in knowledge management for its development.

M. Polanyi implicit knowledge concept in combination with the concept of performativity of J. Austin the founder of speech act theory - was used to achieve this objective and solve problems.

\section{MATERIALS AND METHODS}

The experience of theoretical research shows that to solve an existing research problem, as well as a new problem, it is possible to use suitable ideas from other scientific fields. When trying to cope with a complex economic problem, familiar mental schemes that are not obviously related to economics and management are used. In economic and management terms, the borrowed principles first acquire a different meaning, and then are transformed into new functions. Thus, the known principles of functioning of non-economic social institutions are increasingly used when solving economic and managerial problems. In the framework of this study, we consider language as such a tool. 
The study showed that storytelling is a concentrated practical application of language in knowledge management. Broadly speaking, storytelling is "a sophisticated approach to managing the flow of communication and understanding within an organization" (Lesser \& Prusak, 2005). Storytelling is the direct application of language in a firm. Managers at companies such as IBM, Disney, CapGemini, Ernst \& Young, Aventis, and others exploit cautionary stories to their fullest potential (Edvinsson, 2002) to generate profits and increase firm value.

Speech act theory and performativity concept seem to be the most productive linguistic approaches in the context of this article. Researchers agree that the concept of "performativity" was first introduced into science in 1950 by the English philosopher John Langshaw Austin, the author of speech act theory (Austin, 1972). Studying the types of "utterances", J. Austin developed speech act theory, in which he considered a speech act carried out in direct communication with an interlocutor as a unit of communication, which was the object of his research.

The author developed performativity concept and speech act theory as part of analytical philosophy; his speech act theory became a key component of linguistic pragmatics. A distinctive feature of AngloAmerican analytical philosophy is the pursuit of logical accuracy and linguistic transparency when formulating problems and their solutions. This desire makes this science related to Anglo-American management. The philosopher associated a speech act with the expression of an assertion, explanation, description, etc., and believed that it proceeds according to generally accepted principles and rules of behaviour. J. Austin adhered to the position of scientists who saw the main task of philosophy in clarifying and refining the expressions of everyday language, which implies an analysis of its incorrect application. Austin defined a performative as a judgment equal to an action.

The discovery of "performatives" is of great importance for knowledge management. So, Austin noticed that the first person singular verb cancels the function of truth or falsity of an utterance and becomes reality itself. As in everyday and business speech, language is used as a tool for performing various actions: greetings, promises, giving orders, etc. Saying such phrases, a person does not describe the action, but performs it. Such expressions as "I promise you", "I refuse", "I demand" are examples of a performative. There are quite a lot of similar expressions that can be used performatively in the language of a manager, and they cannot but affect the efficiency of his or her work.

Performatives, which at the time of their uttering already perform an action, as methods of practical use of language in the form of management orders are applicable to transform an organization. They also include exclamations that create an emotional background that is important in any communication. Obviously, performatives make a lot of sense for knowledge management, although they are neither true nor false.

The recognition of the limits of applicability of the concept of truth for the assessment of utterances is one of the consequences of speech act theory that are important for knowledge management. As the analysis of J. Austin has shown, the concept of truth is generally not applicable to performative utterances. They are not utterances related to any facts, and therefore cannot be "true" or "false" in the scientific sense (Austin, 
1972; 1975). Like any other human action, a performative can be felicitous (in management terminology effective) or infelicitous, but in no way true or false. For example, a dishonest or illegal labour contract with a knowledge worker, formally called an effective contract, is in reality more likely a bad - invalid, ineffective - contract than a false or untrue one.

Felicitous performative utterances are expressions that produce the desired effect. At the same time, the felicity of a performative depends on a number of conditions, called by J. Austin "felicity conditions". These basic conditions are: 1) the presence of a conventional procedure, a kind of rules of the game, according to which the utterances are made; 2) compliance with these rules by the speaker; 3) the speaker has thoughts, feelings and sincere intentions to take appropriate actions. The absence of such intentions, thoughts, and feelings means that there are invalid speech actions (Austin, 1972; 1975). Thus, depending on the type of performative infelicities, infelicitous utterances can also be interpreted as insincere, invalid, unauthorized, erroneous, etc. What has been said entirely concerns managers in knowledge management, for whose work the unity of thought and word, thinking and speech is of paramount importance. In our opinion, the opposite is also true: insincere utterances lead to erroneous actions.

Statements, promises, responsibility are an integral part of the work of a manager at any level and in any area, especially such an important one as intellectual knowledge-based activity. In knowledge management, word and action are important interrelated elements of the management process. According to M. Foucault, knowledge is a historically contingent system of ordering things through their correlation with words (Foucault, 2001). The logical chain here is as follows: word - knowledge - word - deed (action). Turning to speech act theory will help to explore the gaps between word, knowledge and action. The use of performatives - utterances equivalent to actions - in the practice of knowledge management narrows this gap. The concept of performativity and speech act theory are useful in knowledge management primarily for understanding the human aspect of socio-economic and managerial relations in the processes of reciprocal conversion of formalized and non-formalized knowledge.

According to the thesis about the performativity of economics, the dissemination of economic knowledge and related techniques significantly transforms economic practice, thereby confirming the reality of economic theories. It seems that this thesis is all the more true for management technologies in the economic sphere. Management practices in this area are described by Pfeffer and Sutton (Pfeffer \&Sutton, 2000). Their presence indicates the possibility of applying the concept of performativity in knowledge management as a type of functional management.

The similarity between the ideas of S. Denning's book "The Springboard: How Storytelling Ignites Action in Knowledge-Era Organizations" (Denning, 2000) with J. Austin's book "How to Do Things with Words" (Austin, 1975) can be traced in the titles of the books. From "true descriptions" to "felicitous actions" are the principles of knowledge management in terms of storytelling and performativity. Studying the similarities and differences, a new approach to solving the problem under study can be proposed. 


\section{RESULTS AND DISCUSSION}

To solve the first problem of this study - to determine the possibility and area of application of speech act theory in knowledge management - let us compare speech act with storytelling in terms of their influence on the knowledge conversion processes (Table 1).

Table 1. The influence of storytelling and speech act on the processes of converting non-formalized knowledge into formalized knowledge and vice versa

\begin{tabular}{|l|l|l|}
\hline \multicolumn{1}{|c|}{ Tools } & \multicolumn{1}{|c|}{ Storytelling } & \multicolumn{1}{c|}{ Speech act } \\
\hline 1. Implicit to explicit & $\begin{array}{l}\text { Stories are ideal carriers of tacit } \\
\text { knowledge, a way to combine verbal } \\
\text { and visual information. Encouraging } \\
\text { action by telling the moral-based } \\
\text { story about implicit knowledge. }\end{array}$ & $\begin{array}{l}\text { A means of encoding information, a } \\
\text { verbal form of stories that helps } \\
\text { them be richer, increasing the } \\
\text { strength and duration of impact. } \\
\text { Development of the lexicon of the } \\
\text { organization, the language model of } \\
\text { the organization. }\end{array}$ \\
\hline 2. Explicit to Implicit & $\begin{array}{l}\text { Impact on consciousness and } \\
\text { subconsciousness in order to change } \\
\text { behaviour. Transfer of skills with a } \\
\text { lot of tacit knowledge. Reproducing } \\
\text { the experience of others. }\end{array}$ & $\begin{array}{l}\text { Transfer of knowledge in } \\
\text { understandable language using } \\
\text { refined terminology. Use of } \\
\text { motivating words. Descriptive self- } \\
\text { awareness. }\end{array}$ \\
\hline
\end{tabular}

Source: Own compilation

The verbal form of stories in knowledge management indicates the possibility of applying speech act theory there. The performative use of linguistic expressions (speech acts) differs from the descriptive use in the form of storytelling. The storytelling method formalizes only a certain part of tacit (implicit) knowledge, which is beneficial to the manager and owner of the company. And the rest of the tacit knowledge of workers is formalized by the methods of speech act and performative.

A comparative analysis of storytelling and speech act (performative) made it possible to find what is common in them: 1) the speaker's belief in what is being said, 2) motivation by oral stories to action, 3) similar conditions for the felicity of performative and storytelling

Differences: 1) the knowledge management language texts, like the science language texts, should be explicit, that is, they should not allow ambiguity, inaccuracy, incompleteness, reticence, and subtext. Guessing is not allowed here. Subtext or implicit content is a piece of information that is not directly expressed in the linguistic signs that make up an utterance, but is somehow extracted from it. All communication participants make such an extraction in different ways. The subtext of an utterance cannot be consciously perceived by the addressee if it is not meaningful and motivating for him. A good manager is, above all, a motivator. And storytelling is a powerful tool for motivating, inspiring staff, influencing the consciousness and subconsciousness of employees; 2) the selectivity of the language in the use of performatives should be taken into account. So, for example, you can say, "I am begging you", but this will not be an act of begging. Or let's consider "I'm trying to persuade you". This will be, for example, a story: "I 
have been persuading you for two hours", - you can say so. But "I'm trying to persuade you" is impossible to be said as a persuasion (Austin, 1972; 1975).

Thus, we link the possibility and area of application of performativity concept and speech act theory in knowledge management with storytelling as a tool for converting knowledge for its practical use in a firm. We consider storytelling, speech act and a performative as a linguistic addition to knowledge management, a kind of human (anthropic humanistic) prism of rational analysis in this type of functional management.

The second problem of this study is to determine the reciprocal conversion of formalized and nonformalized knowledge as an area of application of performativity concept and speech act theory in knowledge management for its development. To solve it, we will use the technique for determining the purpose of storytelling, proposed by (Weil, 1998). The author believes that it consists in giving answers to three simple questions: "Who am I? Who are we? Where are we going?" (Edvinsson, 2002).

Answering these questions, let us designate two areas of application of speech act theory and performativity concept in knowledge management: 1) the answer to the question "Who am I?" implies the sphere of anthropic origin (in the Figure 1 it is designated as AO), which means humanization; 2) the answer to the question "Who are we?" is associated with the sphere of social order (in the Figure 1 it is designated as $\mathrm{SO}$ ), that is, with socialization. The answer to the question "Where are we going?" in the processes of cognitive conversion is to an increase in the knowledge of the firm's employees. This is clearly shown in the Figure 1.

Humanization Socialization Humanization

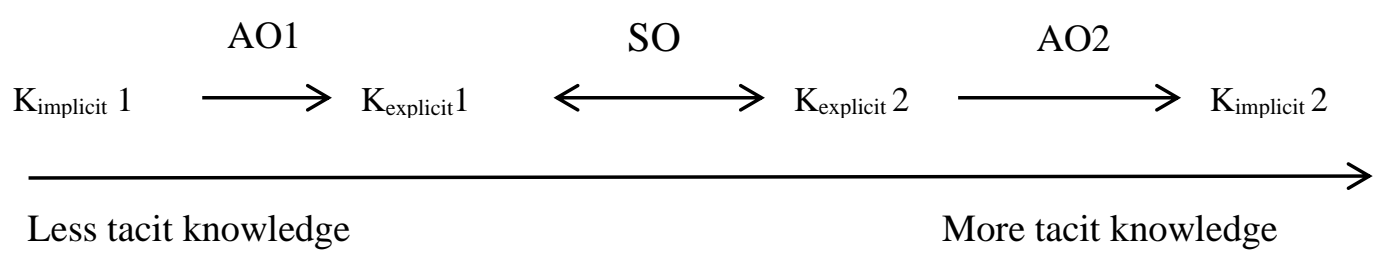

Fig. 1. The continuum of knowledge in a firm in reciprocal cognitive conversion processes Source: Author's illustration

It can be seen from the Figure 1 that through the conversion of knowledge in a firm, an increment of knowledge occurs:

$\mathrm{K}_{\text {implicit }} 2=\mathrm{K}_{\text {implicit }} 1+\Delta \mathrm{K}$ from knowledge conversion,

where $\mathrm{K}_{\text {implicit }} 1-$ implicit knowledge of the employee before conversion,

$\mathrm{K}_{\text {implicit }} 2$-implicit knowledge of the employee after conversion,

$\Delta \mathrm{K}$ - increment of knowledge in the process of exchange of explicit knowledge between employees. 
Implicit, non-formalized knowledge is transferred directly through actions, here a person is perceived at the level of worldview. Explicit, formalized, encoded knowledge is transferred from person to person indirectly through language and text. This forms a person's understanding of a person at the level of text. Explicit knowledge is expressed in words. Implicit knowledge is not expressed in words. The hypothesis put forward by us is confirmed: the reciprocal conversion of explicit and implicit knowledge in a firm changes the economic and managerial reality in the direction of socialization and humanization thanks to language knowledge as a word, a word as an action.

The organization is formed by individuals, therefore the first area of application of the considered linguistic concepts must be sought at the level of the individual, let's call it the anthropic origin.

The concept of performativity is of practical interest for knowledge management, since it conditions the transition from the traditional concept of knowledge of the subject of cognition and activity to understanding them as a set of cognitive competencies that the employee-object of management has acquired. By the influence of management, he or she is forced to transfer his or her tacit knowledge to the bank of explicit knowledge of an organization. For example, in organizations where there were no initial job descriptions, employees were asked to describe their functions. And then, with managerial adjustments, this material was used to prepare official job descriptions - a direct guide to action. So, the first area of application of the concept of performativity in knowledge management is seen the formation of competences and functions of an employee of a firm.

The task of knowledge managers through formalizing knowledge of employees using computer technologies is to give their thoughts a strictly service orientation. For this, storytelling also serves: relying on corporate base of stories, an employee completing a project can record within an hour what would have taken half a day to describe.

In knowledge management, like in no other form of functional management, the practical value of the language is important. Accordingly, all sorts of descriptions of the best practices for converting knowledge are assessed from a pragmatic position. Managers accept certain descriptions of their work by a person not because they are "true", but probably because they offer really possible options for efficient activity in the form of their interpretations by an employee. From this point of view, the manager is interested in the question not of whether or not employees perceive their work reality, whether the chosen way of using words (terms, utterances) corresponds to it, but about what the firm and personally he / she, the manager, gains from their use.

Language makes a person understand his / her subjectivity - "who I am". It is unlikely that the status of a faceless competence-function will satisfy an employee as a person. With the help of stories, even the most complex analytical data gets a "human face" - humanization through storytelling. "Storytelling is, first of all, a deeply human technique that does not accept mechanistic and authoritarian approaches" (Lesser \& Prusak, 2005). 
The story should evoke sincere human emotions: understanding / bewilderment, sympathy / irritation, joy / anger, confidence / doubt. The lack of a dichotomy of emotions devalues the outcome of a story. Storytelling technique allows language to be used in conjunction with intonation, vocalization to bring imagery and other elements of a story to life in front of an audience. The manager's precise use of unique words also contributes to the bright colours of a story.

Thus, the first individual humanistic (anthropic) area of application of speech act theory and performativity concept is the construction of a competence-function due to the discourse stored in the language and objectified previous experience of a particular employee. Language also contains the means of objectifying new experience, hence, the possible change by an employee of everyday work reality. Thus, performativity transforms cognitive conversion.

The second area of application of linguistic theories in knowledge management is the social one. The language area is inherently social. Linguistic knowledge is inherent in a person as a social being. People are encouraged to take action by other people through a message. For a prime example of the importance of verbal behaviour in a meeting, see (Simon et al., 1962). The authors show the correlation of the verbal level of discussion of a business proposal in terms of the values of an organization with the actual personal motives and individual values of each participant in the meeting. Individual values, as the authors rightly point out, are "mostly unspoken and partially unconscious" (Simon et al., 1962). "Motivations based on feelings of satisfaction or dissatisfaction that arise during the meeting itself will be hidden even deeper in the subconscious" (Simon et al., 1962). Thus, the verbal expression of the feelings and thoughts of the meeting participants will determine its outcome for the activities of the organizational unit.

Taking the situation of the meeting as a basis, one can give an answer to the question "Who are we?". In other words, to illustrate the process of socialization in the exchange of formalized knowledge. The use of language in business communication indicates the characteristics of a specific social group, expressed by a specific type of social order. By prescribing specific speech behaviour for each social role, language contributes to the maintenance of microsocial order in the organization.

Considering the selected linguistic concept and theory from our point of view, we can say that socialization is the merging of informal knowledge of the participants into the common base of a firm thanks to language. In this regard, Gergen's remark is important for knowledge management: "words acquire their meaning depending on the way they function within human systems of relations" (Gergen, 1997), that is, when they are used in human relations".

Social relations and social order as a whole are reproduced through language. Business language contains discursive constructs used in management, for example, "goal", "activity", "efficiency", "productivity", within which an employee is invited to think and work. If the professional language reproduces and maintains the competence-functions of a particular employee, then communication, which is the highest form of language use, is the basis of social interactions. In communication, language shows its efficiency in comprehending and producing reality. 
The presence of the revealed performative phenomena proves once again that knowledge cannot exist in isolation from a person. At the same time, not all the tacit knowledge of an employee can be displayed and transferred using language. Some of the knowledge of a creative intellectual worker is the product of his individual intuition, the so-called creative "instinct", which contains the anthropic origin. Therefore, they cannot be transferred either by order or for any reward. And employees can't be punished for their absence either. This is for management the difficulty of converting the disparate tacit knowledge of workers into the system of explicit knowledge of an organization (a firm). After all, while the orders to one person are given by another person, that is, the process of management as vertical communication is carried out between people.

In this regard, Austin's theory of infelicity is important for the knowledge management practice: it considers the necessary conditions for felicitous / infelicitous communication. The subject of analysis for J. Austin is the circumstances that prevent the conduct of any social communicative procedure. In the knowledge management practice, such a procedure is the exchange of knowledge - this is the second area of application of the concept of performativity in knowledge management. The already mentioned J. Austin's performative felicity conditions are especially important for it. Obviously, these conditions can only be provided by people in the process of their communication. With regard to knowledge management, the considered process is (1) horizontal communication - the exchange of professional knowledge between employees of a firm; (2) vertical communication ("order-fulfilment") between managers and employees. According to Gergen, not only emotions, but also cognitive processes can be explained in terms of social relations, mutual exchange and conventions (Gergen, 1997). Horizontal culture is more conducive to this explanation than vertical one. The first culture will be fostered by Dennig's proposal to change the descending commands by conversation. Implicit knowledge, which is not "spoken" and, therefore, is not recorded in consciousness, turns out to be ambiguous and fragile. "Conversation gives clear contours to previously vague and unclear subjects" (Berger \& Luckmann, 1966).

Interaction within each identified areas and between the anthropic and social areas in everyday reality occurs through language. In everyday working life, language objectifies events and gives stability and clarity to what is happening, endowing it with the clarity and practical logic necessary for production. Language, being an effective means of accumulation, preservation and transfer of human knowledge in time and space, provides a ready-made discourse for comprehending reality, therefore, the ability to transform the reality of anthropic and social, "speaking" (Bakhtin, 1986) being.

Both the areas considered, formalized linguistically, form a kind of subsystems in the knowledge management system that can increase the efficiency of knowledge conversion mechanisms. Their functioning contributes respectively to the humanization and socialization of a firm based on the knowledge of employees. 


\section{CONCLUSION}

The directions of increasing the efficiency of the knowledge-based firm's activity are the humanization and socialization of knowledge management. The possibility of using J. Austin's performativity concept and speech act theory in knowledge management is due to the increasing importance of storytelling in the reciprocal conversion of formalized and non-formalized knowledge.

The increase in the influence of the institution of language in knowledge management is due to the synthesis of storytelling and speech act theory. The transfer of linguistic techniques and concepts to the field of knowledge management contributes to its humanization and socialization

The efficient areas of application of speech act theory in knowledge management in a firm are: 1) formation of competencies as official functions of employees - the anthropic sphere; 2) exchange of professional knowledge in the process of communication between employees - the social sphere.

The combined application of speech act theory and the knowledge management theory reveals the potential of both theories to improve the efficiency of knowledge management through its humanization and socialization.

\section{Conflict of interests}

The authors declare no conflict of interest.

\section{References}

Austin, J. (1972). Performative-Constative. The Philosophy of Language, 13-22.

Austin, J. (1966).Three Ways of Spilling Ink. Philosophical Review 75 (4): 427-440. https://doi.org/10.2307/2183222

Austin, J. (1975). How to Do Things with Words. Harvard University Press, Cambridge, 192 p.

Bakhtin, M. (1986). Estetika slovesnogo tvorchestva / Aesthetics of verbal creativity. Iskusstvo, Moscow, 445 p. (RU)

Berger, P., Luckmann, T. (1966). The Social Construction of Reality: A Treatise in the Sociology of Knowledge. Anchor, New York, $219 \mathrm{p}$.

Denning, S. (2000). The Springboard: How Storytelling Ignites Action in Knowledge-Era Organizations. ButterworthHeinemann, Oxford, 248 p.

Denning, S., Prusak, L., Groh, K., Brown, J. (2012). Storytelling in Organizations. Routledge, New York, 550 p.

Edvinsson, L. (2002). Corporate Longitude: What You Need to Know to Navigate the Knowledge Economy. Financial Times Management, New York, $256 \mathrm{p}$.

Foucault, M. (2001). The Order of Things: An Archaeology of the Human Sciences. Routledge, Classics, New York, $448 \mathrm{p}$.

Gergen, K. (1997). Realities and relationships: soundings in social construction. Harvard University Press, Cambridge, $368 \mathrm{p}$.

Lesser, E., Prusak, L. (2005). Creating Value with Knowledge: Insights from the IBM Institute for Business Value. Oxford University Press, London, 240 p.

Pfeffer, J., Sutton, R. (2000). The Knowing-Doing Gap: How Smart Companies Turn Knowledge into Action. Harvard Business School Press, 314 p.

Polanyi, M. (2015). Personal Knowledge: Towards a Post-Critical Philosophy. The University of Chicago Press, Chicago, 464 p. 
Simon, H., Smithburg, D. Thompson, V. (1962). Public Administration. NY publishers, New York, 582 p.

Snowden, D. (1999). Story telling: an old skill in a new context. Business Information Review 16: $30-37$. https://doi.org/10.1177/0266382994237045

Weil, E. (1998). Every leader tells a story. https://www.fastcompany.com/34330/every-leader-tells-story. (accessed: June 2021).

\section{About the authors}

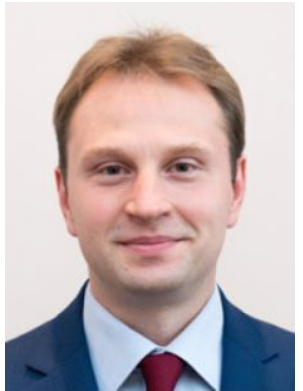

\section{Evgeny ZHERNOV}

Associate Professor, Cand. Sci. (Economic), T.F. Gorbachev Kuzbass State Technical University, Institute of Economics and Management, Head of Department of Economics (Kemerovo, Russian Federation).

Research interests: knowledge management, socialization of the economy, humanization of the economy.

ORCID ID: https://orcid.org/0000-0003-3558-0802

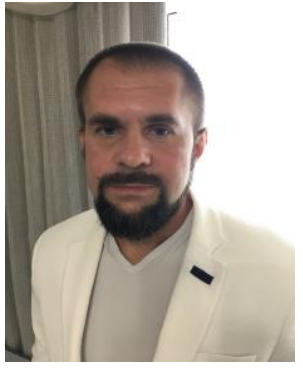

\section{Pavel A. STRELNIKOV}

Associate Professor, Cand. Sci. (Pedagogy), T.F. Gorbachev Kuzbass State Technical University, Foreign Languages Department (Kemerovo, Russian Federation).

Research interests: linguistics, communication, professional education, pedagogy.

ORCID ID: https://orcid.org/0000-0001-6366-585X

Copyright (C) 2020 by author(s) and ACCESS Publishing Press This work is licensed under the Creative Commons Attribution International License (CC BY) 


\title{
DIGITALIZATION OF DATA ANALYSIS TOOLS AS THE KEY FOR SUCCESS IN THE ONLINE TRADING MARKETS
}

\author{
Andrii Roskladka ${ }^{1}$, Roman Baiev ${ }^{2}$ \\ ${ }^{1,2}$ Kyiv National University of Trade and Economics, Kyiv, Ukraine \\ E-mails: ${ }^{1}$ a.roskladka@knute.edu.ua, ${ }^{2}$ roman.baiev8@gmail.com
}

Received: 10 July 2021; $\quad$ Accepted: 04 August 2021; Online Published: 07 August 2021

\begin{abstract}
:
Digitalization is the process, which takes places in the contemporary world, severe competition in all markets, growing demand for new and easy technologies, changing software user preferences, and much more. For the past decades of years, the share of online forex trades that had place in the world accounted for more than 90\% of all forex deals. This article discusses the main points of the online trading, the prospects of this industry and key factors that may affect the industry; also, the crucial attention was paid to the online trading tools segment, as a part of the immense market in general and as a tool in the portfolio of every modern online trading specialist. The online commerce industry is one of the largest and fastest growing sectors of the world economy. It creates jobs and assets, makes people richer and provides truly equal access for all. An analysis of existing online trading tools, such as the MT4 platform, was conducted. The main characteristics of online trade in European countries and the problems of its development in Ukraine are studied. The main components of trade in the supply area were studied in detail. Based on the research of the authors, the algorithmic rules of the automated trading system (expert advisor) were described and its software implementation is created. Similar automated systems are especially helpful when specialists need to work with many charts and timeframes at once, because the system might indicate the proper market situation better, and the system won't have any humanbiased feelings, just pure strategies and algorithms.
\end{abstract}

Keywords: innovation, online trading, algorithmic trading, strategies, stocks, forex, digital economics

JEL classification: C190, G150, F370

Citation:

Roskladka, A., Baiev, R. (2021). Digitalization of data analysis tools as the key for success in the online trading markets. Access to science, business, innovation in digital economy, ACCESS Press, 2(3): $222-233$. https://doi.org/10.46656/access.2021.2.3(2)

\section{INTRODUCTION}

The online trading tools are the possible key to make a decent fortune off the online markets of shares and investments. According to the most trusted magazines, every prosperous entrepreneur, CEO or Head manager nowadays possesses at least some assets in shares and short-term or long-term investments. Therefore, it might not amaze that the online trading or online investments are ones of the most popular and most profitable and at the same time ones of the most risky industries.

In this paper, we will pay thorough attention to the online trading market and the automated systems and tools which are called to facilitate people who are willing to start off on these markets or who are seeking for new methods to scale up their portfolios or bankrolls. 
Human life is full of a variety of emotions, but not all of them are directly derived from the basic emotion and might be helpful to establish the proper market conditions to make entries. Many academic papers scientifically research human-biased emotions while they are trading (M.Douglas, 1995).

The online trading industry has been gaining its power for the past decades and to help us understand the current conditions better we will review some latest studies from trusted broker research. (BN Research Report, $2018 \& 2021)$

The "robots" known as the automated trading systems (further in this article you might see the word "system" which relates to the trading system with some predefined algorithms, acronym is "ATS") are controlling more and more financial operations, so the development works in this article tend to be actually in step with the times (CNBC, Guy De Blonay, 2018)

Goals and objectives of the study. To be adaptive is one of the most demanded traits in our society at present. People's inherent behavior is often built on the two main factors as cues that might measure your wealth, such as money and power, although, we are living in the modern era, where human qualities are being treated accordingly, but a lot of us are willing to establish their own independent fund. The main purposes of this work are to explore the markets of online trading and investments and develop new and successful automated tools for these markets.

Results and Discussion. As of 2021, online trading industry is one of the most dynamically developing sectors of the global economy, it creates jobs and assets, it makes people richer, and it provides truly equal access for everyone.

Why this market is so crucial and needs more our attentions, considering the data from the study published by the Contentworks Agency in 2019, only the global forex trading market worth is estimated to be around 2.4 quadrillion USD.(Contentworks Agency, 2021)

This example should suffice to prove the contention as per Visual Capitalist studies, money can make you happier and can provide you more items of your wish. (Charted: Money Can Buy Happiness After All, 2021.

The most significant highlights from the online trading market are listed and described beneath:

1. According to BIS's 2019 triennial survey, trading in FX markets reached an incredible $\$ 6.6$ trillion per day in April 2019. It's comparable to the entire GDP for a year of Germany and Italy combined.

2. The worth of the entire global forex trading market is estimated to approximately $\$ 2.4$ quadrillion - in other words, around \$2409 trillion.

3. Over $85 \%$ of the global forex market transactions happen on just 7 major pairs GBPUSD, EURUSD, USDJPY, AUDUSD, NZDUSD, USDCHF, USDCAD. The automated trading system which was built conceives all these currency pairs and analyzes them best. During the development and testing work vast majority of time the system was run on these pairs and showed positive results.

4. Only about $15 \%$ of forex traders make a profit. When the authors first viewed this number, it was perceived as a challenge to create a special tool that will be performing positive on the markets and making 
profits off the currency pairs or stokes the tool would be applied to (Forex Statistics \& Trader Results From Around the World, 2020).

5. The most popular trading platform is still the classic MT4, which is used by $85 \%$ of traders. The second most popular platform is the MT5, which is used by only 6\% of traders (BIS-2019 Quarterly Review, 2019).

6. There are approximately 10 million forex traders in the world in 2017 and over 14 million in 2020 (BN Research Report, 2021).

7. The US Dollar is the most popular forex trading currency - with $88.3 \%$ of global trades involving the ever-reliable greenback (Forex Trading Industry Statistics and Facts, 2020).

8. The second most popular currency in the forex market is the Euro - accounting for $32.3 \%$ of trades (Forex Trading Industry Statistics and Facts, 2020).

Taking into consideration the facts listed, it was decided to think about developing the strategy and the trading tool which will be suitable with the most popular pairs, from the fifth item it was decided to establish the strategy for the MT4 trading accounts. The MT4 platform can be trusted as it makes possible placing trades within seconds, the average response time which was counted during the strategy testing is less than 2 seconds, when all factors are set properly.

The trading strategy all above should be connected to as many trading instruments (currency pairs, and contiguous instruments as following: stocks, options, indices, etc.) as possible.

The online trading is getting more popular and as per brokers analytics, it's particularly popular among the young people aged 25 to 34 (fig. 1).

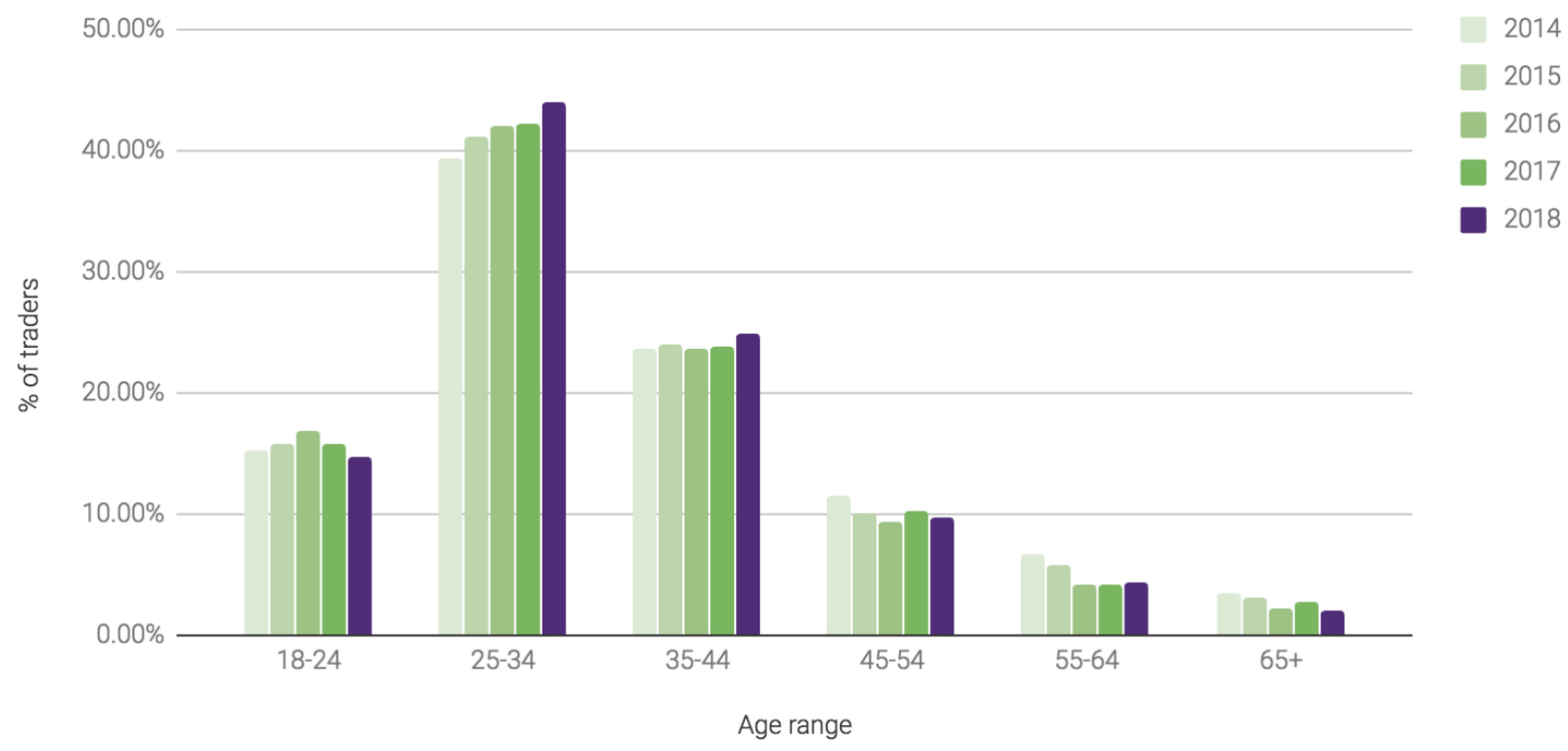

Fig. 1. Age ranges of all online traders, 2018

Source: formed by authors based on BN Research Report, 2018

To prove that online trading now is in 2021 way more popular and easy-to-access industry, let's just overview one short story from the financial markets. Users from the Reddit page "r/wallstreetbets" earlier this 
year gobbled up stock from floundering chain GameStop, sending the price soaring and forcing institutional investors who bet against the company to back out -- performing what's known as a "short squeeze." [8]

For several days, lots of big investors and huge hedge funds might have lost millions of dollars due to the common work of the young traders, Reddit-users.

The industry clearly gains its popularity, in 2017 there were around 9.5 million registered online traders with real trading accounts, whereas in 2021, there are over 13.9 million registered online traders, according to The Modern Trader study and research papers, the $45 \%$ growth for mere 4 years. Not every industry is capable to show such development over the past years.

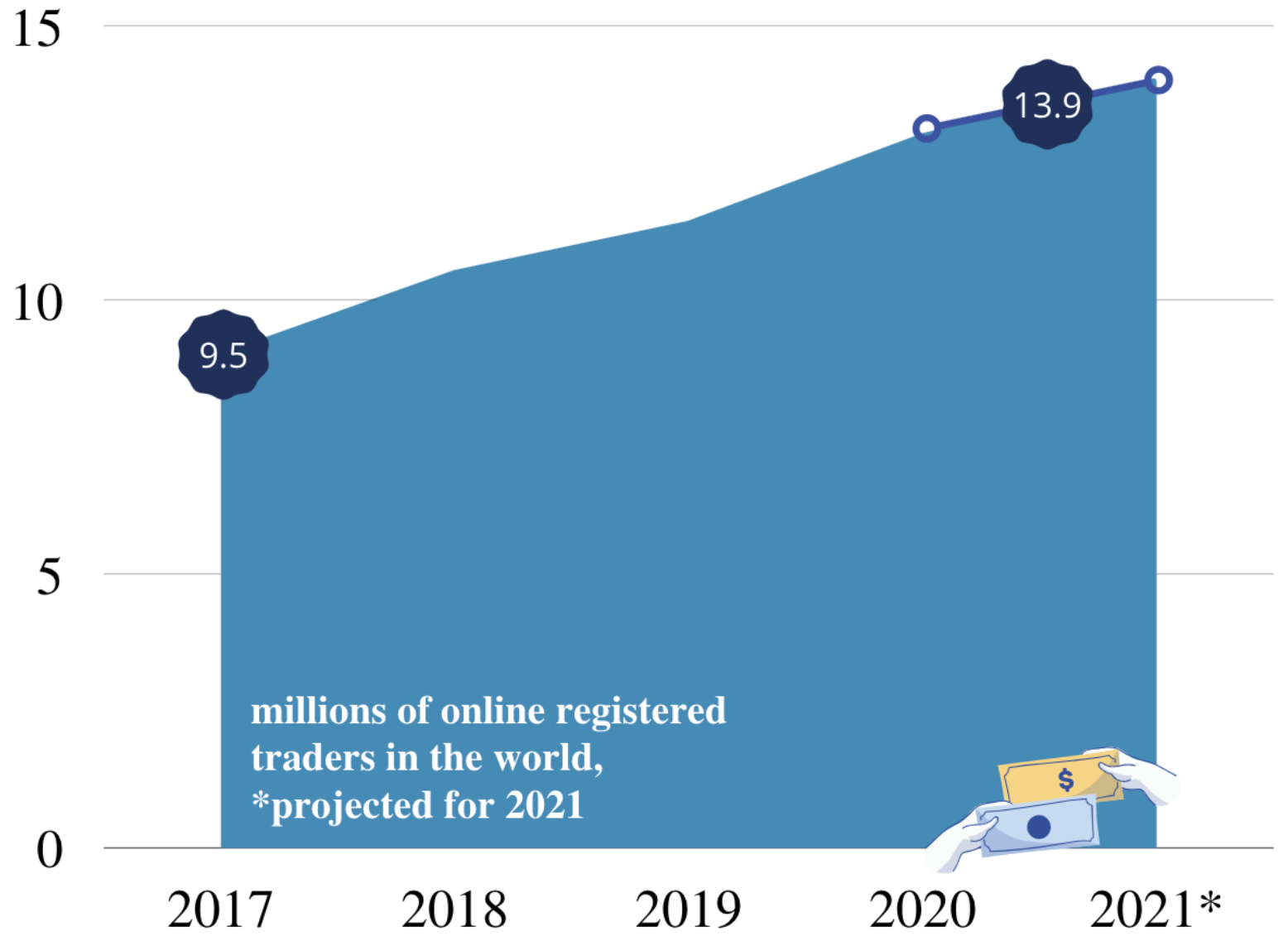

Fig. 2. Number of registered online trading participants for the past 5 years, in millions Source: created by authors based on BN Research Report, 2020.

According to the data above (Fig.2) we are able to spot the proper tendency on the financial markets, the number of registered online traders who hold trading accounts with real money has been constantly growing and the number will only keep raising as the financial market itself does.

The problem which arises: how to be prosperous in the field of online trading? Per the trading broker research, only $15 \%$ of traders make constant profit off the online markets, and over one third of traders are breaking even, which means they have neither significant losses nor profits for months or even years. 
And since about $15 \%$ of forex traders make constant profit, we have decided to think through and configure the trading tool for online traders to help them profit more frequently from their daily trading transactions, openings and closings. (Forex Statistics \& Trader Results from Around the World, 2020)

For almost 3 years, one of article's authors had worked in one of the biggest trading brokers as a strategy tester \& customer care advocate. He operated close with clients, regular workers who started trading as a side hustle, as well as with fund admins who had tens of years of experience in the markets. Therefore, author started gaining more valuable understanding from the real experience communicating with real traders throughout the world, from the USA to Germany, from China to Nigeria, he started analyzing the market and feeling traders' main wishes.

The biggest brokers are seeking to involve more institutional traders, entailing specialists who will operate decent trading accounts with typical deposit size of over 10 thousand USD, as the trading brokers receive some commission. Below you might see the study from Broker Notes Research papers (Fig.3), showing that many traders around $10 \%$ regardless of their gender tend to deposit over 10 thousand USD into their trading accounts, and over $3.5 \%$ of online traders possess trading accounts with over 100 thousand USD. Mainly, the greater the deposit size, the smaller risks and drawdown the traders want to see.

\begin{tabular}{|c|c|c|c|c|}
\hline Deposit size & \# of Males & \# of Females & \% of Males & $\%$ of Females \\
\hline Under $\$ 500$ & 5,072 & 832 & $42.40 \%$ & $50.36 \%$ \\
\hline$\$ 500-\$ 1,000$ & 2,817 & 368 & $23.55 \%$ & $22.28 \%$ \\
\hline$\$ 1000-\$ 10,000$ & 2,816 & 304 & $23.54 \%$ & $18.40 \%$ \\
\hline$\$ 10,000+$ & 1,256 & 148 & $10.50 \%$ & $8.96 \%$ \\
\hline
\end{tabular}

Fig. 3. Typical deposit sizes of online traders

Source: formed by authors based on BN Research Report, 2018.

The number of the registered online traders in European countries also shows the constant growth (Fig.4).

In Ukraine slightly over 40 thousand of online traders who have been registered in international brokers and possess at least one trading account with real investments, unfortunately due to the industry specification and confidentiality it's impossible to count all trading accounts or all live online traders per country, but relying on the studies from the Broker Notes in Ukraine the number of traders has been doubled since 2017 year. Many countries such as Poland and Romania has paid proper attention to developing the trading markets lately, and it has resulted in more people involved in to the industry and more companies has gone IPO, which symbolize good trend for economies (BN Research Report, 2018). 

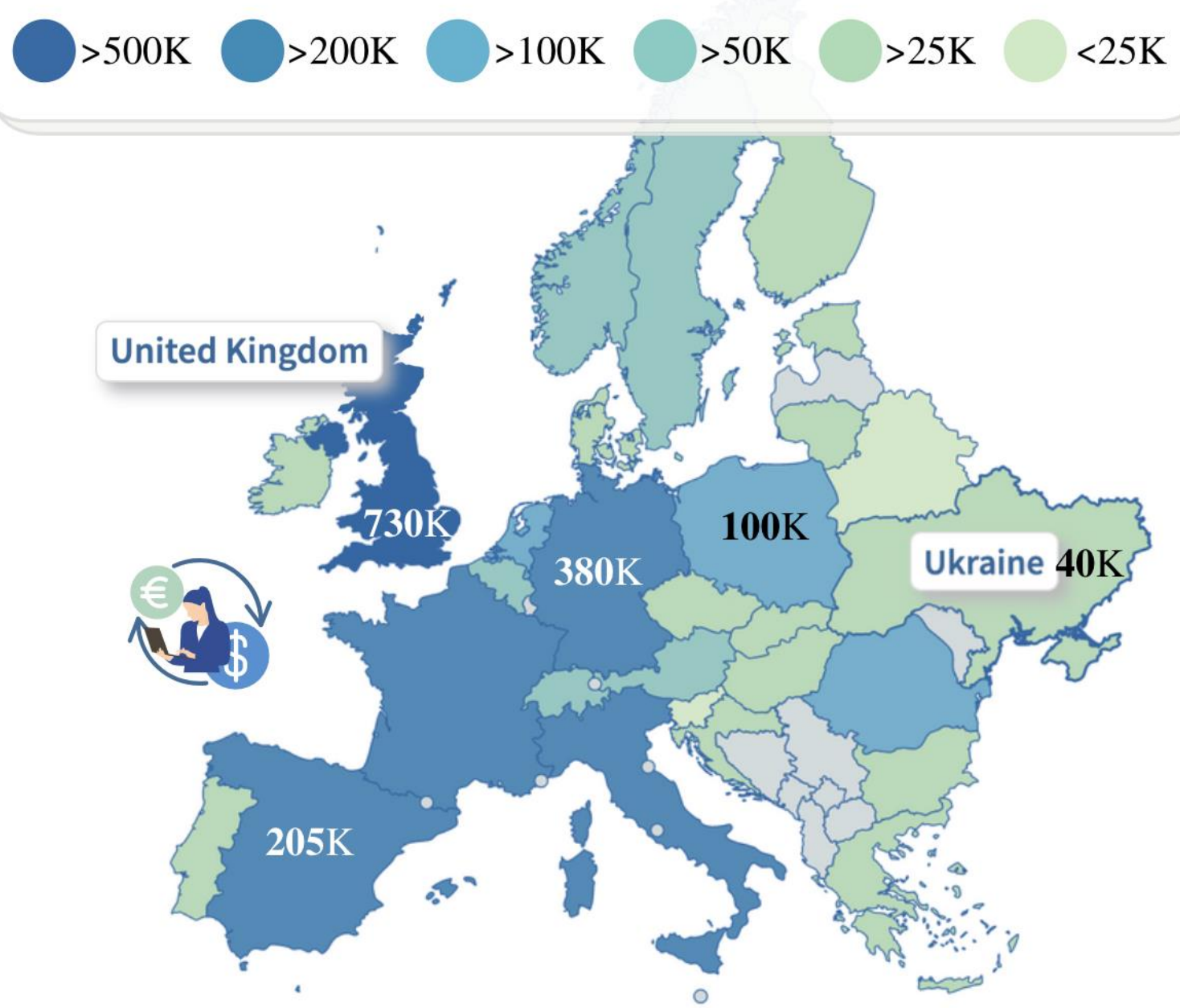

Fig. 4. Number of online traders in European countries, "K" means a thousand on this map, as per 2019. Source: created by authors based on BN Research Report, 2021

Considering the data from the image above (Fig.4), we might see that the United Kingdom is in the first place in Europe with more than 730 thousand online traders, the runner-up in Europe is with around 380 thousand of online traders.

For the past years, especially after the Brexit deal, two new trading hubs have been highlighted in Europe, such as Amsterdam and Frankfurt, therefore, in the forthcoming reports, it's expected to see intensive growth of traders and deposited sums for the Netherlands and Germany.

Practical realization of the automated trading system. After diligent investigations in the area of the automated trading systems and their strategies, it was determined to build the system on a foundation of the demand and supply methods. Supply and demand trading is a trading method where the idea is to find points in the market where the price has made a strong advance or decline and mark these areas as supply and demand zones using rectangles, which are shown in the image, orange rectangles for sell-positions and blue rectangles for buy-positions. 
The ecosystem overviews. The main chart types the automated trading system is working with is the Japanese Candles (Fig.5)

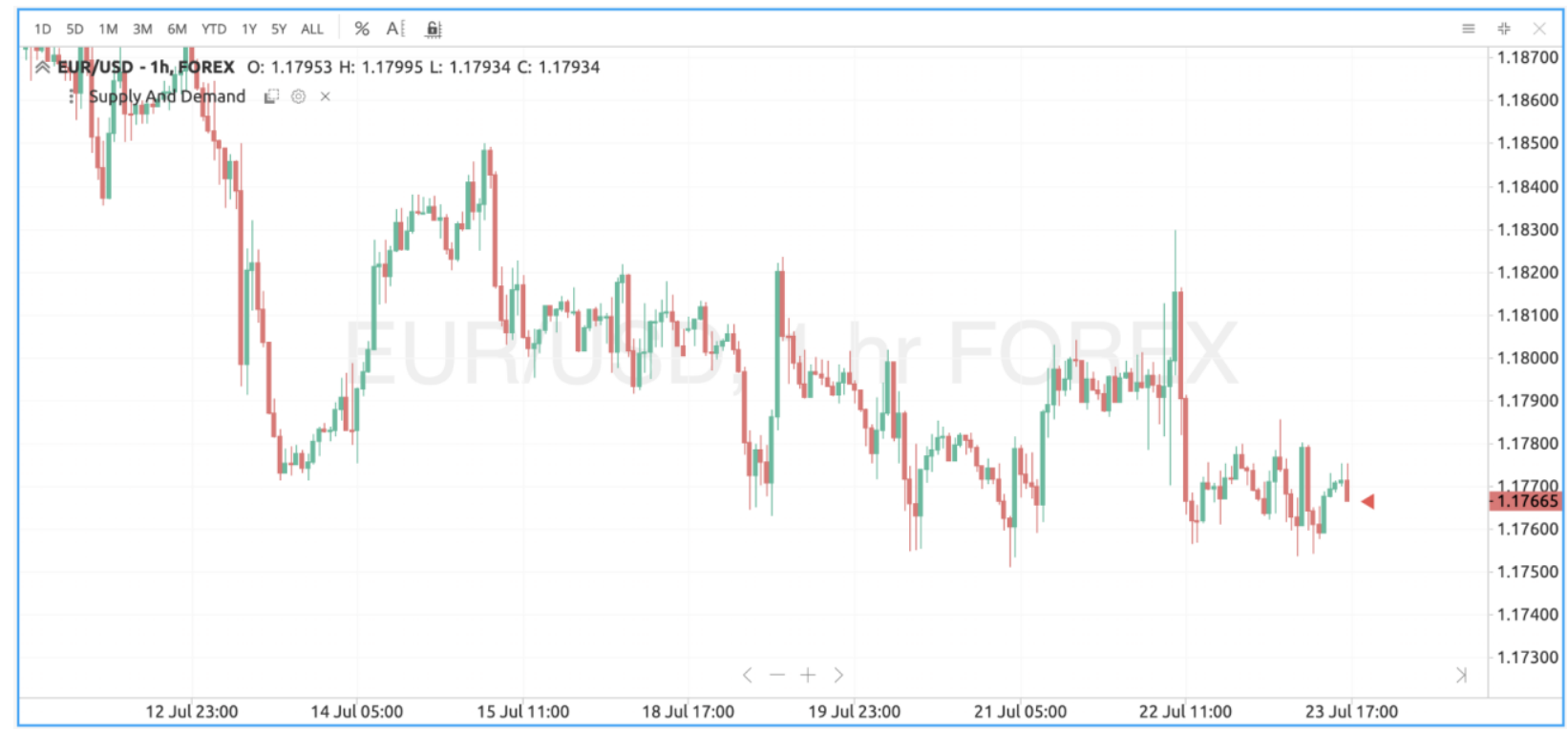

Fig. 5. The Japanese Candles trading chart.

Source: created by authors

The chart above represents the most commonly used trading chart for online traders, it's called Japanese Candles. Candle charts are useful when trading as they show four price points (open, close, high, and low) throughout the period of time the trader specifies. Many algorithms are based on the same price information shown in candlestick charts. The algorithms that are used in the automated trading system which was built during the research are supposed to work based on the Japanese Candles charts, with all timeframes, entailing that the automated trading system may be run on any MT4 trading chart, 1-minute, 15-minute, 1-hour or 1-day charts will be accepting the system and will mark the chart as it is controlled by the developed trading system.

Upon the outlying investigation, it was defined that most online traders are interested in the following core qualities when the traders are applying some automated systems or scripts, these all qualities are available in the trading strategy that has been developing. The main components of the supply zone trading:

- Low and moderate volatility trades: A lot of traders do not have an inclination for highly volatile trading instruments (currency pairs, stock indexes, etc.) or trading systems what work on highly volatile strategies. A supply zone during the work on charts typically shows narrow price behavior. Lots of candle wicks and strong back and forth often cancel a supply zone for future trades.

- Timely market exit: The online traders don't want to see price spending too much time at a supply zone. Although position accumulation does take some time, long ranges usually don't show institutional buying. Good supply zones are somewhat narrow and do not hold too long, these factors have been taken into 
consideration during the development works of the automated trading system. A shorter accumulation zone works better for finding re-entries during pullbacks that are aimed at picking up open interest.

Good supply zones are somewhat narrow and do not hold too long. A shorter accumulation zone works better for finding re-entries during pullbacks that are aimed at picking up open interest.

- The false springs on the charts: The projected automated system doesn't count few candles on the chart, the algorithms tries to annihilate wrong entries, which doesn't result in many open positions after false springs on the trading charts.

- Strong force leaving the zone: This point is one of the most important, which I have explored during speaking sessions with traders and trading broker clients. At one point, price leaves the supply zone and starts trending. A strong imbalance between buyers and sellers leads to strong and explosive price movements. As a rule of thumb, remember that the stronger the breakout, the better the demand zone and the more open interest will usually still exist - especially when the time spent at the accumulation was relatively short.

When price goes from selling off to a strong bullish trend, there had to be a significant amount of buy interest entering the market, absorbing all sell orders and then driving price higher - and vice versa. Always look for extremely strong turning points; they are often high probability price levels.

When should we consider using this automated trading system, which is built on the concept of supply and demand?

When we know the support and resistance zones. Supply and demand zones are natural support and resistance levels, and it pays off to have them on your charts for numerous reasons. Combining traditional support and resistance concepts with supply and demand can help traders understand price movements in a much clearer way. The concepts of trading level support and resistance are undoubtedly two of the most highly discussed attributes of technical analysis in trading. Part of analyzing chart patterns, these terms are used by traders to refer to price levels on charts that tend to act as barriers, preventing the price of an asset from getting pushed in a certain direction. Support levels are usually lows on the charts, and resistance levels are highs. While applying the system, supply and demand zones can be easily found just below/above support and resistance levels.

When we are interested in having automatically populated Stop Loss and Take Profit points. When it comes to profit placement, supply and demand zones can be a great tool. The developed system always places the profit target ahead of a zone so that the traders who apply it don't risk giving back all profits when the open interest in that zone is filled.

Discovery of the new supply and demand technology has been the best practicalities for the change on the markets. Since the very beginning of applying the strategy, it has been a great help for the online traders and trading institutions who may operate millions of dollars.

The Supply and Demand indicator which has been build during the development works visualized on the Forex chart using the MT4 trading account (Fig.6). The indicators also shows red and green lines, which might be interpreted as suitable places for opening, closing, and keeping open the market positions. 


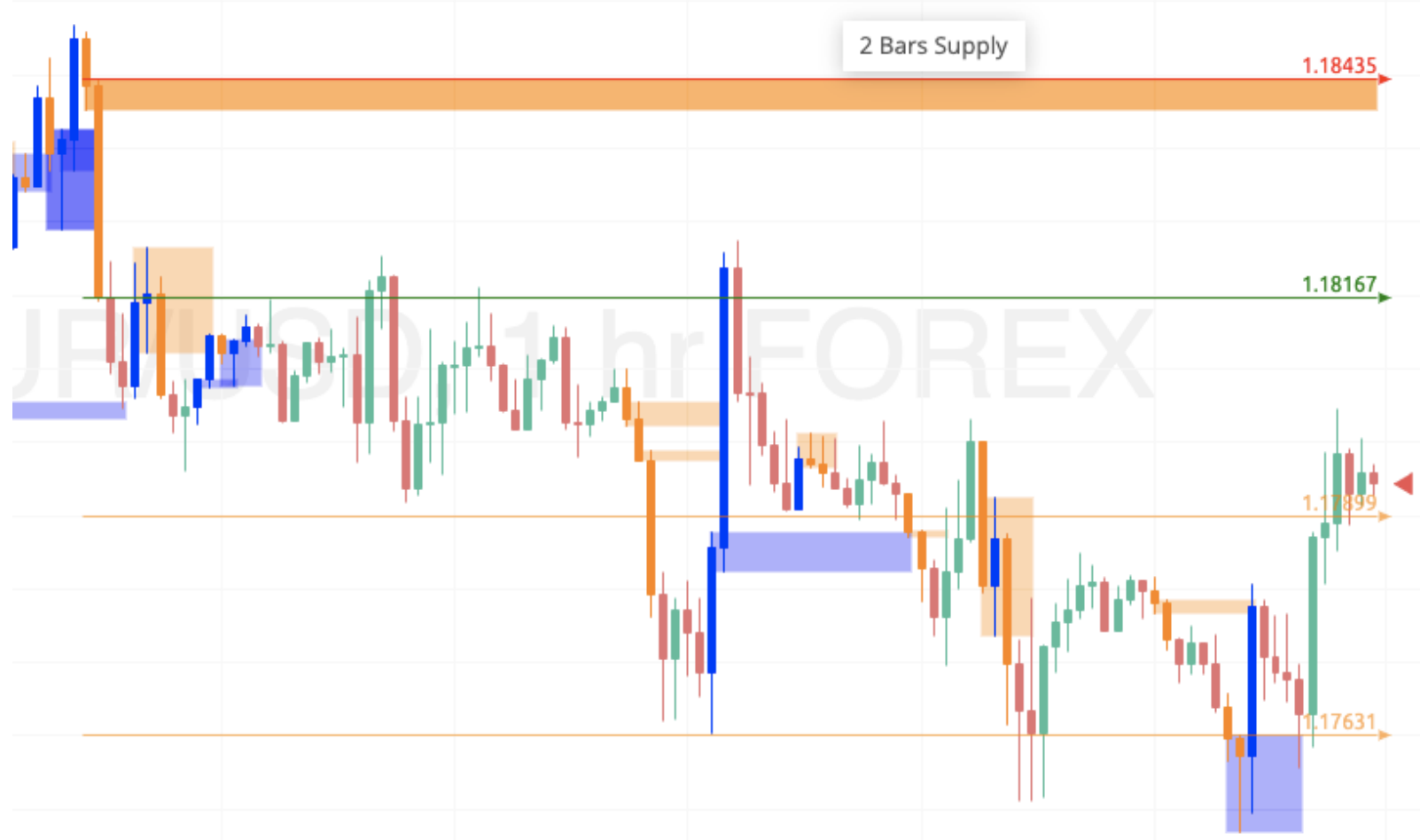

Fig. 6. Supply and Demand Indicator visualized on the Forex chart.

Source: Created by authors using MQL programming language

The orange and blue shadowed areas on the Fig. 6 facilitate us view the quick market changes and once such zone is open, it might be closed within next several chart moves. Analysing the zones based on the strategy in the automated trading system, we can consider placing our own positions within zones in order to gain profits.

Below, the algorithmic rules of the automated trading system (expert advisor) are described:

- When the price of the trading instrument such as Forex pair or Stock reaches the proximal level of an untested supply zone, it will enter a sell trade.

- When the price of the trading instrument reaches the proximal level of an untested demand zone, it will enter a buy trade (Fletcher, T. Machine Learning for Financial Market Prediction, 2012).

- The stop loss is placed automatically once the market is entered with position.

- The take profit is considered to be greater than the stop loss (Mathematical Programming, 1983).

- It has been developed and supported in mq14, means it is supposed to run on the MT4 trading platform.

Also, below, we have highlighted the input values from the programming code and added comments which may provide clearer understanding of the initial default system settings (Fig.7). 


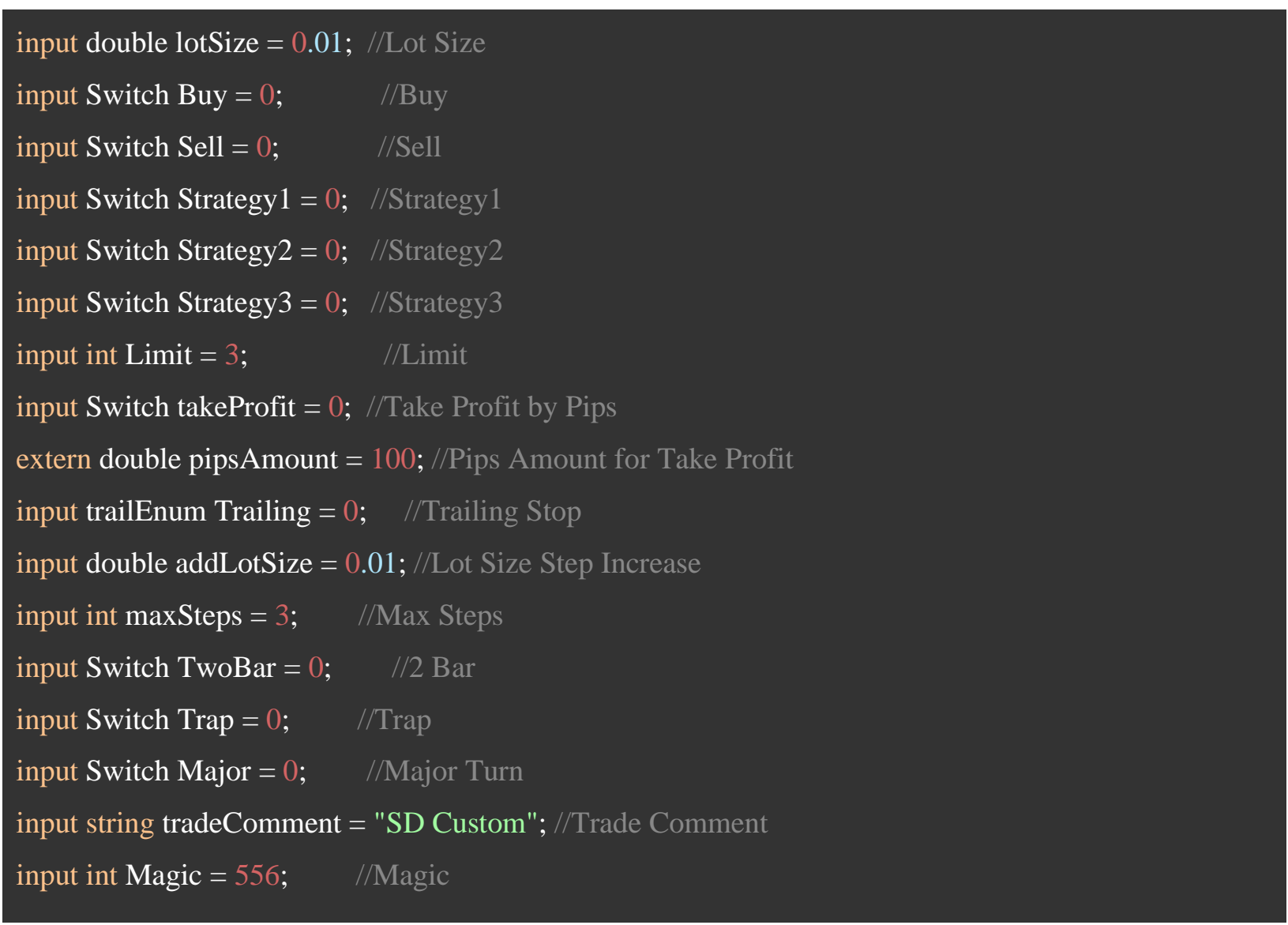

Fig. 7. Input details in the code of the automated trading system.

Source: Created by authors for the MT4 Trading Platform

The input details can be adjusted as the system is starting. While using the automated trading system, it's easy to change the values for Take Profit or Stop Loss entries. (Fletcher, T. Machine Learning for Financial Market Prediction, 2021)

The system has been designed to be able to determine the best zones on the trading charts to enter the market with new positions.

The main premise of supply and demand strategy which is built in the automated trading system is when the market makes a sharp move up or down the large institutions i.e. banks/hedge funds are not able to get their entire trade placed into the market, therefore they leave pending orders to buy or sell at the zone with the expectation the market will return to the zone and the rest of their trading position will be filled.

Strategy testing results have displayed strong leaning for placing the proper market positions on the charts.

During trial runs on different timeframes and charts, the developed Supply and Demand strategy has shown positive performance. The system works best with 1-hour and 4-hour timeframes, as it's mainly developed using this timeframe to avoid any high-volatility and high-liquidity zones. 
As follows, the automated trading system built on the Supply and Demand strategy has shown strong positive performance on main currency pairs and other trading instruments, thus the system might be applied to a versatile portfolio and for different investment types, might it be short-term as well as long-term runs.

\section{CONCLUSIONS}

More and more automated trading systems are being launched on the financial markets, over $80 \%$ of all trades are under the control of such systems, thus it's particularly important to get the topic well sorted out (CNBC, 2018). Similar automated systems are especially helpful when specialists need to work with many charts and timeframes at once, because the system might indicate the proper market situation better, and the system won't have any human-biased feelings, just pure strategies and algorithms.

Many thoughts from the market leaders have been construed during the work on the article and the automated trading system in order to receive the best practices. As regards the forthcoming prospects, the automated system and algorithms will handle more and more trading operations and market specialists will seek for the best options for their funds.

\section{Conflict of interests}

The authors declare no conflict of interest.

\section{References}

ABC News, (2021). GameStop Timeline [Electronic resource] Access mode: https://abcn.ws/2Vc1X2C

Bennett, M. J. (1986). Proving Correctness of Asynchronous Circuits Using Temporal Logic [Electronic resource] Access mode: https://bit.ly/3eW3dxO

Bennett, M. J. (2014). Data Mining with Markowitz Portfolio Optimization in Higher Dimensions, [Electronic resource] Access mode: https://bit.ly/3BEp6eX

BIS, (2019). Quarterly Review, International banking and financial market developments [Electronic resource] Access mode: https://www.bis.org/publ/qtrpdf/r_qt1912.pdf

Bodie, Z., Kane, A., Marcus, A. (2013). Investments, Tenth Edition. McGraw-Hill, September.

Broker Notes Research Report, (2018). THE MODERN TRADER Edition 2018 [Electronic resource] Access mode: https://bit.ly/3rxZls9

Broker Notes Research Report, (2021). THE MODERN TRADER Edition 2021 [Electronic resource] Access mode: https://bit.ly/2UREfJ4

Carmona, R. (2004). Statistical Analysis of Financial Data in S-Plus, Springer Texts in Statistics.

CNBC, Guy De Blonay (2018). Sell-offs could be down to machines that control $80 \%$ of the US stock market [Electronic resource] Access mode: https://cnb.cx/3eWfgv8

Contentworks Agency, (2019). Forex Statistics Study Portfolio [Electronic resource] Access mode: https://bit.ly/3yc4A3i

Douglas, M. (1995). Trading in the Zone: Master the Market with Confidence, Discipline and a Winning Attitude. [Book] Pp.5-14

Eddelbuettel, D., Sanderson, C. (2014). RcppArmadillo: Accelerating R with High-Performance C++ Linear Algebra. Computational Statistics and Data Analysis, Volume 71. 
Fletcher, T. (2012). Machine Learning for Financial Market Prediction, Ph.D. Thesis, University College of London, [Electronic resource] Access mode: https://bit.ly/3yaNX7W

Fletcher, T., Hussain, Z., Shawe-Taylor, J. (2010). Multiple Kernel Learning on the Limit Order Book. JMLR Proceedings, 11: pp. 167-74. [Electronic resource] Access mode: https://bit.ly/3eW7HVh

Forex.com, (2020). Forex Trading Industry Statistics and Facts [Electronic resource] Access mode: https://bit.ly/3BAhhXH

ForexSchool, (2020) Forex Statistics \& Trader Results from Around the World [Electronic resource] Access mode: https://bit.ly/36ZvFKK

FT. (2019). 2019 Forex Trading Stats for Marketers [Electronic resource] Access mode: https://bit.ly/2UFnSzx

Goldfarb, D., Idnani, A. (1983). A Numerically Stable Dual Method for Solving Strictly Convex Quadratic Programs. Mathematical Programming. 27: pp. 1-33.

GoogleFinance.com (2021), Titanium Metals Corp (NYSE:TIE), July 2021. [Electronic resource] Access mode: www.google.com/finance

Morandat, F., Hill, B., Osvald, L., Vitek, J. (2012). Evaluating the Design of the R Language, ECOOP 2012-ObjectOriented Programming, 104-131.

Shreve, S. (2004). Stochastic Calculus for Finance I, The Binomial Asset Pricing Model. New York: Springer.

Shreve, S. (2004). Stochastic Calculus for Finance II, Continuous Time Models. New York: Springer.

Stern NY, (2010). Damodaran, A. Notes from New York University Stern School of Business, [Electronic resource] Access mode: https://bit.ly/3zyTsO3

Visual Capitalist, C. (2021). Charted: Money Can Buy Happiness After All [Electronic resource] Access mode: https://www.visualcapitalist.com/chart-money-can-buy-happiness-after-all/

\section{About the authors}

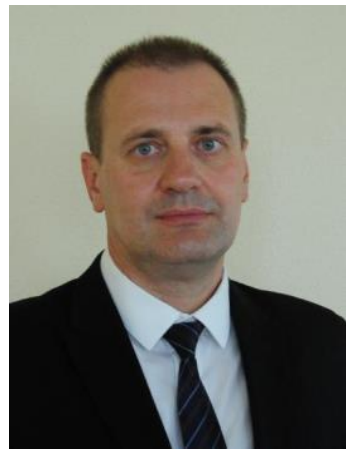

\section{Andrii ROSKLADKA}

Doctor of Sciences in Economics, Professor,

Head of the Digital Economics and System Analysis Department, Kyiv

National University of Trade and Economics, Ukraine.

Research interests: Data Science, Data Mining, Business Intelligence, Statistical Analysis, Forecasting methods, Mathematical and Computer Modelling

ORCID ID: https://orcid.org/0000-0002-1297-377X

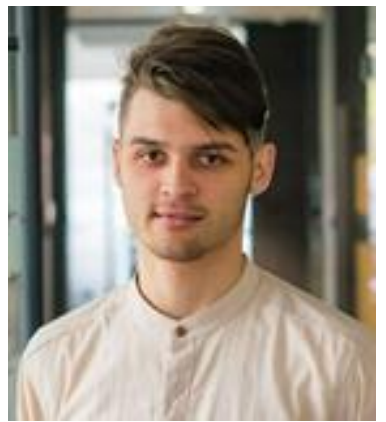

\section{Roman BAIEV}

PhD Student, Faculty of Information Technologies, Kyiv National University of Trade and Economics, Ukraine.

Research interests: Data analysis, financial analysis, statistics, visualization, financial trading markets, statistical maps and studies, programming.

Practical activities: QA Strategy Tester and Customer Care for one of world's biggest trading brokers, Technical Project Manager for international ITcompany

ORCID ID: https://orcid.org/0000-0001-5803-2257

Copyright $(\odot 2020$ by author(s) and ACCESS Publishing Press This work is licensed under the Creative Commons Attribution International License (CC BY) 


\title{
CONSUMER BEHAVIOR CLUSTERING OF FOOD RETAIL CHAINS BY MACHINE LEARNING ALGORITHMS
}

\author{
Olena Liashenko ${ }^{*}{ }^{* 1}$, Tetyana Kravets², Matvii Prokopenko ${ }^{3}$ \\ 1, 2,3 Taras Shevchenko National University of Kyiv, Kyiv, Ukraine \\ e-mails: ${ }^{1}$ lyashenko@univ.kiev.ua, ${ }^{2}$ tankravets@univ.kiev.ua, ${ }^{3}$ matveyy58@gmail.com
}

Received: 10 July 2021 ; Accepted: 04 August 2021; Online Published: 08 August 2021

\begin{abstract}
Analysis of the behavior of an economic agent is one of the central themes of microeconomics. Right now, with the comprehensive increase in the amount of data and the expansion of the computing capabilities of personal computers, there is a need to implement methods of behavioral economics in the study of human behavior. In the course of this study, a survey was created aimed at identification of patterns of behavior of the modern consumer according to his selection criteria stores and reactions to questions based on Behavioral Economics theorems. Clustering the obtained results were performed using machine learning algorithms, after which the Random Forest classification algorithm was trained. According to the results of Silhouette analysis, $K$-means clusters were selected as the main ones for further modeling. $T$ SNE algorithms, hierarchical and spectral analysis were used for additional visual representation. This study offers a tool for classifying customer preferences and analyzing current industry trends. A tool has been created to classify consumers of food retail chains in order to improve their "buyer's journey" and better understand their needs. The created tool for clustering and classification by machine learning methods can be used in business processes. To improve the result, it is necessary to choose a more representative sample, because used in this study consists of an average rationally thinking and knowledgeable individuals, which cannot be said of the average consumer not only among the older generation but also among the younger. Therefore, the next directions in the study may be to identify new ones behavioral trends in other industries; deepening understanding of food retail; use of geodata to improve analysis, etc. Potentially attractive the direction may be to add an assessment of the impact of network advertising on behavior consumers through semantics analysis and image recognition.
\end{abstract}

Keywords: clustering, machine learning algorithms, food retail, behavioural economics, consumer behavior

JEL classification: C83, C890, D120, D910

Citation:

Liashenko, O., Kravets, T., Prokopenko, M. (2021). Consumer behavior clustering of food retail chains by machine learning algorithms. Access to science, business, innovation in digital economy, ACCESS Press, 2(3): 234-251. https://doi.org/10.46656/access.2021.2.3(3)

\section{INTRODUCTION}

Currently, players in the food retail industry are rapidly recovering from the pandemic, testing new formats and approaches. It is important to identify fundamental changes in consumer needs for better business adaptation. The food retail industry, both worldwide and in Ukraine, was hit hard during the pandemic, but that allowed it to transform it into a new and better version of itself. First, the e-commerce segment has grown extremely rapidly - networks have had to build entire infrastructure in a few weeks to improve the consumer experience. Leading chains have launched their own delivery services (Silpo) or developed an ecosystem of

\footnotetext{
1 Corresponding author Olena Liashenko - lyashenko@univ.kiev.ua
} 
stores (Auchan Pick-Up Point). Due to the increasing role of location, the segment of "home shops" has grown significantly, which led to the opening of mini-analogues of supermarkets - Varus-To-Go, Novus Mi and the above-mentioned Pick-Up Point from Auchan).

According to a study by Deloitte (2021), Ukrainians began to spend less on alcohol and more on medicines. The segment of online shopping and the total cost of products on the Internet has grown, and most purchases are now paid by card or gadget (Fig. 1). It is also noted that $73 \%$ of Ukrainians use delivery services, but their own experience and the results of the study suggest that this figure is much lower, especially in the regions of the country. However, one fact remains the same - the niche of delivery services in Ukraine is developing rapidly with the entry of new players and the establishment of internal logistics networks of leading stores.

? What payment method do you prefer the most when shopping for particular kind of goods?

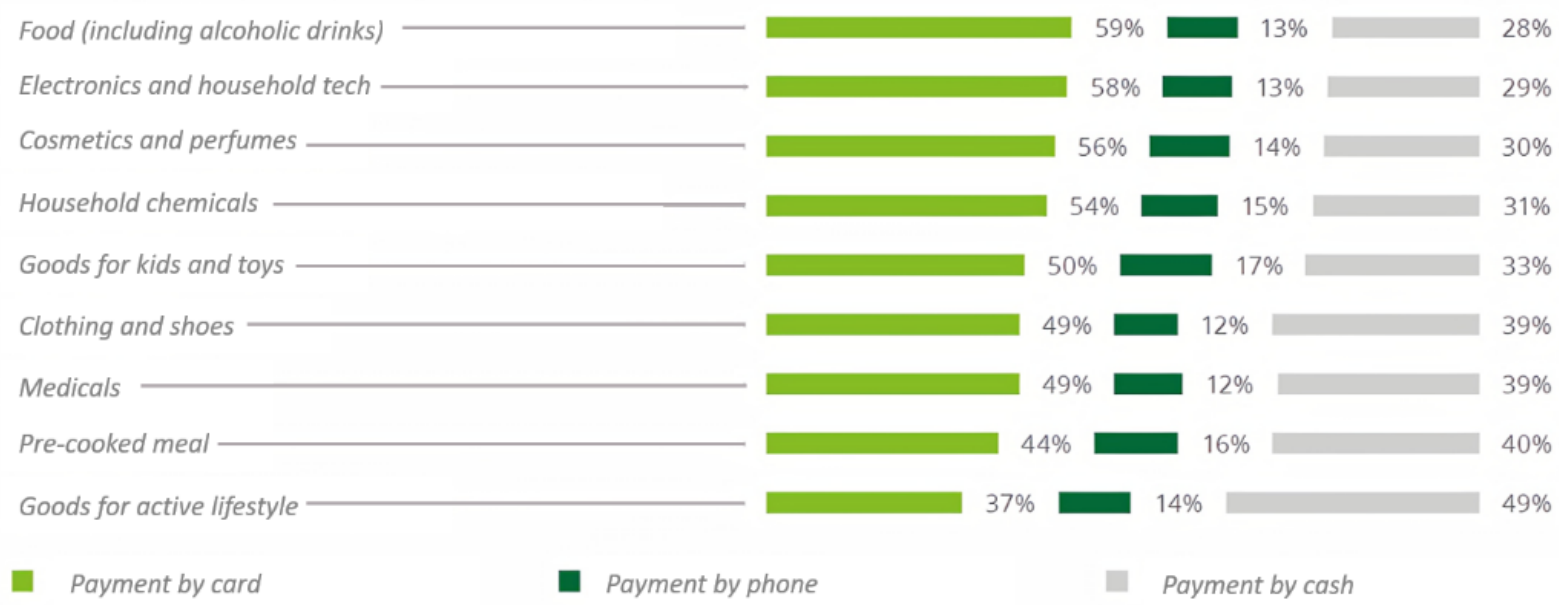

Fig. 1. Contactless payment by Deloitte (2021)

Among the changes in the industry in 2021, McKinsey (2020) highlighted the development of clearly differentiated formats (as opposed to conventional supermarkets); higher requirements for budget products; trend towards healthy eating and eco-awareness. And, of course, the powerful development of analytics and new methods of collecting and processing consumer information. For example, specially selected promotions in loyalty applications based on purchases, or the use of customer order patterns through the internal delivery service for notifications at certain times (such information is not widely disclosed by networks, so these applications are theoretical assumptions, although quite likely). In addition, respondents often noted that they choose stores by price and convenience of location (Fig. 2).

Thanks to the above, food retail, like almost all industries, is beginning to take wide strides towards the total personalization of "consumer travel". This term means the general experience of the client from the moment of the beginning of use of any service till the end of the current session (in this case it is stay in shop 
and use of applications of loyalty programs). All these changes make the tool proposed in this study relevant and possible for use in business processes.

Analysis of the behavior of an economic agent is one of the central themes of classical microeconomics. However, a strong focus on standardized examples did not allow researchers to draw real conclusions. The emergence of economic psychology in the works of Gabriel Tarde, George Cato, Laszlo Garai allowed the modification of purely theoretical models. The real impetus for the emergence of behavioral economics was the work of Daniel Kahneman and Amos Tversky - they developed alternative models of behavior of economic agents, taking into account the inconsistency of their adherence to the principle of maximizing utility.

\section{Nearly 60 percent of consumers cite value and convenience as drivers for trying new places to shop}

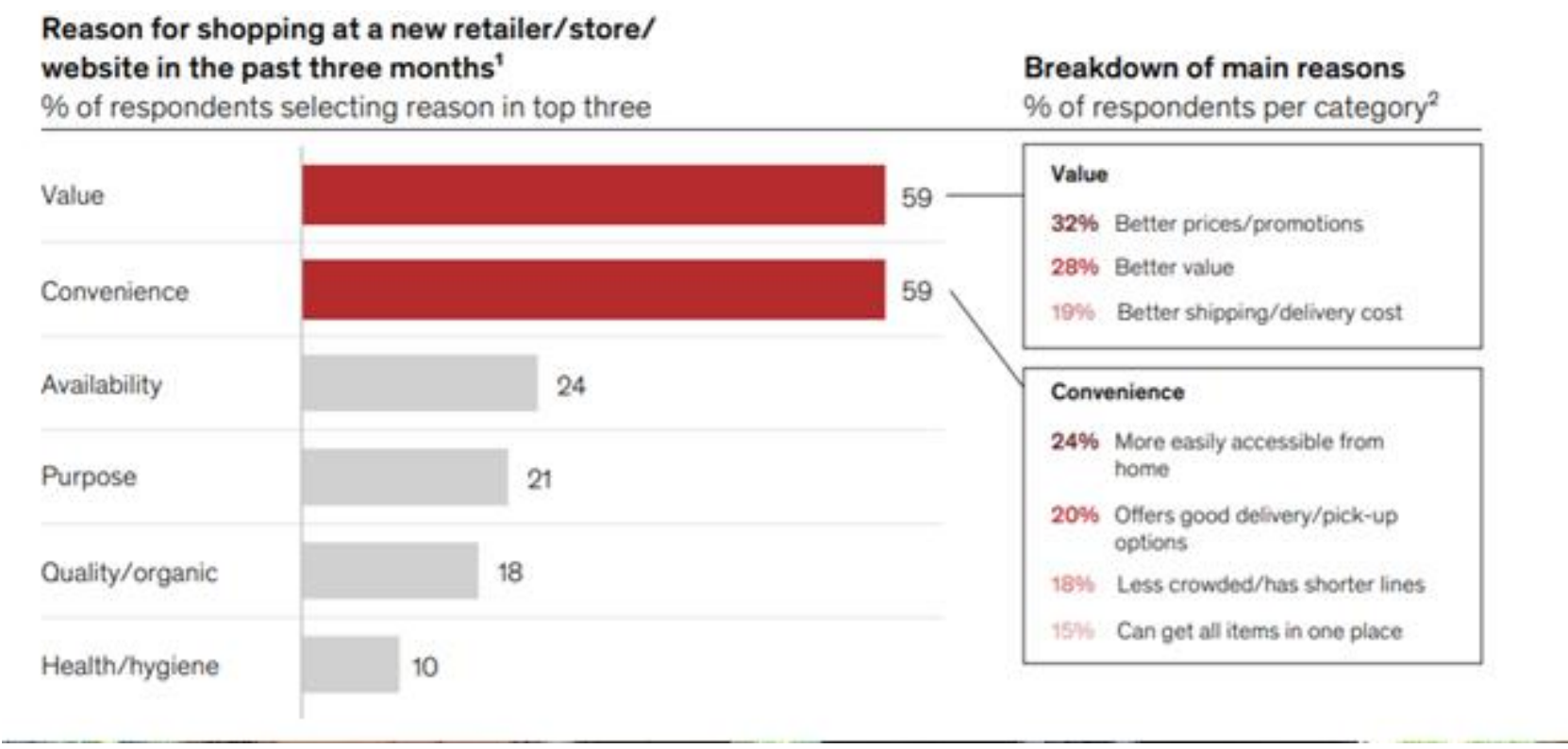

Fig. 2. Factors for choosing a new place to shop by McKinsey (2020)

Right now, with the comprehensive increase in the amount of data and the expansion of the computing capabilities of personal computers, there is a need to implement methods of behavioral economics in the study of human behavior. This is also evidenced by the work of recent years - for example, (Kolumbus\&Noti, 2019).

Consumer habits are the most important external factor influencing retail, which must be taken into account when formulating a strategy. The process of consumer decision-making to purchase goods is influenced by various factors: economic, cultural, social, personal, psychological and situational factors. Such factors include the global pandemic, which has globally changed the lives of consumers.

This study offers a tool for classifying customer preferences and analyzing current industry trends. Determining current industry trends through the eyes of consumers is done using clustering tools that are applied to respondents' responses to an online survey based on the principles and theorems of behavioral 
economics. The survey took place in December 2020 during Late Covid. According to the results of the survey, the classification was carried out using machine learning algorithms. And also, the Random Forest in-depth learning method was used to classify consumer preferences.

\section{ANALYSIS OF RECENT RESEARCH}

Behavioral economics is a branch of economic theory that is based on the psychological characteristics (cognitive, emotional, social aspects) of human actions, decisions and perceptions in various economic situations (Della Vigna, 2018). For some time, thanks to classical economic theory, it was believed that most actors always choose the optimal course of events. However, there are now studies that emphasize that $80 \%$ do not follow such a strategy (İnaç, 2019).

In 1979, D. Kahneman and A. Tversky proposed the theory of perspectives, which explained the irrational decisions of the individual. It has been shown that with a medium level of risk, people tend to maintain their current financial position rather than increase it. And even a paradox was revealed: individuals tend to take greater risks to avoid losses. At the same time, most will not try to benefit more by taking on an additional level of risk. It is these scientists who have identified the most common standard types of human behavior (heuristics), namely: similarity (based on self-confidence, the illusion of control, bias); availability (decisionmaking based on recently received information or on that which is most vividly reflected in memory) and anchors (the foundation is the basic assessments, perceptions, experience) (Lekovic, 2019).

Behavioral economics argues that man is able to act "limited by the rationalist method", while being influenced by many other factors: the behavior of others; level of economic, social and psychological satisfaction, etc. As the famous economist Richard Thaler proved in 2017, even the simplest thing, such as the "fly in the toilet" can dramatically change the type of behavior of the individual (de Arruda et al., 2015).

To create the survey, the effects of behavioral economics were selected, which clearly describe the specific characteristics of the individual's behavior. The first is Risk Aversion (Reyes et al., 2019). It describes the behavior of individuals who, when faced with uncertainty, try to reduce its degree. In practice, this is manifested when a person chooses an option with smaller achievements, but one that gives confidence in obtaining them, avoiding a riskier, but one that promises greater achievements. The opposite effect is "RiskSeeking". It describes the actions of an individual who, on the contrary, in most cases will choose the option with a higher degree of uncertainty.

The second effect is Disposition Effect (Reyes et al., 2019). A classic example is an investor who sells stocks that have risen in price but hold those that have lost some of their value. Thus, this effect shows that the individual is much less satisfied with additional income than suffers from excessive losses.

The third effect is Loss Aversion (Reyes et al., 2019). It notes that the individual will make more effort to avoid losses than to receive equivalent additional income. This differs from previous effects in that the expected utility depends on events that have already occurred or are expected in the future. 
The fourth effect is Mental Accounting (Reyes et al., 2019). It is that individuals perceive the value of the same amount of money differently, depending on the situation and subjective opinion. Therefore actions are often based not on the present optimality, and on subjective.

The fifth effect is Subjective Probability (Reyes et al., 2019). It consists in the fact that the individual determines the possibility of the occurrence of an event based on his own empirical experience or ephemeral instinct (the so-called "sixth sense"). Thus, no calculations take place, but a person's confidence in his own rightness remains high.

The sixth and final effect is "Big Fish Little Pond" (Marsh, 2005). It is that when they are in an environment where they are the best at something (or have the most pronounced trait), individuals feel better in the short term. However, in the opposite situation (the worst in a particular case, the least pronounced trait), individuals receive greater benefits in the long-term game.

\section{METHODOLOGY}

In this work we used machine learning algorithms that learn "without a teacher" - k-means, spectral clustering, hierarchical clustering, t-sne. Additionally, algorithms such as principal component analysis (PCA) and MinMaxScaler were used for data reprocessing. The Random Forest Classifier algorithm, which works on the basis of a combination of decision trees, was used to classify consumers. All algorithms were used from the library of the scikit-learn (sklearn) Python programming language (Ahuja et al., 2020).

The basis of clustering algorithms is minimization in different ways the distances between groups of datapoints in order to highlight the groups as close as possible to each other. Most often, the data are divided into training and test samples to verify the accuracy of models in a completely unfamiliar situation and to avoid retraining (giving increased level of importance to characteristics that are clearly manifested only in training data).

$\mathrm{K}$-means selects $\mathrm{K}$ centroids randomly or from those suggested by the user. After that, the algorithm calculates the distance from each point in the dataset to the centroids, updates the position of the centroids, putting them in the position of the arithmetic mean of the points of the cluster that they describe. In the following steps, the algorithm lists the points belonging to the clusters and again updates the position of the centroids according to the formula $V=\sum_{i=1}^{k} \sum_{x \in S_{i}}\left(x-\gamma_{i}\right)^{2}$, where де $k$ is the number of clusters, $S_{i}$ are the obtained clusters, $i \in\{1 ; k\}, \gamma_{i}$ are the centers of mass of all vectors $x$ from the $S_{i}$ cluster.

The stage when the position of the latter remains unchanged is called the final - it becomes the basis for clusters, which gives the model output. To improve the operation of the algorithm, it is recommended to use methods to reduce the dimensionality of the data, such as Principal component analysis (PCA) (Roweis, 1998).

PCA is used to display a multidimensional data array on a two-dimensional plane or to improve the performance of clustering algorithms. It minimizes the sum of the squares of the deviations of the vectors $x_{i}$ 
from the linear spaces $L_{k}$ by the formula $\sum_{i=1}^{m} d i s t^{2}\left(x_{i}, L_{k}\right), d i s t^{2}$ is Euclidean distance. The method requires a predetermined number of principal components. PC1 absorbs the vector of the largest variance of dataset characteristics, PC2 - the second largest, and so on. Thus, according to the Pareto principle, the first two components must absorb most of the data information - but they are not informative in themselves (Von Luxburg, 2007).

Spectral clustering is an algorithm that, unlike K-means, works better with non-standard data (such as a spiral). It uses a pairwise similarity matrix to pre-reduce the dimension, such as a symmetric normalized Kirchhoff matrix given by the formula $L^{\text {norm }}=I-D^{-\frac{1}{2}} A D^{-\frac{1}{2}}$, where $D$ is diagonal matrix $D_{i i}=\sum_{j} A_{i j}$. This is followed by a process of recalculating the matrix until it is possible to increase the similarity of the two points without reducing their similarity with others [(Murtagh\&Contreras, 2012).

Hierarchical clustering works iteratively, where in the first step each point is its own cluster. At each subsequent step, the algorithm merges the two nearest clusters until one cluster remains. At the same time the method of singular communication is used $R_{\min }(U, V)=\min _{u \in U, v \in V} \rho(u, v)$, where $R(U, V)$ is distance between clusters, $\rho(u, v)$ is the distance between the points of these clusters. At the output you can get a graphical interpretation of all steps, which potentially allows the researcher to identify hidden common features of different clusters and analyze how many groups to choose (at which step to set the stop signal) (Roweis, 1998).

T-SNE - map clustering algorithm and dimension reduction. At each step, the Gaussian distribution of neighbors is modeled for each point. The task of the algorithm is to find a position in two-dimensional space that minimizes the distance between the t-distribution built on it and the previous Gaussian distribution at all their points based on the Shannon entropy. Like PCA, the algorithm is often used to visualize multidimensional datasets (Wattenberg et al., 2016).

To improve the performance of clustering algorithms, the MinMaxScaler procedure was used, which normalizes the data by minimum/maximum. This avoids further algorithms to reduce the dimensionality of the data giving more weight to the characteristics with greater variance.

The next step was to use Principal Component Analysis to be able to visualize a multidimensional dataset on a two-dimensional graph and simplify further work with it. The elbow method and the silhouette coefficient were used to determine the optimal number of clusters (Yadav, 2017).

The "elbow method" is to select the number of clusters that correspond to the largest positive change in mathematically explained oscillations (explained variation). That is, it is the choice of the point where an additional explanation of the model of oscillations in the data is not worth highlighting additional clusters. This is because the more clusters, the easier it is to explain all the connections in the dataset - but at some stage the model begins to relearn, highlighting purely specific to the training sample characteristics. Alternatively, instead of explained variation, the inertia index can be used - the sum of the quadratic distances of points to their nearest cluster centers (Yadav, 2017). 
Silhouette score (SI) assesses how the points collected in one group are identical in characteristics. It is

calculated by the formula: $\frac{b-a}{\max (a, b)}$, if the number of clusters is greater than 1 , where $a$ is the average intracluster distance; $b$ is the average near-cluster distance (average of the distances from the point to all others in the nearest cluster). If the cluster is only 1 , then SI is 0 . The final value varies within $(-1 ; 1)$, where 1 means the most clearly demarcated clusters; 0 - clusters with points that are very close to the boundaries of neighboring clusters; and a negative value indicates that an error has crept into the process of assigning observations to the clusters (Yadav, 2017).

The modern method of solving classification and regression problems is a set of decision trees, the socalled Random Forest (Liaw\&Wiener, 2002). In contrast to the previously described algorithms, this is an example of "guided learning" or "learning with a teacher". This means that in addition to the mandatory division of the sample into training and test, it is necessary to label educational data.

The basis of any variation of the random forest algorithm is an ordinary decision tree. A random forest is a collection of $N$ decision trees, each of which receives an incomplete random set of characteristics and builds its own forecast or classification. The final option is one that has been chosen by most trees (Liaw\&Wiener, 2017).

All committee trees are built independently of each other according to this procedure:

- A random subsample with a repetition of size $N$ from the training sample is generated. (Thus, some examples will get into it several times, and about N/3 examples will not be included in it at all).

- A decision tree is constructed that classifies examples of such a subsample, and during the creation of the next node of the tree, the feature on the basis of which the partition is performed is selected not from all $M$ features, but only from $m$ randomly selected. The choice of the best of these $m$ features can be done in different ways (for example, the criterion of information growth is used).

- The tree is built until the subsample is completely exhausted and will no longer undergo the procedure of pruning.

The classification of objects is done by voting: each tree of the committee assigns the object to be classified to one of the classes, and wins the class for which the largest number of trees voted.

\section{RESULTS}

An online survey based on the principles of behavioral economics was created. A total of 141 respondents passed it. The works of D. Kahneman and A. Tversky, in particular (Kahneman\&Tversky, 1979) and (Kahneman, 2011), were taken as the theoretical basis for creating this survey. In addition, materials from the online course Behavioral Finance from Duke University on the Coursera platform, podcasts "Freakonomics Radio" and "No Stupid Questions" and articles (Roweis, 1998), (Prince, 2018), (Beerbaum\&Puaschunder, 2018), (Hrnjic\&Tomczak, 2019), (Najdenovska et al., 2018), (Dyer\&Kolic, 2020), (March, 2019), (Bechara, 2002) were used. 
The final version of the survey consisted of 26 questions, where questions 1-5 gave general information about the respondent, questions 6-15 focused on behavioral drivers (Kahneman, 2003), (Kahneman, 2011), questions 16-26 - on food retail trends and consumer habits.

The first and second questions characterize riskiness or prudence. This is an example of the Risk Seeking effect or Risk Aversion (Stefansson\&Bradley, 2017). In the question, it is suggested to play a game where you can either take a guaranteed amount of money (option A), or toss a coin, and with a probability of 50\% get a bigger prize or nothing (option B). In total, out of 141 respondents in the first question, $66 \%$ chose option A. In the answers to the second question, in which the amounts were 10 times larger, the effect of Risk Seeking is even more noticeable $-82.3 \%$.

The third and fourth questions are examples of Disposition Effect (Barberis\&Xiong, 2009). In the third question, the respondent is given 7,000 hryvnias and is offered to either receive 3,000 hryvnias guaranteed (A), or toss a coin and with a probability of 50\% receive 6,000 hryvnias (B). In the next question, the initial rate is higher, because 1000 hryvnias is added to the capital left over from the previous question, and the options are as follows: losing 6,000 hryvnias is guaranteed (A), or tossing a coin and losing 12,000 hryvnias with a $50 \%$ probability (B).

Most respondents choose 3-A (3,000 hryvnias guaranteed) and 4-B (lose 12,000 hryvnias or nothing). In this case, if you choose 3-A (get 3000 hryvnias guaranteed) and 4-A (lose 6000 hryvnias guaranteed), then in both cases the prize will be 12000 hryvnias. Also, if the respondent chooses 3-B and 4-B, the win is ranked from the negative (loss of 4,000 hryvnias) to 14,000 hryvnias. The effect is that most people tend to become "risk-free" when it comes to being able to gain something, and "risky" when it comes to losing something (Johnson et al., 2006) The percentage distribution in the questions is as follows: $61.7 \%$ (A) in the third and $50.4 \%$ (B) in the fourth.

The following questions demonstrate such effects as Mental Accounting (Tversky, 1986), Subjective Probability (Machina\&Schneider, 1992) and Big Fish Little Pond (Roweis, 1998), (Marsh et al., 2008). The first shows how different individuals give different subjective weight to the same amount of money. Two situations of buying a ticket to the cinema were presented in the question. In one individual buys a ticket in advance and loses it. In this situation, $51.1 \%$ of respondents said they would not buy a ticket again. In another, the individual loses money on the ticket amount. In this case, $53.9 \%$ of respondents said they would buy a ticket. Thus, in both cases the same amount was lost, but the perception of this loss is different.

The Subjective Probability effect is based on the fact that the individual, assessing the probability of a particular event, often does not make calculations, but refers to their own feelings or experiences. One historical example is the mass phobia of aircraft after 9/11, although according to statistics, driving a car is a much more dangerous choice. When asked where poker players with the same experience but different winnings over the last few games are represented, $81.6 \%$ of respondents correctly stated that everyone has an equal chance of winning the next game. 
The Big Fish Little Pond effect is based on a constant choice of environment. Being the smartest / sexiest can be quite a tempting option, but in the long run it is more profitable to be a "little fish", because it gives more opportunities for development. In answering the question with mental injection, $78.7 \%$ of respondents chose the option of becoming 10\% smarter (but everyone around them will be smarter than them) instead of becoming 5\% smarter (and smarter than everyone else). When it comes to earnings, $82.7 \%$ of respondents chose to earn 35,000 hryvnias (all others earn at least 40,000 hryvnias) instead of earning 30,000 hryvnias (all others earn no more than 25,000 hryvnias). Finally, when it comes to using an experimental drug to increase sexuality, $75.2 \%$ of respondents chose the assessment of their expected condition after the procedure as 9 out of 11 (surrounding - 11 out of 11) instead of 7 out of 11 (but surrounding 5 out of 11).

Despite the fact that the questions from the block of determining behavioral characteristics are quite abstract, they nevertheless demonstrate that the surveyed respondents are more knowledgeable than the average individual.

The next block of questions was aimed at identifying Late-Covid trends in food retail in Kyiv, as almost all respondents live in the capital. According to the results of the survey, $61.7 \%$ of respondents buy products from Silpo, 54.6\% - from ATB, 41.1\% - from Novus, 36.9\% - from Auchan, 19.9\% - from Varus, less - in other networks (respondents had the opportunity to choose up to 3 options).

When choosing a store, most respondents preferred the proximity of the location, range of products and prices of products. More than half of the respondents (55.3\%) stressed that the proximity of the store location became the most important criterion for choosing a place of purchase after the pandemic, which is confirmed by the rapid development of the segment "at home" in 2020 (Fig. 3).

Choose 3 most important features that you consider when choosing where to shop:

141 replies

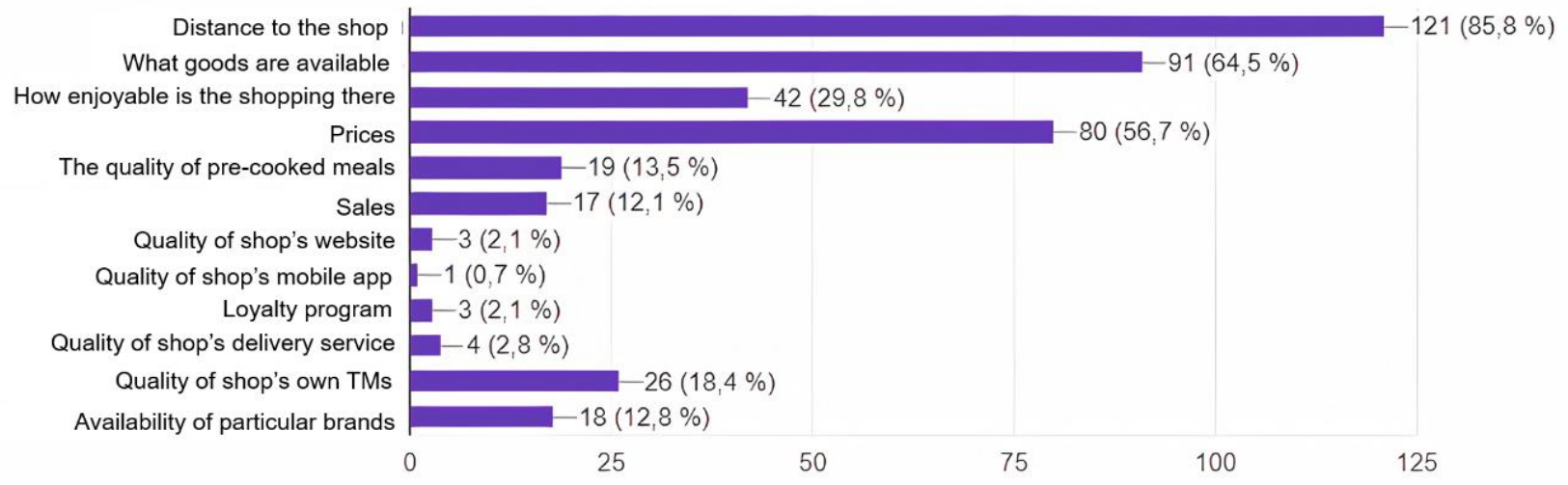

Fig. 3. Distribution of the sample according to the criterion of choosing the place of purchase 
The most popular products were the segment "fresh" (fresh vegetables and fruits), dairy products and cereals / pasta. In the publications of public food retail companies, these types of products are also highlighted as the main ones. This fact confirms the current trend towards healthy eating.

Interestingly, $39.7 \%$ of respondents admitted that they make impulsive purchases during almost every visit to the store, and $36.9 \%$ do so several times a month. At the same time, only $9.9 \%$ check the list of components of each product, but for $38.3 \%$ this action is only as an exception to the rules.

As for environmental initiatives of food retail, $72.3 \%$ of respondents consider them interesting, but in no case as reasons to buy in the stores that conduct such initiatives.

Even after the pandemic, $66.7 \%$ of respondents either do not buy food online or make less than 1 purchase out of 10 online purchases. But only $9.2 \%$ of respondents use paper money to pay. This shows that the pandemic has greatly increased the use of electronic funds. However, in Ukraine there is still distrust in ordering food online, even among young people (Fig. 4).

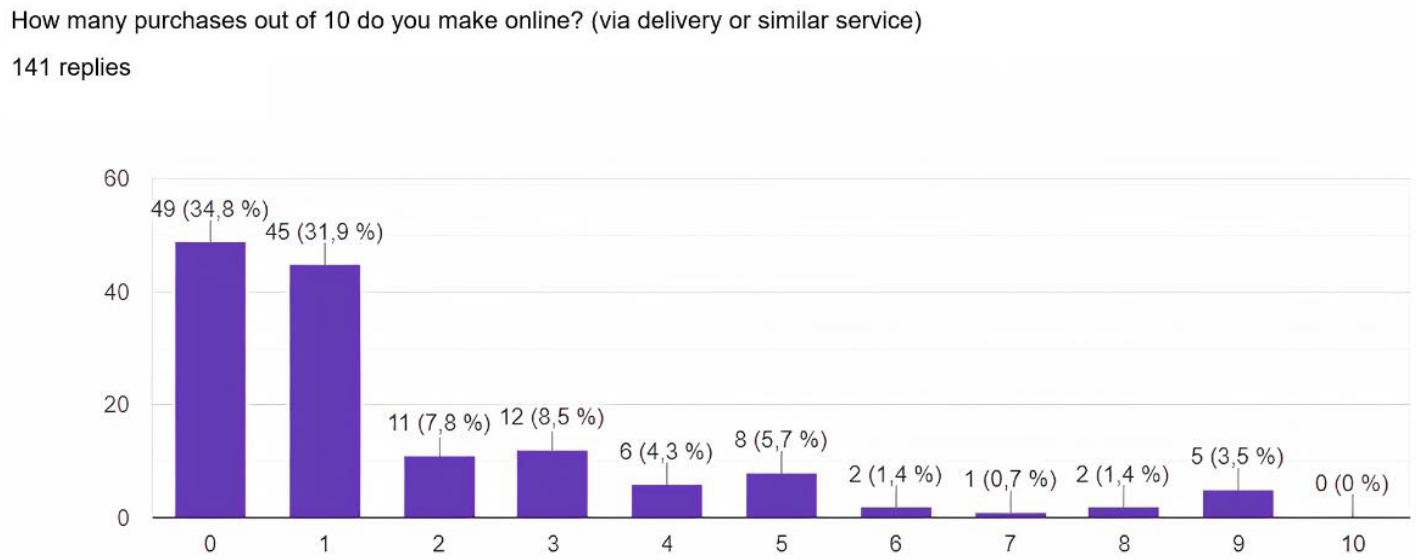

Fig. 4. Number of food orders online

The next step in the study was to identify clusters of consumers of food retail chains in order to improve their "buyer's journey" and better understand their needs.

When clustering with K-means, three clusters were identified. SI was 0.48 , which shows the average distance of the clusters. Fig. 5 presents a visualization of the results of clustering, relative to the first (PCA1) and second (PCA2) main component. PCA1 lies on the abscissa axis. It is worth noting that there were more women than men in the sample, so the sex parameter is not significant in the clusters. 


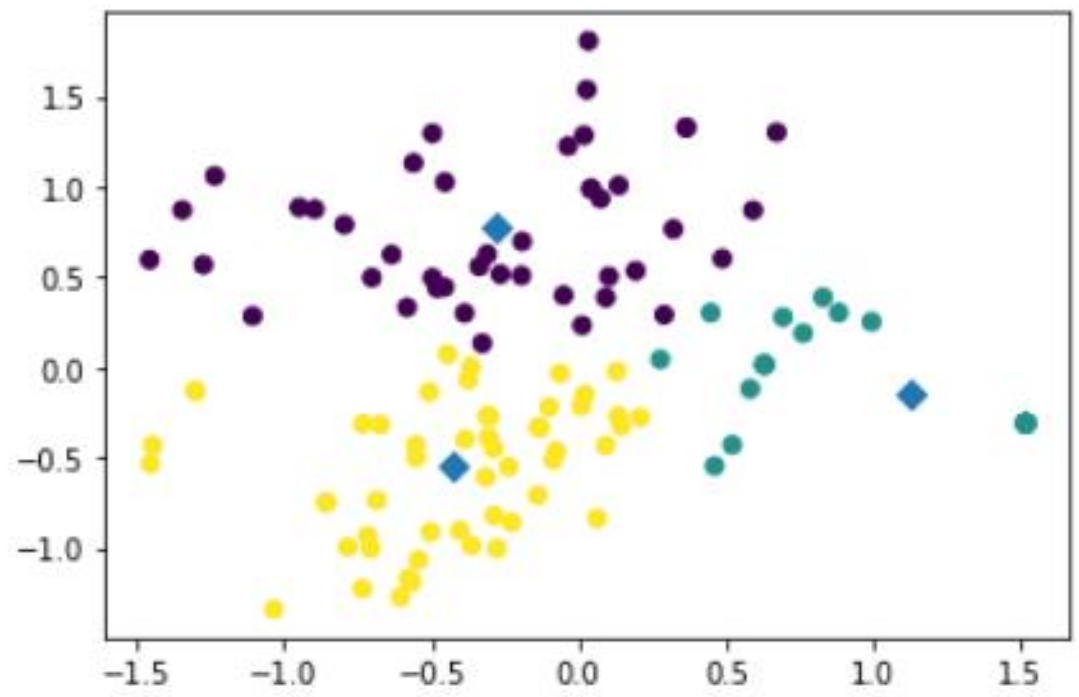

Fig. 5. Graphical interpretation of K-means clusters

PCA1 and PCA2 explain 57\% and 43\% of the scatter, respectively. This means that the PCA-analysis passed normally and gives significant results. Each characteristic has its own level of impact on the main components. The larger the Scores in absolute terms, the more important the characteristic for the corresponding component. Using the "elbow method", 3 clusters were identified.

In addition, a Silhouette analysis (SA) was performed to confirm the selection of the optimal number of clusters. In Fig. 6 you can see the result of SA, which is a calculation of SI for a different number of clusters. The choice is made on the most balanced result. For example, the graphs show that the 4th cluster is becoming too specific.

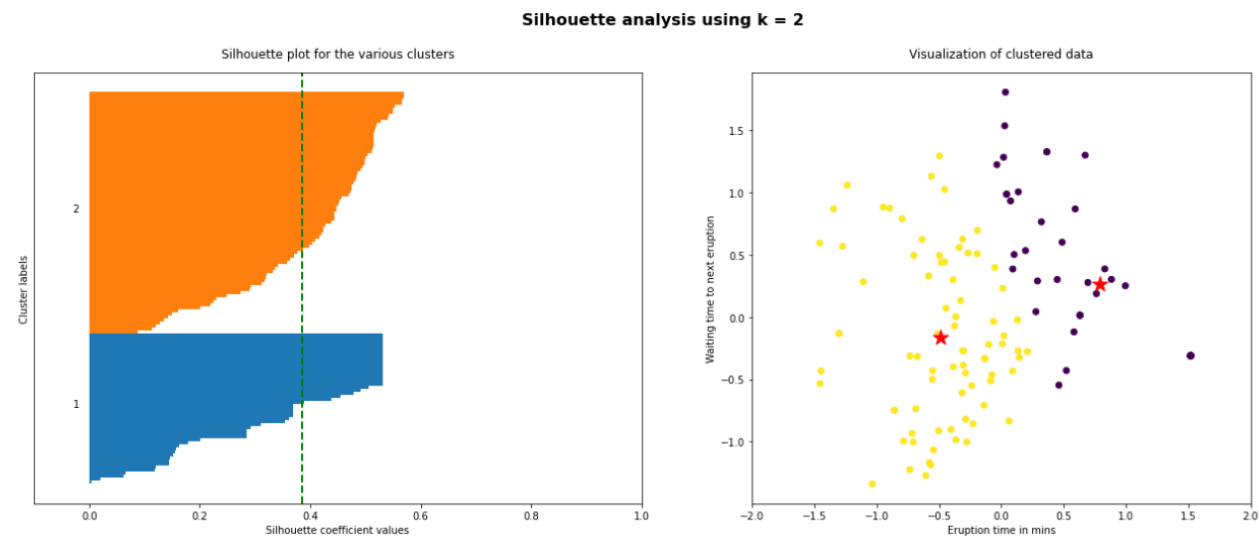



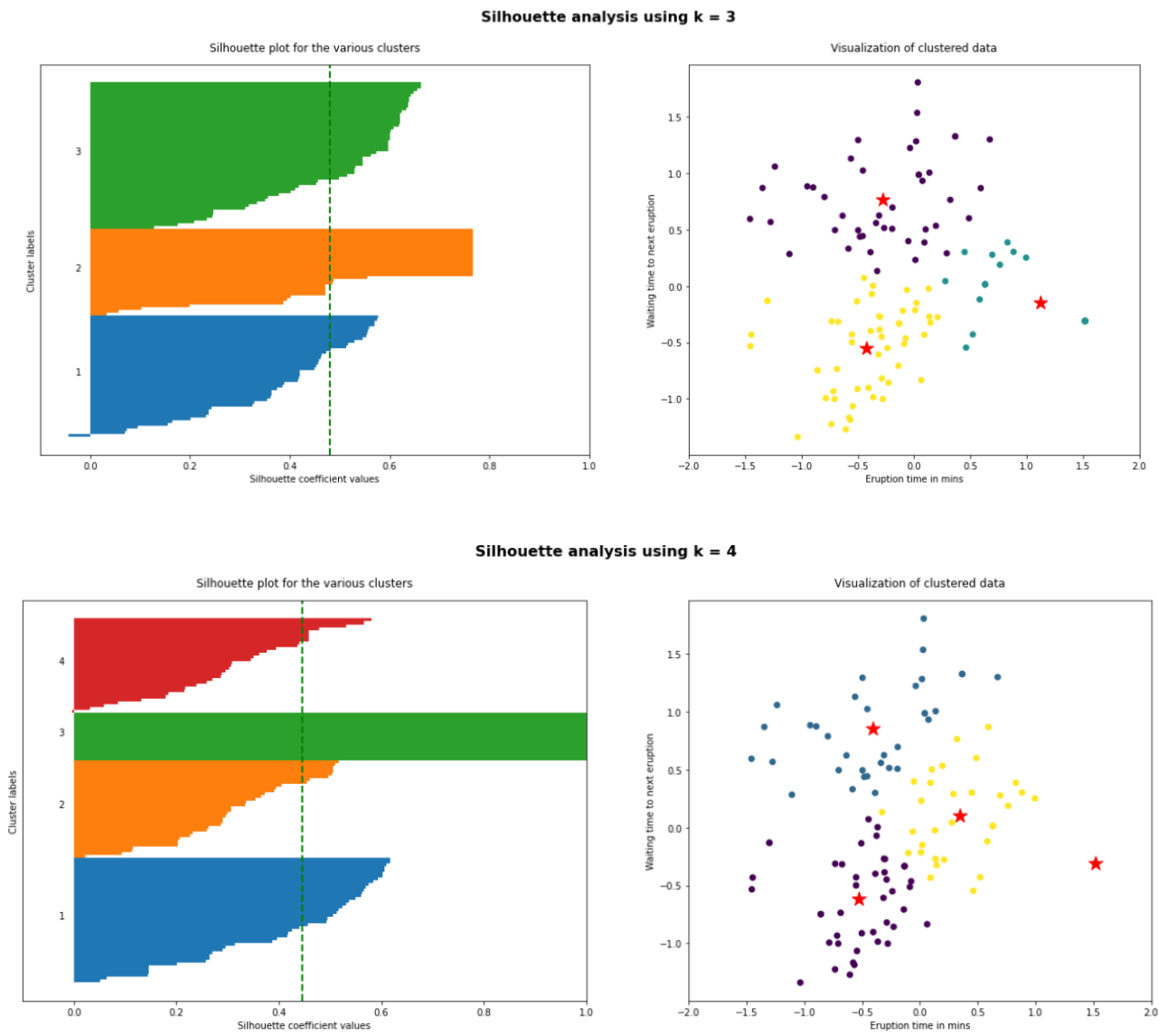

Fig. 6. Silhouette analysis for $\mathrm{k}=2 ; 3 ; 4$

For Spectral clustering, 3 clusters were also used as the optimal number. SI was 0.45 , in addition, on the visual representation you can clearly see the problem of this method - the allocation of emissions into a separate cluster (regardless of the number of selected). Thus, in this case it is a less accurate representation of the internal groups of the dataset than K-means (Fig. 7).

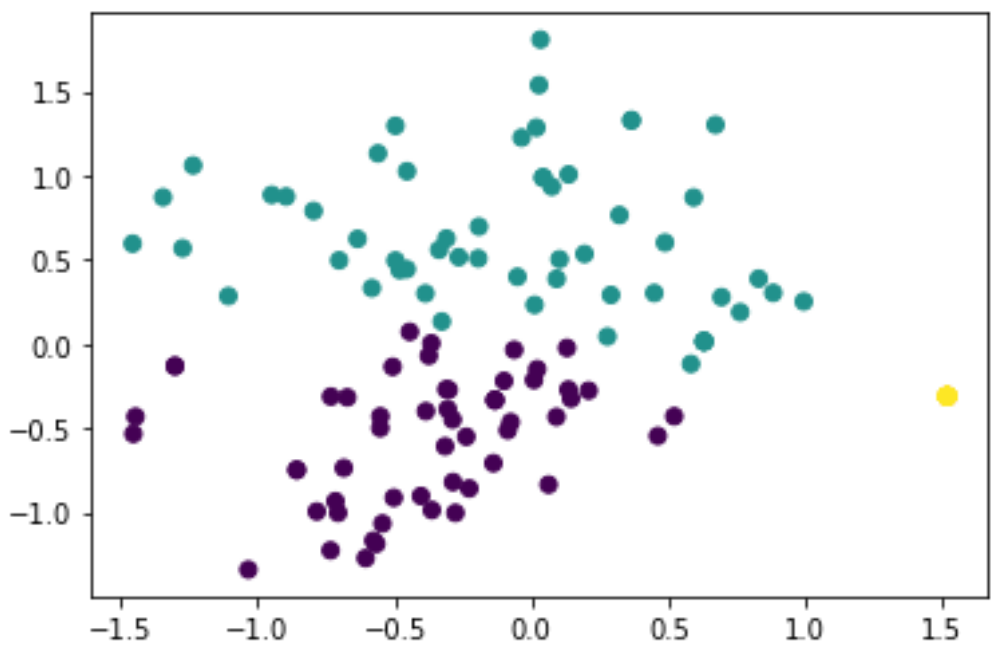

Fig. 7. Spectral clustering results 
The hierarchical method and T-SNE were used for additional visual representation. The first showed that in the data set (dataset) there are two rather large and full clusters and one consisting of a much smaller number of observations (Fig. 8).

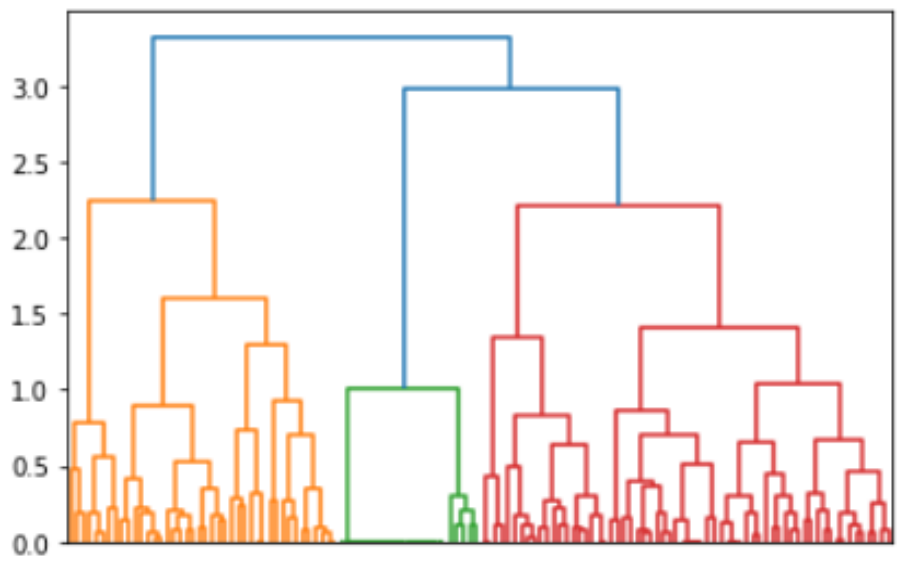

Fig. 8. Hierarchical clustering results

The T-SNE method identified rather strongly superimposed clusters, so this clustering is not significant (Fig. 9).

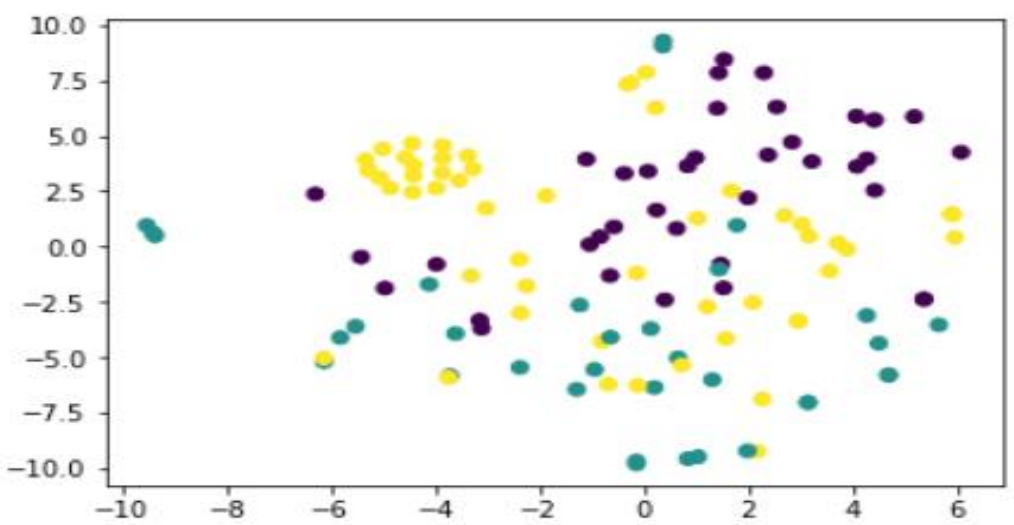

Fig. 9. T-SNE clustering results

Therefore, clustering by the K-means method was the best, so clusters by K-means were used to analyze the dataset (table 1).

Table 1. K-means cluster centroids

\begin{tabular}{|r|r|c|r|r|r|r|r|r|r|r|}
\hline Cl/Q & $\mathbf{1}$ & $\mathbf{2}$ & $\mathbf{3}$ & $\mathbf{4}$ & $\mathbf{5}$ & $\mathbf{6}$ & $\mathbf{7}$ & $\mathbf{8}$ & $\mathbf{9}$ & $\mathbf{1 0}$ \\
\hline $\mathbf{1}$ & 0 & 1 & 0 & 0 & 1 & 1 & 3 & 2 & 1 & 1 \\
\hline $\mathbf{2}$ & 1 & 1 & 1 & 0 & 0 & 1 & 3 & 2 & 1 & 1 \\
\hline $\mathbf{3}$ & 1 & 1 & 1 & 1 & 0 & 0 & 3 & 2 & 1 & 1 \\
\hline $\mathbf{C l} / \mathbf{Q}$ & sex & IOS/Andr & work & study & Silpo & ATB & Varus & Novus & Auchan & fin \\
\hline
\end{tabular}




\begin{tabular}{|l|l|l|l|r|r|r|r|r|r|r|}
\hline $\mathbf{1}$ & 2 & 2 & 1 & 1 & 1 & 0 & 0 & 1 & 0 & 2 \\
\hline $\mathbf{2}$ & 2 & 2 & 1 & 1 & 1 & 0 & 0 & 0 & 1 & 3 \\
\hline $\mathbf{3}$ & 2 & 1 & 1 & 1 & 0 & 1 & 0 & 0 & 0 & 3 \\
\hline
\end{tabular}

Source: Own calculations

It can be seen that the majority of respondents in all clusters are women $(\operatorname{sex}=2)$, work or do internships ( work $=1$ ), study at university (

Among the main defining characteristics of the first cluster are the following: respondents are more risky (in the first and third questions about tossing a coin or a fixed win, they choose a coin); buy a ticket in any case (the fifth and sixth questions); are consumers of the Novus and Silpo network and fully self-sufficient (fin $=2$ ).

The second cluster is less risky (in the first and third questions a fixed win is chosen); ticket purchase occurs only in case of loss of funds (the fifth and sixth questions); respondents are consumers of Silpo and Auchan; they partially provide for themselves.

The third cluster has respondents who are risk-free even in case of loss of money (the fourth question); they are consumers of ATB stores and partially provide for themselves.

In order to confirm the practicality of using this survey, Silpo clients were classified by the Random Forest algorithm. The binary characteristic ( 1 - client, 0 - no) was taken as the dependent variable, which was explained by the answers to other questions. Initially, the sample was divided into training and test in the proportion of $80 \%$ by $20 \%$ using random sorting algorithm train_test_split. The next step was normalization by the MinMaxScaler algorithm.

After cyclic training of 30 models with random characteristics, a random forest was built, which included 100 decision trees. Depth of each tree was 10 (maximum number of division of branches); the algorithm uses bootstrap (each tree receives a random incomplete set of data from the total sample). The accuracy of the Random Forest Classifier was assessed by several metrics from the sklearn library.

Traditional methods of evaluating classifiers in machine learning use a confusion matrix, which shows how different the data classified by the model differs from the true data set. Matrix elements are denoted as TP - True Positive, FN - False Negative, TN - True Negative, FP - False Positive. Using an error matrix, you can calculate several metrics that will assess the effectiveness of classification algorithms (Murtagh\&Contreras, 2012).

Precision is the share of correctly classified elements (True Positive) among all positives: $p r e c=\frac{T P}{T P+F P}$ . Recall is the share of correctly classified elements among all relevant elements $r e c=\frac{T P}{T P+F N}$. Accuracy is 
the share of correctly classified elements $a c c=\frac{T P}{T P+F P+T N+F N}$. Balanced accuracy score, calculated as the average of all class corrections: $b a c c=\frac{1}{2}\left(\frac{T P}{T P+F N}+\frac{T N}{T N+F P}\right)$.

F1 measure (F1 score) is the average harmonic Precision and Recall: $F 1=2 \cdot \frac{\mathrm{prec} \cdot \mathrm{rec}}{\mathrm{prec}+\mathrm{rec}}=\frac{2 T P}{2 T P+F P+F N}$. The highest possible value of the F-measure is 1, which indicates ideal accuracy and sensitivity, and the lowest possible value is 0 if either accuracy or completeness is zero.

The quality of the constructed classifier is characterized by the following values of measures (Table 2). The Accuracy score metric, which determines the accuracy of the multiclass classification, became 0.73 . The Balanced accuracy score metric, calculated as the average of all class corrections, showed a close value of 0.725 . The values of these metrics do not match because the number of examples in each class is not the same. A balanced F-score or F1-measure gave a score of 0.77 .

The average accuracy of the model based on the data of three metrics is 0.742 , which is a rather mediocre result and requires further adjustment. One such option is to discard redundant characteristics by processing data by methods such as linear regression, lasso regression, recursive feature elimination (RFE), and so on.

Table 2. Effectiveness metrics of Random Forest classification

\begin{tabular}{|l|c|c|c|c|}
\hline Metrics & Accuracy & $\begin{array}{c}\text { Balanced } \\
\text { Accuracy }\end{array}$ & F1 & Average \\
\hline Scoring & 0.730 & 0.725 & 0.770 & 0.742 \\
\hline \multicolumn{5}{|c}{ Source: Own calculations } \\
\hline
\end{tabular}

\section{CONCLUSION}

In the course of this study, a survey was created aimed at identifying patterns of behavior of the modern consumer according to his criteria for choosing stores and reactions to questions based on the theorems of behavioral economics. The survey took place in December 2020 during Late Covid. Clustering using machine learning methods was applied to the obtained results. The next stage of the study was the classification based on the Random Forest algorithm.

Using Silhouette analysis, the optimal number of clusters was determined and the database was divided into three K-means clusters. T-SNE algorithms, hierarchical and spectral analysis were used for additional visual representation.

According to the results of the analysis, it was found that the respondents of the first cluster are at risk, self-sufficient and are clients of Novus and Silpo. The second cluster includes moderately risky respondents who are partially self-sufficient, consumers of Silpo and Auchan. The third cluster is formed by respondents who are risk-free, partially self-sufficient, and use the services of the ATB stores. It is recommended to take 
these characteristics into account when creating personalized consumer offers, for example, to offer a more "aggressive" one for customers from the first cluster.

The created survey-tool for clustering and classification of consumers by machine learning methods is suitable for use in business processes. One application is, for example, allocation customers of a food delivery company to clusters by customer behavior patterns.

However, to improve the result, it is necessary to have a more representative sample, because used in this study consists of on average rational and knowledgeable individuals. It should be borne in mind that the average typical consumer does not necessarily have such qualities, and this applies to both older and younger generations.

Machine learning algorithms have shown their effectiveness in studying consumer behavior. This technique can be successfully used as a tool of behavioral economics. Promising areas for further research are to identify new behavioral trends in other industries; deepening understanding of food retail; use of geodata to improve analysis, etc. A potentially attractive area would be to consider assessing the impact of advertising on consumer behavior through semantics analysis and image recognition.

\section{Conflict of interests}

The authors declare no conflict of interest.

\section{References}

Accuracy Score. Retrieved from: https://scikit-learn.org/stable/modules/model_evaluation.html\#accuracy-score. (accessed: June 2021)

Ahuja, Ravinder, et al. (2020). Classification and clustering algorithms of machine learning with their applications. Nature-Inspired Computation in Data Mining and Machine Learning. Springer, Cham, 225-248.

Balanced Accuracy Score. Retrieved from: https://cutt.ly/ibZ3IgM. (accessed: June 2021)

Balanced Accuracy Score. Retrieved from: https://scikit-learn.org/stable/modules/generated/sklearn.metrics.f1_ score.html. (accessed: June 2021)

Barberis, N., Xiong, W. (2009) What drives the disposition effect? An analysis of a long-standing preference-based explanation, The Journal of Finance, LXIV(2).

Bechara, A. (2002) The somatic marker hypothesis: a neural theory of economic decision. Games and Economic Behavior, 52(2), 336-372.

Beerbaum, D., Puaschunder, J.M. (2018). A behavioral economics approach to digitalisation - the case of a principlesbased taxonomy. Advances in Social Science, Education and Humanities Research, 211, 45-53.

de Arruda, T.J., de Moraes, M.B., de Araujo Querido Oliveira, E.A. (2015). Behavioral finance: a study on investments decisions, Business and Management Review Special Issue, 4(7). Retrieved from: http://www.businessjournalz.org/bmr (accessed: June 2021)

Della Vigna, S. (2018) Structural behavioral economics, Handbook of Behavioral Economics, vol. 1 (eds. D. Bernheim, S. DellaVigna, and D. Laibson), Elsevier.

Deloitte. 2021. Consumer sentiment of Ukrainians in 2020. Industry group for retail and wholesale distribution. Retrieved from:https://www2.deloitte.com/ua/uk/pages/press-room/press-release/2021/2020-consumer-behavior-in-ukraine. html (accessed: June 2021)

Dyer, J., Kolic, B. (2020). Public risk perception and emotion on Twitter during the Covid 19 pandemic. Applied Network Science, 5(99). 
Food retail trends by foodnavigator. Retrieved from: https://www.foodnavigator.com/Article/2021/01/06/Retailpredictions-2021-Experts-forecast-food-plastic-and-climate-smart-trends. (accessed: June 2021)

Google Trends in Ukraine (food retail), Retrieved from: https://rau.ua/novyni/5-golovnyh-tendentsij-v-marketyngu/. (accessed: June 2021)

Hrnjic, E., Tomczak, N. (2019) Machine learning and behavioral economics for personalized choice architecture, preprint, arXiv:1907.02100v1 [econ.GN], 2019.

İnaç, H. (2019) A Theoretical Perspective on Behavioral Finance with Lagrangian Approach, Quantrade Journal of Complex Systems in Social Sciences, 1(1), 22-27.

Jabnidze, N.; Tsetskhladze, L.; Meskhidze, I. (2021). Food Security Problems for Developing Countries in the Conditions of COVID-19: Case of Georgia. Economics. Ecology. Socium , 5, 8-17.

Johnson, E.J., Gächter, S., Herrmann, A. (2006). Exploring the nature of loss aversion. IZA Discussion Papers, Institute for the Study of Labor, 2015.

Kahneman, D. (2003). Maps of bounded rationality: psychology for behavioral economics. The American Economic Review, 93(5), 1449-1475.

Kahneman, D. (2011). Thinking, fast and slow, New York: Farrar, Straus and Giroux.

Kahneman, D., Tversky, A. (1979). Prospect theory: an analysis of decision under risk. Econometrica. 47, $263-291$.

Kolumbus, Y., Noti, G. (2019). Neural networks for predicting human interactions in repeated games. Proceedings of the Twenty-Eighth International Joint Conference on Artificial Intelligence Main track, 392-399.

Lekovic, M. (2019). Behavioral portfolio theory and behavioral asset pricing model as an alternative to standard finance concepts, Economic Horizons, 21(3), 255 - 271.

Liaw, A., Wiener, M. (2002). Classification and regression by randomForest. $R$ news, 2.3, 18-22.

Machina, M., Schmeidler, D. (1992). A more robust definition of subjective probability. Econometrica, 60(4), 745-780.

March, C. (2019) The behavioral economics of artificial intelligence: lessons from experiments with computer players, CESifo Working Paper, 7926, category 13: Behavioural Economics.

Marsh, H.W. (2005). Big Fish Little Pond Effect on Academic Self-concept: Cross-cultural and Cross-Disciplinary Generalizability, SELF Research Centre, University of Western Sydney.

Marsh, Herbert W., et al. (2008). The big-fish-little-pond-effect stands up to critical scrutiny: Implications for theory, methodology, and future research. Educational psychology review 20(3), 319-350.

McKinsey\&Company, 2020. Perspectives on retail and consumer goods. Retrieved from: https://cutt.ly/ebZ1Ylb. (accessed: June 2021)

MOOC «Behavioral Finance». Retrieved from: https://www.coursera.org/learn/duke-behavioral-finance/home/welcome. (accessed: June 2021)

Murtagh, F., Contreras, P. (2012). Algorithms for hierarchical clustering: an overview. Wiley Interdisciplinary Reviews: Data Mining and Knowledge Discovery 2.1, 86-97.

Najdenovska, I., Stojanovska, F., Gievska, S. (2018). Detecting emotions in tweets based on hybrid approach, Proceedings of the 15th Conference for Informatics and Information Technology: CIIT 2018, 20-22 Mavrovo, Macedonia, pp. 235-240. Retrieved from: https://www.researchgate.net/publication/331089014. (accessed: June 2021)

Podcast "Freakonomics Radio". Retrieved from: https://freakonomics.com/podcast/. (accessed: June 2021)

Podcast "No Stupid Questions". Retrieved from: https://freakonomics.com/podcast/. (accessed: June 2021)

Prince, E.T (2018). Risk management and behavioral finance. Financial markets, institutions and risks, 2(2), 5-21. DOI: 10.21272/fmir.2(2).5-21.2018.

Reyes, J.A.P., Miranda, M.R., Vera-Martinez, J. (2019). Capital structure construct: a new approach to behavioral finance. Investment Management and Financial Innovations, 16(4), 86-97.

Roster on Debit Cards in food retail. Retrieved from: https://rau.ua/novyni/novini-kompanij/53-vyruchky-restoratorivkartamy/. (accessed: June 2021)

Roweis, S. (1998). EM algorithms for PCA and SPCA. Advances in neural information processing systems 626-632. Retrieved from: https://scikit-learn.org/stable/modules/generated/sklearn.preprocessing.MinMaxScaler.html. (accessed: June 2021) 
Stefánsson, H.O., Bradley, R. (2017). What is risk aversion? The British Journal for the Philosophy of Science, 70(1), $77-102$.

The Behavioral Economics Guide 2014. Introduction to behavioral economics. Retrieved from: https://www.behavioraleconomics.com/resources/introduction-behavioral-economics/. (accessed: June 2021)

Train_test_split. Retrieved from: https://scikit-learn.org/stable/modules/generated/sklearn.model_selection.train test_split.html. (accessed: June 2021)

Tversky, A. (1986). Rational choice and framing of decisions. Journal of Business, 59, 252-278.

Von Luxburg, U. (2007). A tutorial on spectral clustering. Statistics and computing 17.4, 395-416.

Wattenberg, M., Viégas, F., Johnson, I. (2016). How to use t-SNE effectively. Distill, 1(10).

Yadav, J. (2017). Selecting optimal number of clusters in KMeans Algorithm (Silhouette Score). Medium. Retrieved from: https://jyotiyadav99111.medium.com/selecting-optimal-number-of-clusters-in-kmeans-algorithm-silhouettescore-c0d9ebb11308. (accessed: June 2021)

\section{About the authors}

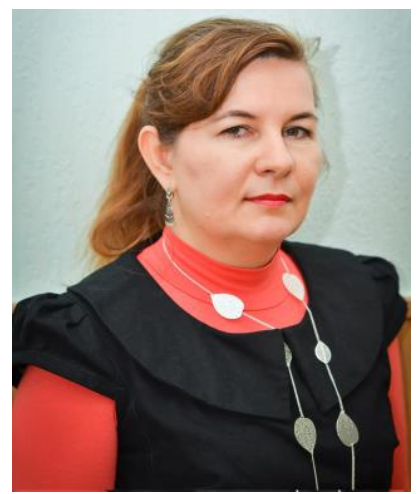

\section{Olena LIASHENKO}

Doctor of Economics, Professor of Taras Shevchenko National University of Kyiv (Ukraine). Head of Economic Cybernetics Department, Economics Faculty, Taras Shevchenko National University of Kyiv, Kyiv, Ukraine. Research interests: nonlinear modeling in socio-economic and environmental systems, financial time series, modelling of economic processes by neuronetworks methods, fractal analysis, economic dynamics modelling.

ORCID ID: https://orcid.org/0000-0002-0197-4179

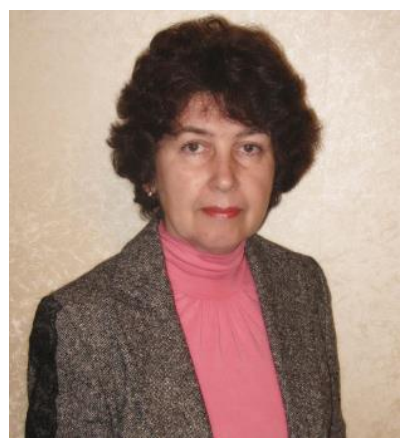

\section{Tetyana KRAVETS}

$\mathrm{PhD}$ (Physics and Mathematics), Associate Professor of Economic Cybernetics Department, Taras Shevchenko National University of Kyiv, Kyiv, Ukraine. Research interests: modeling of economic processes by neuronetworks methods, clusterization, financial time series, wavelet analysis.

ORCID ID: $\underline{\text { http://orcid.org/0000-0003-4823-5143 }}$

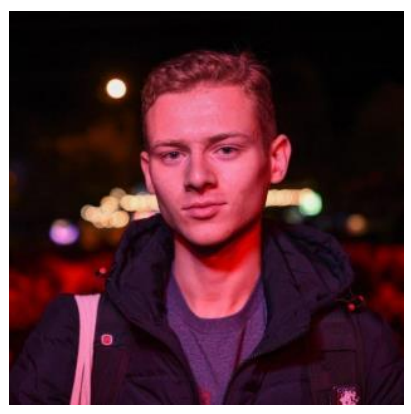

Matvii PROKOPENKO, Student, Economic Cybernetics Department, Taras Shevchenko National University of Kyiv, Kyiv, Ukraine. Research interests: behavioral economics, modeling in economics, data science.

ORCID ID: https://orcid.org/0000-0003-1457-8762

Copyright ( 92020 by author(s) and ACCESS Publishing Press This work is licensed under the Creative Commons Attribution International License (CC BY) 


\title{
THE IMPACT OF THE CONSEQUENCES OF THE COVID-19 PANDEMIC ON THE SOCIAL SECURITY OF UKRAINE
}

\author{
Irada Dzhalladova ${ }^{1}$, Oleh Kaminsky², Oleksandr Lutyj ${ }^{3}$
}

\author{
${ }^{1,2,3}$ Vadym Hetman Kyiv National Economic University, Kyiv, Ukraine
}

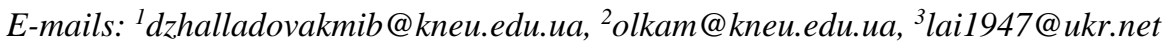

Received: 15 July 2021; $\quad$ Accepted: 05 August 2021; Online Published: 09 August 2021

\begin{abstract}
:
The aim of the work is a systematic analysis of logical, structural connections between different threats to sociocybernetic security. We include in the consideration a wide range of different components, different understandings of social security: security of technical systems, security of cyberspace, security of cyber-physical systems and so on. Everything is almost not studied and not studied in general. An important aspect of state capacity is analyzed in the work with the help of the constructed mathematical model: the problem of threats to social security. Depending on the condition (stable or unstable), there is a system that is characterized by a numerical integrated indicator (number of patients, number of those who passed the test, number of occupied beds in the hospital), social security in a broad and narrow sense, can to be considered and considered as being in a state of threat or protected. Hundreds of thousands of different methods and tools have been built over the millennia, but in modern conditions none is ready. Actually, the situation with COVID-19 showed it. The flexibility of mind and a combination of different methods is the only key to modelling different processes, including security-related processes. In addition, it should be noted that IT tools are not always universal. In modelling these processes, the balance of knowledge in the field of economics, politics, IT, cybersecurity, etc. is important. It is also important to understand that the initial stages of creating algorithms for the protection of the socio-cybernetic system should be considered in the usual senseunderstanding of social security. To do this, it is necessary to establish links between different processes of subsystems.
\end{abstract}

Keywords: social security, resilience, consequences of a pandemic, Covid-19 pandemic, cybersecurity.

JEL classification: A14, C51, J28

Citation:

Dzhalladova, I., Kaminsky, O., Lutyj, O. (2021). The impact of the consequences of the Covid-19 pandemic on the social security of Ukraine. Access to science, business, innovation in digital economy, ACCESS Press, 2(3): 252-260. https://doi.org/10.46656/access.2021.2.3(4)

\section{INTRODUCTION}

The impact of the COVID-19 pandemic on global processes is enormous and it is constantly intensifying and becoming more complicated: from the crisis in the world economy to the breakdown of personal human relations. So far, no country, no business, no community, no family, no person has escaped the consequences of a situation that has suddenly (let's say the term probability theory happened). In addition to the direct impact of the coronavirus on human health and safety, the economic, social, demographic, environmental, behavioral, political and institutional consequences of the pandemic have been and continue to be profound. 
The COVID-19 pandemic is forcing the world to maintain social security and constantly face global challenges to real life. The use of factual data on the consequences of the pandemic by the state leadership, the study of support processes for responding to the COVID-19 pandemic will contribute to the adoption of scientifically sound decisions in the fields of economy, health and security of the state. This in turn will ensure a more humane and equitable policy for all and minimize the destructive impact of pandemics on the poor, vulnerable and vulnerable.

Analysis of recent research and publications. The issue of linking pandemics to threats to social security gained popularity in the 1990s. In 1995, the World Health Assembly (WHO) agreed to revise the International Health Regulations (IHR), the only international legal framework governing how the WHO and its Member States should respond to outbreaks of infectious diseases, on the basis that that the revision was necessary to take "effective account of the threats posed by the international spread of new and recurrent diseases" (World Health Organization, 1995). In 2005, the revised IHRs were adopted as WHO Resolution 58.3 (World Health Organization, 2005). Article 2 of the resolution emphasizes that the scope and choice of IHR instruments is to "prevent, protect, control and ensure public health responses to the international spread of the disease by any means comparable and limited to public health risks".

The study Buckley, Clem \& Herron (2020) notes that in addition to the devastating and widely discussed humanitarian and economic consequences of the COVID-19 pandemic, the current global crisis also exacerbates social security issues related to governments' shortcomings in ensuring the well-being of their citizens. their territory and receive funds for the survival of the population.

Study Andrea Riccardo Migone (2020) discusses the relationship between social policy characteristics and the success of the "smoothing curve" of COVID-19 infection, a widely accepted measure containing the worst medical outcomes of a pandemic. Although some cases require careful and detailed analysis for proper unpacking, the study finds that the best correlation is found in the study of the choice model associated with active or reactive approaches to the implementation of containment measures. This is especially evident for countries that have either very low or very high levels of infection per million people.

In their work, scientists K.Mizumoto \& G. Chowell (2020) assessed the risk of death from COVID-19 in Wuhan, as well as other parts of China, except Wuhan Province, taking into account the time delay to assess the severity of the epidemic in the country . Death risk estimates in Wuhan reached $12 \%$ at the epicenter of the epidemic and $\approx 1 \%$ in other, more affected areas. Increased death risk assessments have been identified as linked to the destruction of the health care system, and the effective role of enhanced health measures, including social distancing and restraint, has been emphasized.

Hoang Pham (2020) discussed a clear model function to estimate the total number of deaths among the population, and in particular to estimate the total number of deaths in the United States due to the current Covid-19 virus. The author compares the simulation results with two existing models based on the new criteria. The results showed that the proposed model was more accurate than the other two related models based on US Covid-19 mortality data. 
In the work of B. Yan, J. Wang, Z. Zhang, X. Tang, Y. Zhou et al. (2020) to solve the problem of predicting mortality from pandemics, an improved method for predicting confirmed deaths based on the neural network LSTM (Long-Short Term Memory). The paper compares the deviations between the experimental results of the advanced forecasting model LSTM and digital forecasting models (such as logistics equations and Hill equations) with real data as a reference. Experiments show that the proposed approach has fewer deviations from the forecast and a better adaptation effect.

The COVID-19 pandemic creates an environment for the development of cybercrime. Decreased vigilance among the population, anxiety disorders, work from home, congestion on the Internet lead to an increase in the flow of cybercrime. Companies that are engaged in the management of day-to-day operations in times of crisis do not pay due attention to the increased threats to information security that arise as a result of these exceptional circumstances.

For companies, teleworking is a risk factor to consider. The risk of attack on information systems, as well as networks, which are in great demand for remote work, is significant. Access to confidential and financial information, document fraud, supply chain adjustments, including food, increased network requirements caused by quarantine measures are all potentially serious consequences for the security system. In this context, competent authorities also need practical guidance on limiting cybersecurity risks to humans and society as a whole. To reduce the spread of COVID-19 and stop the epidemic, global, social and local security authorities need timely and up-to-date data and model forecasts to inform about prevention, control and distancing measures. Policymakers will also need data on behavioral and biomedical interventions during and after a pandemic to reduce the devastating effects, especially on the most vulnerable.

If security is understood as the absence of threats and resilience to threats in cyberspace, then social security in the digital society should be considered as a multilevel structure. In turn, each of the components also has its levels (Fig. 1):

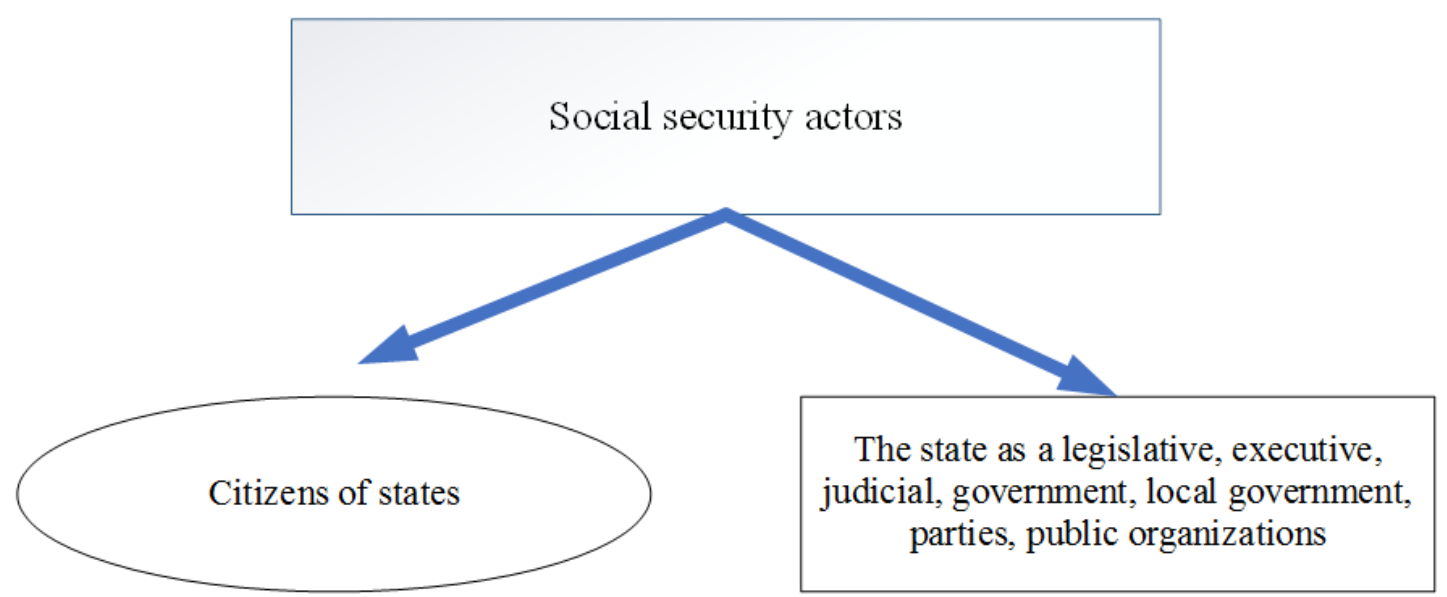

Fig. 1. Subjects of social security

source: developed by the authors 
To imagine the effect of this level of social security in the digital society, each of the components must be considered in the light of its individual actions in the digital society and the multi-level overlapping of links between different objects and actors.

Let's make conditional logical-structural connections between threats: (Fig. 2):

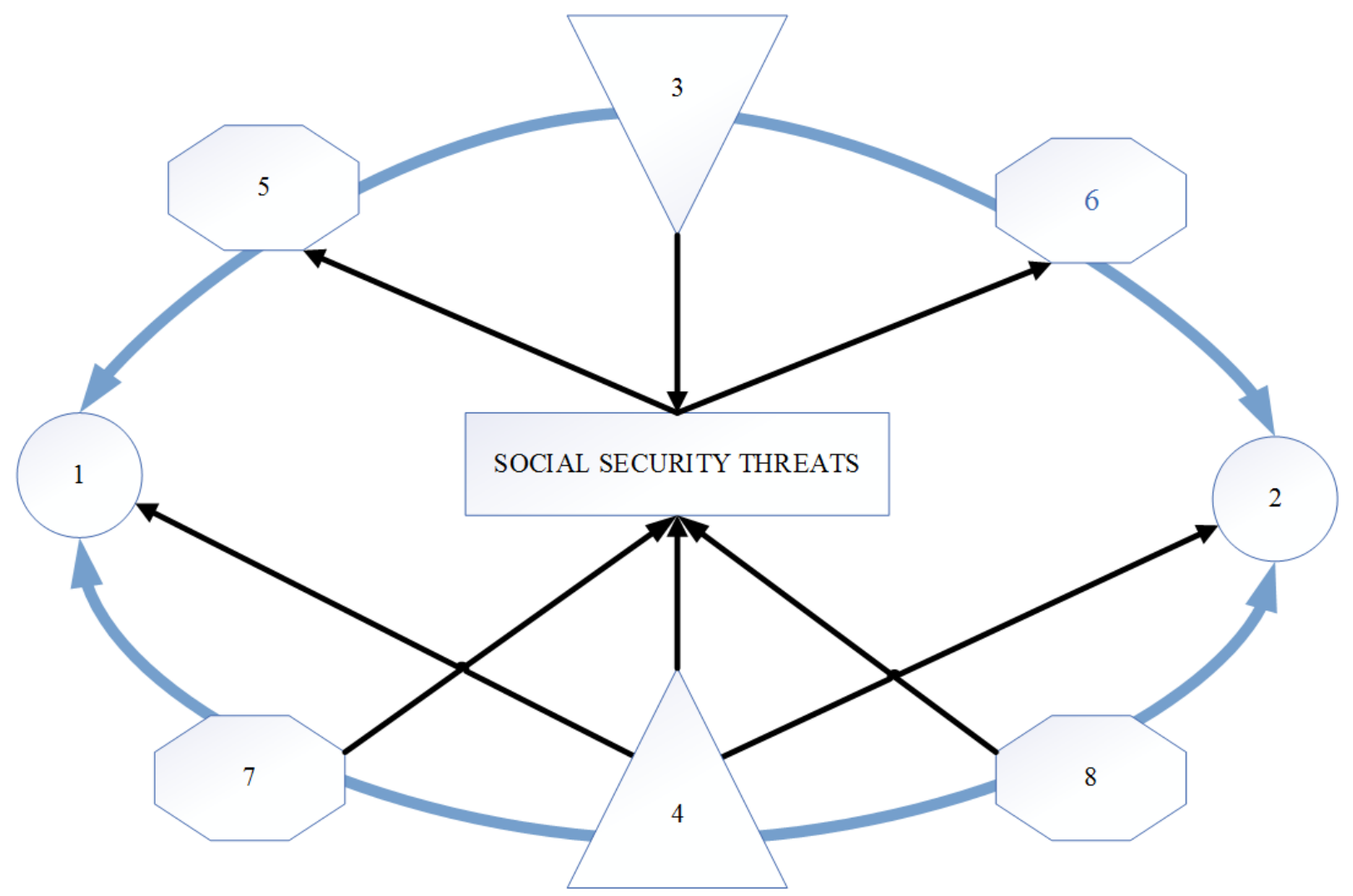

Fig. 2. Logical and structural connection between social security threats source: developed by the authors

where:

1-threats caused by shortcomings in policy and actions of state and political leaders, threats from government institutions;

2- threats related to national disputes, conflicts of interest of the center and regions, violation of the rights and freedoms of citizens, interethnic conflicts;

3-threats caused by violation of legal rights, freedoms to education, health care, inability of the state to protect them;

4-threats caused by the criminal situation, the growth of crime, including cybercrime;

5-threats caused by extremism, terrorism;

6-threats to public health as a result of deteriorating health care, medical care, the spread of infectious diseases, drug addiction, alcoholism, pandemics, mental illness;

7-threats related to the degradation of the population and the environment and livelihoods; 
8- threats are caused by qualitative changes of the HOMOSAPIENCE MAN, increase of egoists, quantitative changes of a demographic situation in the countries, regions, ethnicity.

At each level, an analysis should be conducted and integrated coefficients of social security assessment should be built, which will timely contribute to the necessary steps to prevent destabilization and social upheaval.

At the input of the proposed analysis, the above factors. The output is social transformation, namely: instability of social structures, processes of degradation, usurpation of power not only at the level of the state, regions, but also in families. We will consider this as an indicator of not only socio-security, but also an indicator of sociocybernetic security. For the next step of the analysis we enter 5 levels of social security (fig. 3)

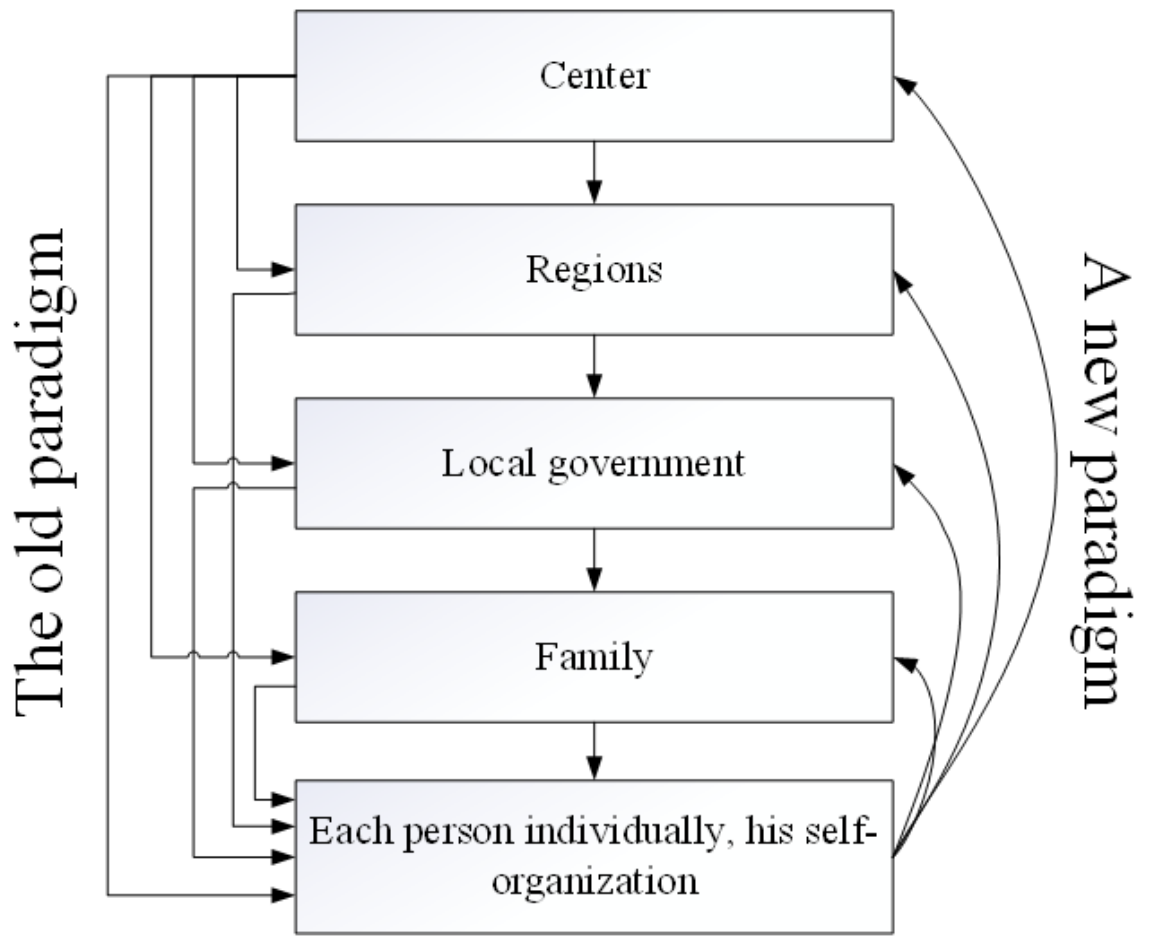

Fig.3. Levels of social security source: developed by the authors

At each of the levels, an analysis should be conducted and integrated coefficients of social security assessment should be built, which will timely contribute to the necessary steps to prevent destabilization and social upheaval.

In our work with the help of the constructed mathematical model another aspect of state capacity is analyzed: the problem of threats to social security. Depending on the condition (stable or unstable), there is a system that is characterized by a numerical integrated indicator (number of patients, number of those who 
passed the test, number of occupied beds in the hospital), social security in a broad and narrow sense, can to be considered and considered as being in a state of threat or protected.

Let the dynamical system be described by a first-order difference equation:

$$
x_{n+1}=x_{n}+\mu \mathrm{a}\left(\xi_{n}\right) x_{n}
$$

where a random process $\xi_{n}$ can take 2 states In the first state, the integral index is a positive number, and in the second state it is a negative number. The system can jump from one state to another. The function a, which depends on a random process, takes two values $\mathrm{a}_{1}, \mathrm{a}_{2}$ with probabilities $\mathrm{P}_{1}(n), P_{2}(n)$, that satisfy the following system of equations due to the Markov character of the described situation.

$$
\begin{gathered}
\mathrm{P}_{1}(n+1)=(1-\alpha) P_{1}(n)+\beta P_{2}(n), \\
\mathrm{P}_{2}(n+1)=\alpha P_{1}(n)+(1-\beta) P_{2}(n),
\end{gathered}
$$

where $0 \leq \alpha \leq 1,0 \leq \beta \leq 1$ i $0<\alpha+\beta<2$.

In this simple case from the mathematical point of view, we use the results of Dzhalladova (2009); Dzhalladova \& Růžičková (2020), where the moments of the equation for the random solution of system (1) are constructed. For partial moments $m_{k}(n)$ of the first order we have a system of difference equations:

$$
\begin{gathered}
m_{1}(n+1)=(1-\alpha)\left(1-\mu \mathrm{a}_{1}\right) m_{1}(n)+\beta\left(1+\mu \mathrm{a}_{2}\right) m_{2}(n), \\
m_{2}(n+1)=\alpha\left(1+\mu \mathrm{a}_{1}\right) m_{1}(n)+(1-\beta)\left(1+\mu \mathrm{a}_{2}\right) m_{1}(n) .
\end{gathered}
$$

We enter variables $m(n)=m_{1}(n)+m_{2}(n), v(n)=\frac{\beta m_{2}(n)-\alpha m_{1}(n)}{\alpha+\beta}$.

We obtain a system of difference equations:

$$
\begin{gathered}
m(n+1)=m(n)+\mu \frac{a_{1} \beta+a_{2} \alpha}{\alpha+\beta} m(n)+\mu\left(a_{2}-a_{1}\right) v(n), \\
v(n+1)=\mu\left(a_{1}-a_{2}\right) \frac{\alpha \beta(\beta+\alpha-1)}{(\alpha+\beta)^{2}} m(n)+(1-\alpha-\beta)(1+ \\
\left.\mu \frac{a_{1} \beta+a_{2} \alpha}{\alpha+\beta}\right) v(n)
\end{gathered}
$$


The system of equations (3) will be investigated for stability on average. The concept of stability on average is considered in Dzhalladova (2009). In the first approximation we find an integral set of solutions of system (4).

$$
v(n)=\mu\left(a_{1}-a_{2}\right) \frac{\alpha \beta(\beta+\alpha-1)}{(\alpha+\beta)^{2}} m(n)+O\left(\mu^{2}\right)
$$

and for the variable $m(n)$ find the equation:

$$
m(n+1)=\left(1+\mu \frac{a_{1} \beta+a_{2} \alpha}{\alpha+\beta}+\mu^{2} \frac{\left(a_{1}-a_{2}\right)^{2} \alpha \beta(1-\alpha-\beta)}{(\alpha+\beta)^{3}}+\mathrm{O}\left(\mu^{3}\right)\right) m(n),
$$

From equation (5) it follows that the zero solution of the difference equation (1) with random coefficients will be stable on average, if the condition:

$$
\mu \frac{a_{1} \beta+a_{2} \alpha}{\alpha+\beta}+\mu^{2} \frac{\left(a_{1}-a_{2}\right)^{2} \alpha \beta(1-\alpha-\beta)}{(\alpha+\beta)^{3}}+\mathrm{O}\left(\mu^{3}\right)<0,|\mu|>0
$$

Condition (6) will make it possible to answer the question of whether there is a threat to the social security of the country or it is under protection. Value $a_{1}, a_{2}, \alpha, \beta$ are set taking into account official statistics.

It should be noted that in more complex situations, such as complex virtualized cloud infrastructures with their dynamic nature Dzhalladova (2020), the application of instantaneous methods Mizumoto \& Chowell (2020) to a nonlinear system of difference equations is also studied, stability conditions are found, but application for real problems is rather cumbersome. Given the numerical methods and tools of computer mathematics, such attempts have been made and they are quite successful (Dzhalladova \& Kaminsky, 2020); Kaminsky \& Poliit (2020).

\section{CONCLUSIONS.}

Thus, the study of the stability in the mean and root mean square solutions of the differential equation with coefficients that depend on the discrete Markov process, thanks to the use of moment equations described in Dzhalladova \& Růžičková (2020), was reduced to solving systems of ordinary differential equations. The obtained approach is applied to the construction and analysis of conditions for the resilience of population recovery in a pandemic. 
The developed model can be used as a basis for determining optimized schemes to contain the epidemic and policies to mitigate its security consequences in Ukraine, to improve national legislation, the state security system and health care.

These results probably indicate certain contradictions: it seemed that on the one hand man, and on the other hand technical, cyber-physical mechanisms, the state. As if the person provides own safety, and on the other hand it is a mission of other structural components of system. But everything becomes clear after the analysis. Even in such a complex system as sociocybernetic security, the main atom is man, that is, the sociocybernetic system begins with human security, which, in fact, begins with man himself. Sociocybernetic security is the cornerstone of social policy, social culture, social rights, national security. Scientists have introduced the concept of social security Dzhalladova (2020), but it is new and insufficiently studied. Socioetal security is a concept that refers to the ability of the digital society to maintain its essence in a constantly changing environment and under real or imagined threats. Social security can be seen as part of sociocybernetic security. As social security is added as an element to the proposed sociocybernetic security system, it is clear that certain structural connections will change. Future research will show in which direction, but predictive system analysis gives hope that the system will be simpler and more convenient for algorithmization.

\section{Conflict of interests}

The authors declare no conflict of interest.

\section{References}

Borges Barbosa, R.; Henrique Costa, J.; Hadi, F. (2021). Economic and Ecological Rationalities: Uses and Abuses of the Political Exceptionality in the COVID-19 Pandemic. Economics. Ecology. Socium, vol. 5, pp.1-7.

Buckley, C., Clem, R., Herron, E. (2020) «National Security Implications of the COVID-19 Crisis: The Urgent Need to Build State Capacity». https://minerva.defense.gov/Owl-In-the-Olive-Tree/Owl_View/Article /2152823/nationalsecurity-implications-of-the-covid-19-crisis-the-urgent-need-to-build/

Dzhalladova I. (2009). A. Research stability of solutions of the systems linear with random coefficient. Studies of the university of Zilina MATHEMATICAL SERIES Zilina, Slovak Republik., Vol. 23/2009. P. 37-43.

Dzhalladova I., Růžičková, M. (2020). A Dynamical System with Random Structure and their Applications. Cambridge Scientific Publishers, 244 pp.

Dzhalladova I. A. (2020). Systemnyi analiz zahroz sotsiokibernetychnoi bezpeky v umovakh pandemii. Modeliuvannia ta informatsiini systemy v ekonomitsi. Vyp.100. S.50-58

Dzhalladova I. A., Kaminsky O. Ye. (2020). Stabilizing steps the security of human and society in the Covid-19 pandemic. Economics Business and Organization Research, p. 295-308 Retrieved from: https://dergipark.org.tr/en/pub/ebor/issue/58610/848963

Kaminsky O.Ye., Poliit D.H. (2020). Analiz dostovirnosti informatsii shchodo pandemii COVID-19 v Ukraini (na prykladi svitovykh ahrehatoriv danykh). Modeliuvannia ta informatsiini systemy v ekonomitsi. Vyp.100. S.83-93

Koval, V.; Sribna, Y.; Mykolenko, O.; Vdovenko, N. (2019). Environmental concept of energy security solutions of local communities based on energy logistics. 19th International Multidisciplinary Scientific GeoConference SGEM 2019, 19(5.3), 283-290. https://doi.org/0.5593/sgem2019/5.3/S21.036 
Migone, A.R. (2020) «The influence of national policy characteristics on COVID-19 containment policies: a comparative analysis». https://doi.org/10.1080/25741292.2020.1804660

Mizumoto K., Chowell G. (2020). Estimating Risk for Death from Coronavirus Disease, China, January-February 2020. Emerg Infect Dis. Jun;26(6): P.1251-1256. https://10.3201/eid2606.200233.

Pham, H. (2020). On Estimating the Number of Deaths Related to Covid-19. Rutgers University, Piscataway, Mathematics, 8(5), 655; https://doi.org/10.3390/math8050655

World Health Organization (1995). Revision and Updating of the International Health Regulations, WHA48.7, Fortyeighth World Health Assembly

World Health Organization (2005). Revision of the International Health Regulations, WHA58.3, Fifty-eighth World Health Assembly

Yan, B., Wang, J., Zhang, Z., Tang, X., Zhou Y. (2020). "An improved method for the fitting and prediction of the number of covid-19 confirmed cases based on lstm," Computers, Materials \& Continua, vol. 64, no.3, pp. 14731490.

\section{About the authors}

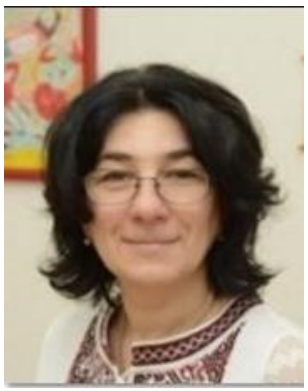

\section{Irada DZHALLADOVA}

Doctor of Mathematics, Professor, Head of the Department of Computer Mathematics and Information Security, Vadym Hetman Kyiv National Economic University

Scopus Author ID: 8671668600

ORCID ID: https://orcid.org/0000-0003-3158-6844

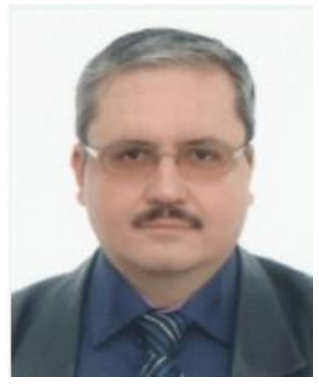

\section{Oleh KAMINSKY}

Doctor of Economics, Associate Professor, Associate Professor of the Department of Computer Mathematics and Information Security, Vadym Hetman Kyiv National Economic University

ResearcherID: AAE-5167-2020

ORCID ID: https://orcid.org/0000-0003-0607-8944

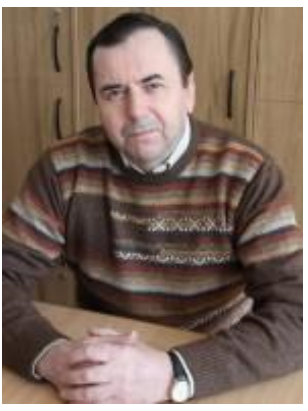

\section{Oleksandr LUTYJ}

Candidate of Sciences in Technology, Associate Professor of the Department of Computer Mathematics and Information Security, Vadym Hetman Kyiv National Economic University

ORCID ID: https://orcid.org/0000-0002-1736-4180

Copyright $(\odot 2020$ by author(s) and ACCESS Publishing Press This work is licensed under the Creative Commons Attribution International License (CC BY) 


\title{
TRENDS IN THE DEVELOPMENT OF REGIONAL TRUST MANAGEMENT MARKETS
}

\author{
Stanislav Perminov \\ Information Systems Management Institute (ISMA), Riga, Latvia \\ e-mail: psb70@protonmail.com
}

Received: 01 May 2021; $\quad$ Accepted: 20 June 2021; $\quad$ Online Published: 11 August 2021

\begin{abstract}
The article discusses the features of the development of the trust management services market. The purpose of the article is to determine the regional features of the development of the trust management services market. The article uses the methods of quantitative empirical research, statistical analysis and visualization, analysis and assessment of the regional dynamics of the main instruments of trust management. The formation of the trust management market takes into account the peculiarities of the development and economies of individual countries, regional regulatory characteristics. Trust management is widespread in advanced countries, while in other countries this market is just emerging. In general, the trust management market in the countries of Eastern Europe and Russia in particular is only in the process of formation, although the services themselves have a long history of development. They are most often viewed as part of the overall market for banking or insurance services. At the present stage, there is a selection of a separate market segment, determination of the place of trust services in the structure of banking services, identification of regional characteristics in the structure of the global market. The peculiarities of the Russian securities market are: active participation of the state in the processes of market trading, a large number of government securities on the market and a relatively low level of involvement in global processes. The market is relatively small, but its development is quite dynamic. The key prerequisites for the development of the market are: the relative closeness of the market, government regulation, a decrease in the attractiveness of other banking or financial instruments, and an increase in the general welfare of investors.
\end{abstract}

Key words: trust, trust management, assets, unit investment fund, mutual investment fund.

JEL classification: F36, G11, G15, G21

Citation:

Perminov, S. (2021). Trends in the development of regional trust management markets. Access to science, business, innovation in digital economy, ACCESS Press, 2(3): 261-273. https://doi.org/10.46656/access.2021.2.3(5)

\section{INTRODUCTION}

Banking services are an important part of the financial market of any country. Building chains of relationships between financial agents, opportunities for making a profit or serving companies is an integral part of the functioning of the economy as a whole. A special place in the financial services market is occupied by the trust management market, which, in turn, is part of the T\&CS (trust management and corporate services) market. The trust management market is both new and has a long history of development. Trust management as a process and economic activity has its roots in Anglo-Saxon law and is understood as specialized property management in favor of a third party. However, at the present stage of development of the global economy, the formation of the world market for trust management (TM) is already taking place. Trust management in 
modern conditions goes beyond the possibilities of functioning and ensuring the management of property within the framework of individual economies or jurisdictions, representing the formation of a single management system or management capabilities throughout the world. It should be noted that the formation of the trust management market takes into account the peculiarities of the development and economies of individual countries, regional regulatory characteristics and provides for investments in various instruments and assets.

The purpose of the article is to determine the regional features of the development of the trust management services market.

\section{MATERIALS AND METHODS}

The article uses the methods of quantitative empirical research, statistical analysis and visualization, analysis and assessment of the regional dynamics of the main instruments of trust management.

In general, trust and asset management is the subject of research by a large number of scientists, given the complexity of the processes and their regulation, depending on the jurisdiction of implementation. General issues of asset management are explored in the works of I. Smirnov (2020); A. Vorotilov (2013); A. Kovalevich (2012), F. Ripol-Saragossi, E. Ternikova, S. Budylgin; Woodhouse J. (2003); Loistl O. \& Petrag R. (2003), Marinov (2012) and others. We find certain issues of managing specific assets in the works of A. Asaul (Asaul and al, 2007); Labunska, Petrova \& Prokopishyna (Labunska et al, 2017), Puchkina E.S., (2016) and other scientists. Legal regulation of asset management processes is the basis of research by Fedulova D. (2010); Mazajeva A. (Mazajeva, 2017); Radukanov (2012); Milinov (2012), Angelov et al (2012); Petrova \& Radukanov (2021). At the same time, the issues of the formation of the international trust management market and the peculiarities of its regional development deserve special attention.

\section{RESULTS AND DISCUSSION}

The development of the trust services market is based on the following key trends: the level of development of the country, economic stability and stability of financial markets; features and characteristics of the development of the banking and financial systems in the country; peculiarities of the behavior patterns of investors or the population in the country; features and models of regulation of trust activities. Taking into account these and other peculiarities in each country, banks form their own model of relations with clients, allowing them to retain and transfer them to the status of "investors". Thus, a wide network of banking services is being formed, including in the field of trust management.

The main prerequisite for the development of the trust management market in various countries is attracting a class of citizens with an average level of income, which makes it possible to expand and increase the capital attracted for trust management. The middle class of citizens has sufficient potential and financial capabilities to be of interest for trust banking and become a target group for creating demand for this kind of services. 
Thus, the development of the middle class contributes to the development of the financial market in general and the securities market in particular. In turn, this can contribute to the formation and development of the middle class, as well as the growth of savings in this class of citizens. The main problems and constraints on the development of the trust management market can be:

- lack of legislative base, its limitations and "gaps";

- underdevelopment of the stock market in certain countries (especially in developing countries), which may lead to a decrease or insufficient profitability of this kind of activity;

- high volatility of markets and a limited number and possibilities of using financial instruments;

- low level of informing the population about the availability of this type of service;

- shortage of highly qualified financial agents capable of working in the stock market and especially in developing countries.

However, most of the restrictions can be resolved with the active development of the stock market with the participation of the state and regulatory authorities. For developing countries, the prerequisites for the development of the trust management market are:

- the formation of a middle class of citizens, which occurs as a result of the growth of savings and financial savings;

- gradual accumulation of the share of financial assets in the structure of capital and the welfare of citizens;

- the need to implement relatively reliable financial instruments and effective management of these assets;

- a sufficient level of development of the banking system and financial institutions;

- accumulation of experience in the field of trust management;

- formation of a legal framework that regulates the trust management market.

In modern conditions, the formation of an international trust management market is taking place, which goes beyond the jurisdictions of financial management of individual countries. There are several regions that have implementation features and specific characteristics of the development of the trust management market. A certain interest is aroused by the market of the CIS countries, where the trust management market is at the stage of its formation. In general, there is a gradual growth of this market, a feature of which is growth at the expense of deposits of individuals, as well as at the expense of clients with large private investment capital. Thus, the volume of assets only managed by the largest market players grew by almost $5 \%$ only in the 4th quarter of 2020. At the same time, the bottom line of assets in the TOP-15 exceeded 100 billion rubles (Table $1)$.

In general, there is a gradual increase in assets to 7.6 trillion rubles, while the growth in the volume of assets of TOP-5 companies - up to 4.5 trillion rubles $(4.1 \%)$. At the same time, the composition of the leaders is constantly changing, which indicates intense competition in this area. For example, the management company 
Gazprombank - Asset Management has increased its assets by more than 50 billion rubles, which allowed it to enter the TOP-5.

Table 1. Rating of the largest asset management companies by the amount of funds raised, Q4 2020

\begin{tabular}{|c|c|c|c|c|c|c|}
\hline $\begin{array}{l}\text { Ranking, } \\
\text { Q3 2020 }\end{array}$ & $\begin{array}{l}\text { Ranking, } \\
\text { Q2 2020 }\end{array}$ & Management Company & $\begin{array}{l}\text { Rating of } \\
\text { reliability } \\
\text { and } \\
\text { quality of } \\
\text { services }\end{array}$ & $\begin{array}{l}\text { Amount of } \\
\text { funds under } \\
\text { management, } \\
\text { 31.12.2020, } \\
\text { million rubles, }\end{array}$ & $\begin{array}{c}\text { Amount of } \\
\text { funds under } \\
\text { management, } \\
\text { 30.09.2020, } \\
\text { million rubles, }\end{array}$ & $\begin{array}{c}\text { Relative } \\
\text { change for } \\
\text { Q4 2020, } \\
\%\end{array}$ \\
\hline 1 & 1 & $\begin{array}{l}\text { Business company "VTB } \\
\text { Capital } \\
\text { Management" }\end{array}$ & $\mathrm{A}++$ & 1275987 & 1164509 & 9,6 \\
\hline 2 & 2 & $\begin{array}{lr}\text { Business } & \text { company } \\
\text { "Sberbank } & \text { Asset } \\
\text { Management" } & \\
\end{array}$ & $\mathrm{A}++$ & 1204467 & 1141389 & 5,5 \\
\hline 3 & 3 & Group MC "Region" & $\mathrm{A}++$ & 870793 & 857634 & 1,5 \\
\hline 4 & 4 & $\begin{array}{l}\text { Asset Management Business } \\
\text { Company "OTKRITIE" }\end{array}$ & $\mathrm{A}++$ & 779802 & 713388 & 9,3 \\
\hline 5 & 6 & «Alfa-Capital» & $\mathrm{A}++$ & 668540 & 607507 & 10,0 \\
\hline 6 & 5 & $\begin{array}{lll}\text { Gazprombank } & - & \text { Asset } \\
\text { Management } & & \\
\end{array}$ & $\mathrm{A}++$ & 614729 & 635120 & $-3,2$ \\
\hline 7 & 8 & "Lider" & $\mathrm{A}++$ & 515207 & 511326 & 0,8 \\
\hline 8 & 7 & TKB Investment Partners & $\mathrm{A}++$ & 472036 & 582560 & $-19,0$ \\
\hline 9 & 10 & $\begin{array}{l}\text { "Progressive investment } \\
\text { ideas" }\end{array}$ & $\mathrm{A}+$ & 357964 & 338898 & 5,6 \\
\hline 10 & 9 & "TRANSFINGROUP" & $\mathrm{A}++$ & 354834 & 352471 & 0,1 \\
\hline 11 & 11 & "IQJ Asset Management" & - & 224299 & 223846 & 0,2 \\
\hline 12 & 12 & "Systema Capital" & $\mathrm{A}++$ & 175460 & 165704 & 5,9 \\
\hline 13 & 13 & "RSHB Asset Management" & - & 139938 & 123200 & 13,6 \\
\hline 14 & 14 & "Raffaizen Capital" & - & 106295 & 110443 & 10,5 \\
\hline 15 & 15 & "Ingosstrah-Investicii" & $\mathrm{A}++$ & 106295 & 106916 & $-0,6$ \\
\hline
\end{tabular}

Note: the table is compiled according to the Preliminary results III, 2020 and Preliminary results IV, 2020

At the end of 2020, the trust management market in Russia has grown significantly and reached 7.9 trillion rubles, mainly due to the growth of investments in various mutual funds (unit investment fund, mutual investment fund) (OPF, ZPF). However, growth has slowed slightly relative to 2019. VTB Capital Investment Management has taken the leading positions with 1.28 trillion. rubles of assets held in trust. The leader of 2019 - Sberbank Asset Management - lost its first place and is in second place with assets of 1.2 trillion. rubles. Key growth parameters are ensured by attracting funds from private investors, whose investments reach 200 billion rubles in total (Assets under management grow on retail, 2021). There is an increase in attention to closed-end mutual investment funds.

Another key feature of the market's functioning is the active growth in the number of investors. So, for example, in VTB Capital Asset Management alone, the number of private investors in 2020 increased by $45 \%$ and totals 92.6 thousand investors in total (Assets under management grow on retail, 2021).

In general, the Russian asset management and trust management market is characterized by active 
participation of state investors. Thus, one of the active participants in this market is Rosvoenipoteka, which is serviced by TKB Investment Partners. In addition, one of the drivers of the development of the trust management market is the introduction of income tax on deposits of individuals, as well as a decrease in rates on deposits, which reduces the attractiveness of this instrument and stimulates the search for more profitable investment instruments (Private investors choose bonds, foreign exchange strategies and mutual funds, 2020).

The largest growth in 2020 was shown by investments in mutual funds, especially industry funds (for example, high-tech companies, the consumer market, etc.) (Change of funds, 2021). The growth is observed mainly due to individual investors (and, accordingly, an increase in the share of individual trust management), military mortgage funds, financial investments in private investment funds. At the same time, activity in the segment of pension savings decreases, although their share remains significant. Nevertheless, the slowdown in growth indicates a decrease in the attractiveness of such an instrument, at least in the short term. The growth leader in Russia is the military mortgage and government investment ("Expert RA", 2021).

It should be noted that recently, due to the pandemic, there has been an increase and activity in the use of remote instruments and investment channels (Private investors choose bonds, foreign exchange strategies and mutual funds, 2020). In Russia, bond and quasi-deposit strategies, as well as instruments with dollar yield, are especially popular, but the market is developing around instruments with a low probability of risk.

In general, 2020 in the Russian market is characterized by an increase of 7\% (source: The bond market in 2020: booming despite the crisis, 2020). Moreover, during the crisis, a significant number of small and medium-sized enterprises entered the investment market, which consider trust management as one of the instruments in the overall investment portfolio. However, such trends were outlined back in 2019 and found their continuation in 2020, which manifested itself in an increase in the number of issuers. An obstacle for the development of such companies and their activation in the investment and trust management market is the low level of transparency of their activities, low ratings, quality and availability of reporting (both financial and non-financial).

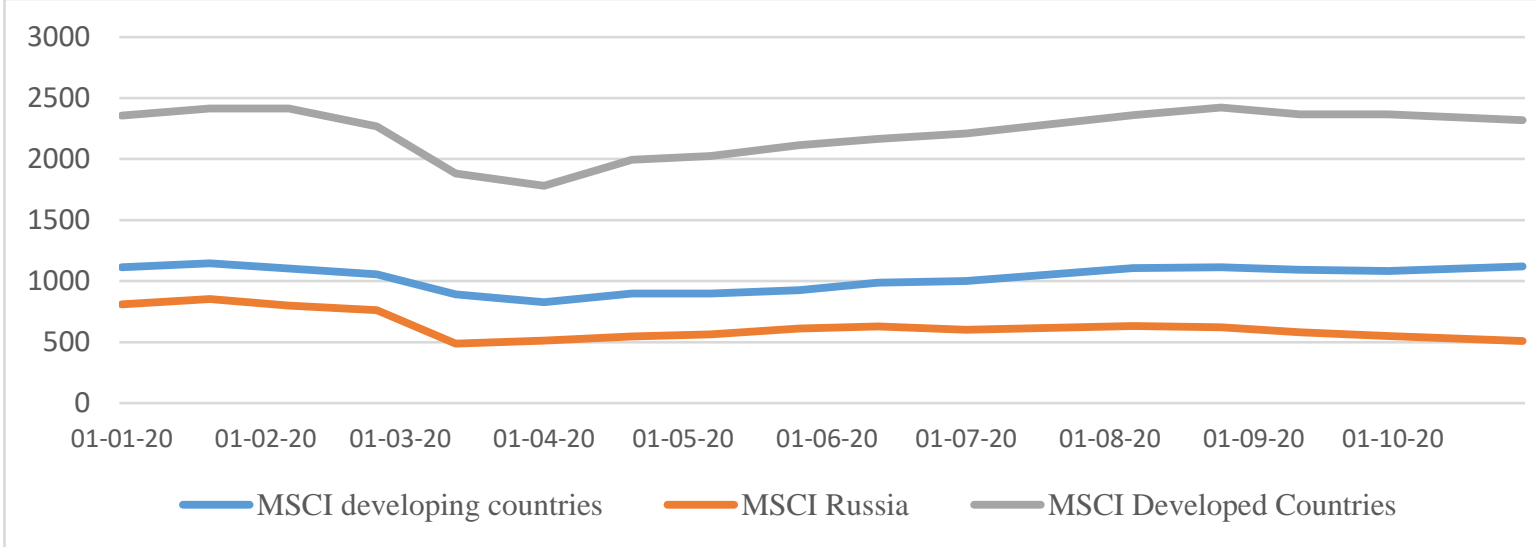

Fig. 1. Dynamics of MSCI indices, 2020

source: own calculations based on: The bond market in 2020: booming despite the crisis, 2020 
The pandemic and, accordingly, the crisis, which manifested itself, among other things, through the fall of key indices, became a serious problem for the development of the market (Fig. 1).

In general, the drop in indices is typical for all market segments and countries. However, the smallest drop was shown by developing countries with a total indicator of $31 \%$, while developed countries sank by $33 \%$. In Russia, the fall was $41 \%$, which was the result of both the global fall and the crisis in the oil market.

However, against this background, the popularity of less profitable and less risky instruments such as Federal Loan Bonds has increased. The profitability of these instruments increased over the same period, which is associated with the goal of withdrawing "extra" money from the market, to reduce the pressure on key players and key indices. The growth is especially noticeable in the segment of medium-term bonds (Fig. 2).

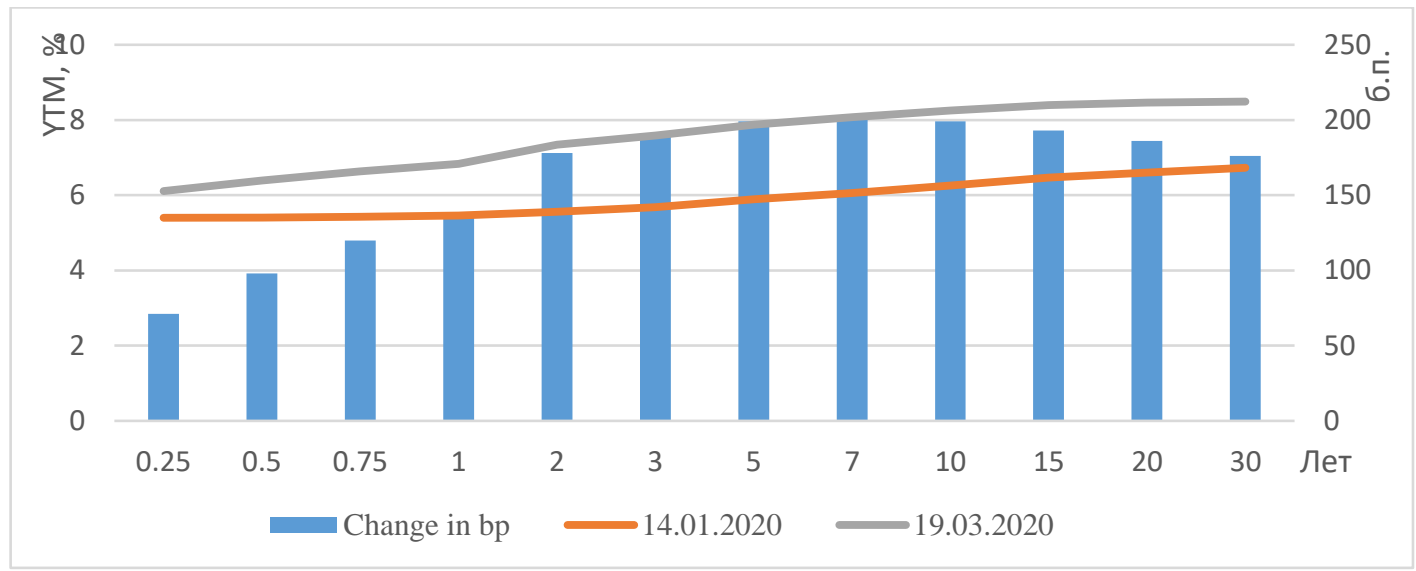

Fig. 2. Yield curve of OFZ, 2020

source: own calculations based on: The bond market in 2020: booming despite the crisis, 2020

At the same time, the relatively low level of Russia's integration into the world community contributed to a softer impact of the global crisis on the country. The high level of presence of state bodies in the market also limits the level of influence and evens out the market a little, although the market drawdown was quite significant (Table 2).

Table 2. Dynamics of GDP of individual countries of the world, 2020

\begin{tabular}{|l|c|c|}
\hline \multicolumn{1}{|c|}{ Country } & GDP growth rate, $\%$ & Credit rating \\
\hline China & $+3,2$ & $\mathrm{~A}+$ \\
\hline India & $-24,1$ & $\mathrm{BBB}-$ \\
\hline EC & $-15,0$ & $\mathrm{AAA}$ \\
\hline United Kingdom & $-21,7$ & $\mathrm{AA}$ \\
\hline Mexico & $-18,7$ & $\mathrm{BBB}+$ \\
\hline USA & $-9,1$ & $\mathrm{AAA}$ \\
\hline Germany & $-11,3$ & $\mathrm{AAA}$ \\
\hline Columbia & $-15,7$ & $\mathrm{BBB}$ \\
\hline Brasilia & $-11,4$ & $\mathrm{BB}$ \\
\hline
\end{tabular}




\begin{tabular}{|l|c|c|}
\hline Russia & $-8,5$ & BBB \\
\hline Turkey & $-9,9$ & BB- \\
\hline
\end{tabular}

Note: the table is compiled according to the Credit ratings, 2019; The bond market in 2020: booming despite the crisis, 2020

In general, we can note a fairly strong drop-in economic activity in the market, which is associated with the global crisis as well. In addition to a drop in GDP, in many countries we are also seeing a drop in interest rates, which is a criterion for an economic downturn and a desire to both attract free money to the market and stimulate economic activity (Fig. 3).

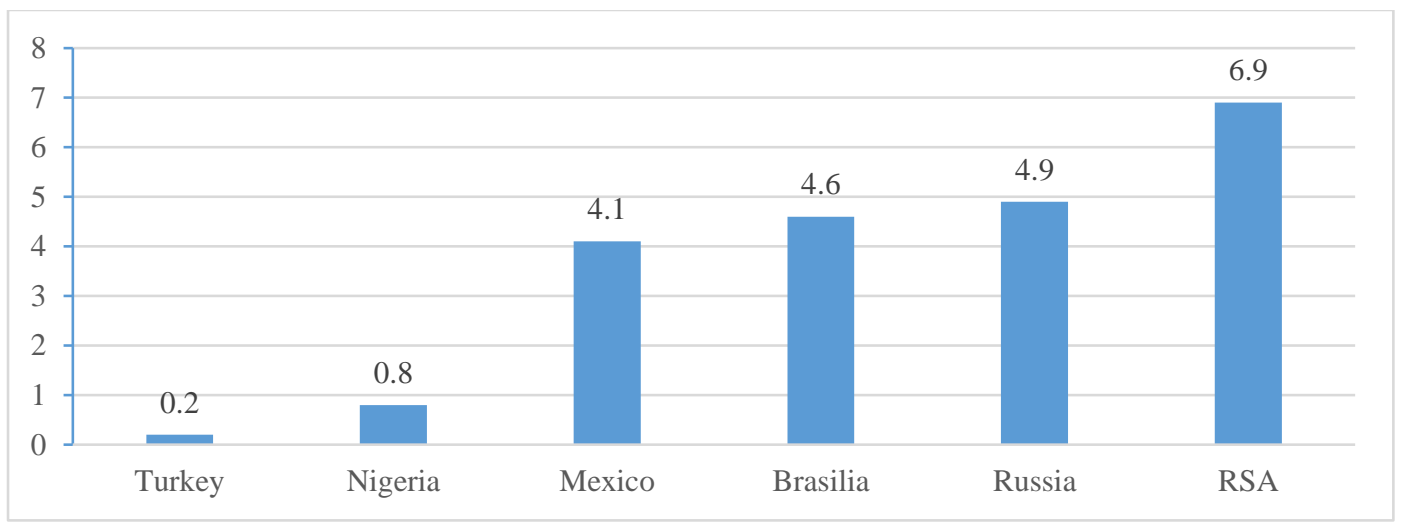

Fig. 3. The level of interest rates in hotel developing countries, 03.03.2020, \% source: own calculations based on: The bond market in 2020: booming despite the crisis, 2020

As you can see from the figure, the level of interest rates at the beginning of 2020 was quite high (relative to developed countries). However, in some countries (Turkey, Nigeria) the level is even lower, which reduces the overall investment attractiveness of the market.

It should be noted that by the end of 2020 , these same markets are showing a change in trends: for example, the attractiveness of Turkey has increased significantly, while the indicators of Russia and Mexico have dropped significantly (Fig. 4).

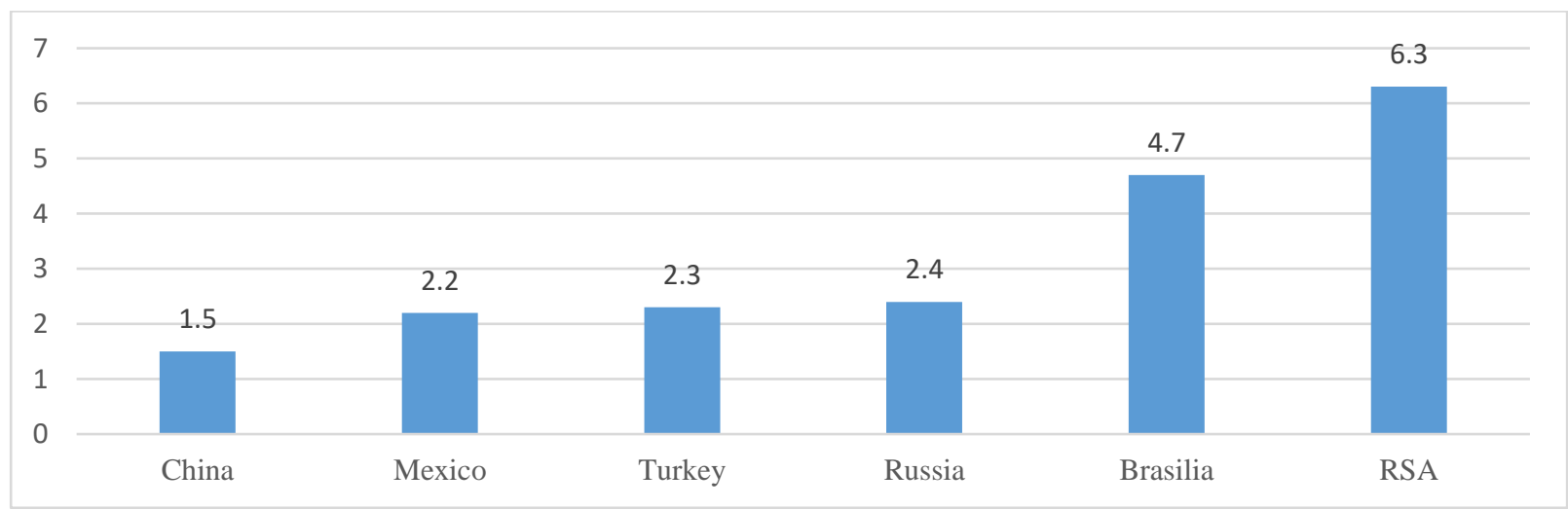

Fig. 4. The level of interest rates in hotel developing countries, $3.10 .2020, \%$ source: own calculations based on: The bond market in 2020: booming despite the crisis, 2020 
Such tendencies may be associated with the general participation of the country in investment flows, political and economic regime, participation of the state in economic processes and opportunities to guarantee investments, including those under trust. The Republic of South Africa has hardly changed its attractiveness, while Turkey has raised its rates from $0.2 \%$ to $2.2 \%$. This demonstrates an increase in the attractiveness of the market, although not enough, since the initial indicators are significantly lower than those of developing countries. In general, the yield on government bonds is at a rather low level and often does not even cover inflation, which does not contribute to the growth of the popularity of such investments. These investments are low risk and this determines the possibility of growth in this market segment. The desire of the governments of the countries to attract free money and accumulate it to cover the needs lead to an increase in interest rates, which is also determined by the desire of investors to abandon risky instruments in times of crisis. In general, in 2020, the volume of the market for government bonds (federal loans) in Russia increased, which just characterizes the demand for low-risk operations and investments (Fig. 5).

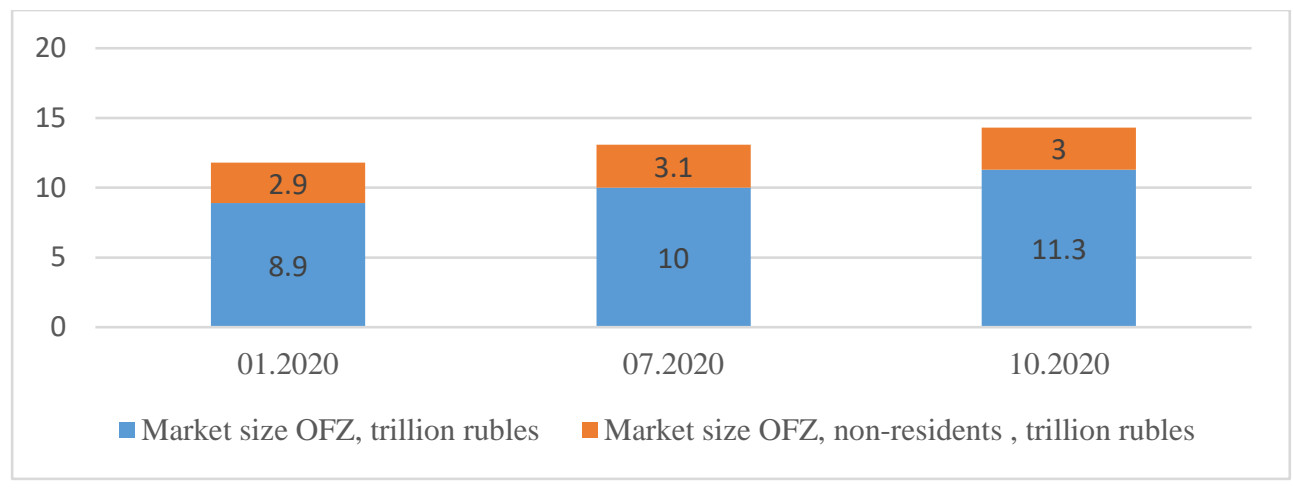

Fig. 5. Structure of the Russian federal loan bond market throughout 2020, trillion rubles source: own calculations based on: The bond market in 2020: booming despite the crisis, 2020

It should be noted that the share of non-residents in the market has significantly decreased, despite the slight change in quantitative indicators: only in the period from April to October, the share of non-residents decreased from $32 \%$ to $27 \%$. The decrease in the share of non-residents is primarily due to geopolitical risks, restrictions, sanctions of the European Union and a general increase in the number of OFZs in circulation. On the other hand, an increase in inflationary risks led to a decrease in the attractiveness of deposits and, as a result, to an increase in the attractiveness of the investment market, including the trust management market. Thus, in 2020, the number of clients on the Moscow Exchange exceeded 11 million. Moreover, there are more than 1 million active clients, and the average monthly turnover indicators showed an increase of $33 \%$ in the market as a whole.

The increase in activity led to the active growth of Individual Investment Accounts (IIA) (including those under trust) (Fig. 6). 


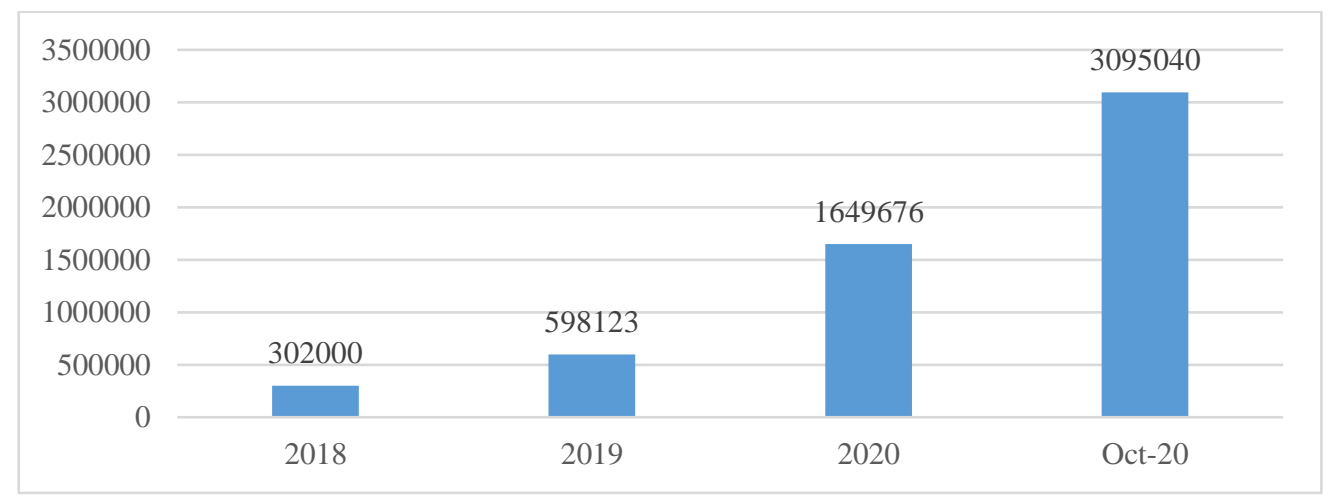

Fig. 6. Number of individual investment accounts, at the beginning of the year, units. source: own calculations based on: The bond market in 2020: booming despite the crisis, 2020

As you can see, in just two incomplete years, the number of individual investment accounts has increased more than 10 times, which is due to the reasons described above. In general, such trends have led to an increase in the bond market and an increase in the amount of financial resources under trust (Fig. 7).

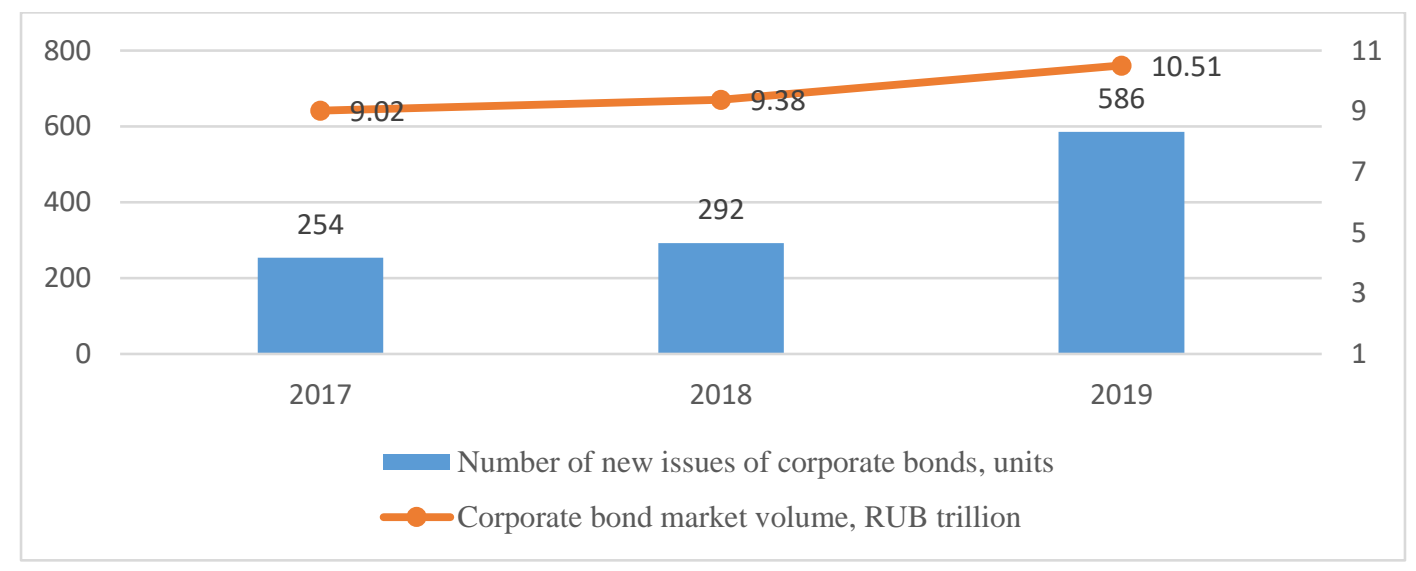

Fig.7. Dynamics of development of the bond market in Russia, 2017-2019.

It is worth noting that market fluctuations were less reflected in large companies: bonds of the first and second tier companies are characterized by a smaller spread, which can actually lead to zero potential profitability. The largest tier 1 companies (blue chips) may have a spread of less than $1 \%$ (Second-tier stocks - what are they? Where to find and how to buy 2nd tier stocks? 2020). In general, during the analyzed period, there is a decrease in the spread for the first echelon shares, where the profitability was practically covered by the difference in value, which is primarily determined by the low level of riskiness of such securities. Securities with AAA - AA- indicators show very low changes in values and, accordingly, a very low spread. At the same time, securities with $A+-B B B$ indicators have a sufficient level of stability and a sufficient level of profitability to attract closer attention of investors in this situation. Similar trends can be noted for these securities in terms of YTM indicators (Yield to maturity, yield to maturity) (Fig. 8). 


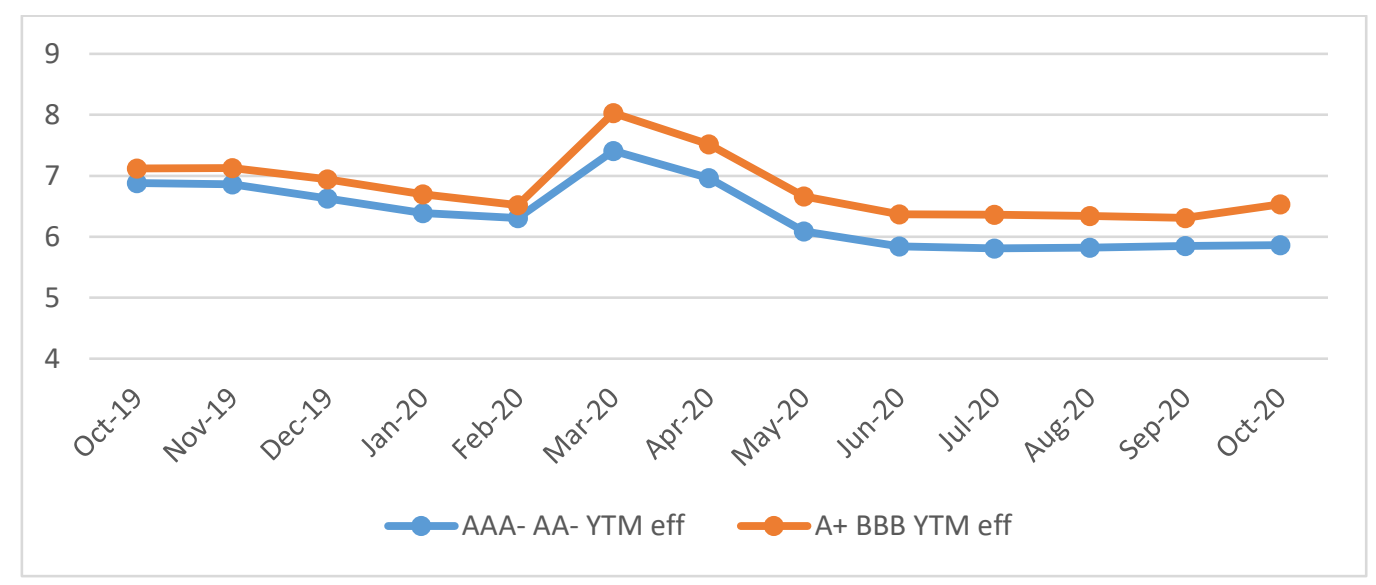

Fig. 8. Yield of bonds to maturity, 2019-2020

As you can see, bonds with a lower credit rating have a higher yield. The dynamics of bond yields declined at a higher rate than for high-yield securities. In contrast, the yields on second-tier securities showed higher stability (especially for securities with BBB and below indicators). Such trends are primarily determined by an increase in the number of individual investors (individuals) in the market (Table 3).

Table 3. Structure of the Russian bond market, \%, 2020

\begin{tabular}{|l|c|c|}
\hline & Primary market & Secondary market \\
\hline Trust management & 25 & 19 \\
\hline Banks and brokers & 38 & 41 \\
\hline Non-residents & 4 & 16 \\
\hline Legal entities & 16 & 14 \\
\hline Individuals & 17 & 11 \\
\hline
\end{tabular}

Note: the table is compiled according to the bond market in 2020: booming despite the crisis, 2020

As you can see, the participation of individuals, represented both in the segment of individuals themselves and in the structure of trust management, constitutes a significant part of the market. At the same time, these market participants are quite cautious and, in case of loss of capital, can leave the market rather quickly. This is especially true for the primary market, since market participants must understand that higher returns are characteristic only for securities with a higher level of risk. Individuals-investors in this market have a low level of financial literacy, not channeling their resources into trust funds and into the hands of more literate market participants. A specific feature of the Russian market is the active participation of unrated issuers, which further complicates the ability to forecast market development (Fig. 9). 


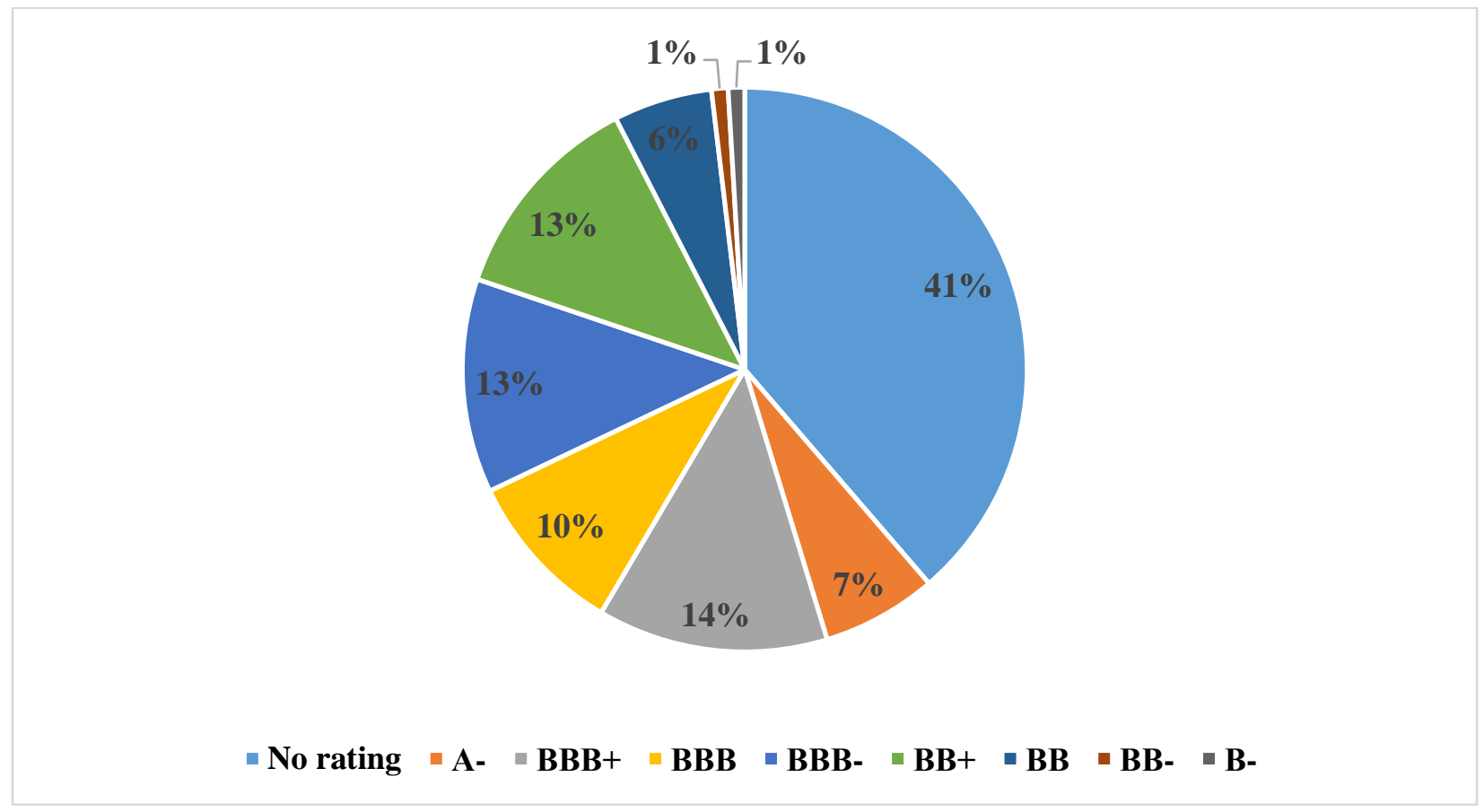

Fig. 9. Structure of the Russian high-yield bond market, \%, 2020

source: own calculations based on: The bond market in 2020: booming despite the crisis, 2020

This situation can lead to underestimation of unrated companies and securities. On the other hand, this contributes to an increase in confidence in issuers with low ratings (BBB and less), for which, however, the rating is determined. In general, $\mathrm{BBB}+$ securities are defined as the minimum investment grade, which determines listing access and, in principle, listing eligibility. In this case, there is a mixture of securities, both unrated and rated $\mathrm{BB}$ and $\mathrm{BBB}$ in the segment of high yield bonds, which in turn leads to a blurring of the boundaries between the segments of securities and issuers of the first and second echelons.

In general, the situation is quite typical for all developing countries. The peculiarities of the Russian securities market are: active participation of the state in the processes of market trading, a large number of government securities on the market and a relatively low level of involvement in global processes. Opportunities for solving key market problems include increasing the general level of financial literacy, increasing information transparency of the market, introducing a workflow that would comply with international standards and corporate governance standards, increasing the rating coverage of issuers, increasing the number of reporting and its transparency (for example, international financial and accounting standards).

\section{CONCLUSION}

In general, it should be noted that the trust management market is only in the process of formation, although the services themselves have a long history of development. They are most often viewed as part of the overall market for banking or insurance services. At the present stage, there is a selection of a separate market segment, 
determination of the place of trust services in the structure of banking services, identification of regional characteristics in the structure of the global market.

We can note that the market of Eastern Europe and Russia in particular is at the stage of its formation. The trust management service is relatively new and has not yet gained popularity as other banking services. The market is relatively small, but its development is quite dynamic. The key prerequisites for the development of the market are: the relative closeness of the market, government regulation, a decrease in the attractiveness of other banking or financial instruments, and an increase in the general welfare of investors. In general, the study of key features and new trends in the development of asset trust management services is of significant scientific and practical interest.

\section{Conflict of interests}

The authors declare no conflict of interest.

\section{References}

Angelov, A., Vytev, Z., Marinov, M., Radukanov, S. (2012). Graphical analysis techniques of market trends. Scientific Research Almanac, DA Tsenov Academy of Economics, Svishtov, Vol. 16, pp.1-12

Asaul A.N., Abajev H.S., Molchanov Ju.A. (2007). Management, operation and development of property complexes. SPb.: Humanistics. URL: http://www.aup.ru/books/m7/2_1_5.htm

Assets under management grow on retail. (2021). URL:https://raexpert.ru/researches/publications/kommersant jan26_2021/

Change of funds. (2021). URL: https://www.kommersant.ru/doc/4660993

Credit ratings of countries of the world: S\&P, Fitch and Moody’s. (2019). URL: https://tyulyagin.ru/ratings/kreditnyerejtingi-stran-mira-sp-fitch-imoodys.html\#: :text=\%D0\%9A\%D1\%80\%D0\%B5\%D0\%B4\%D0\%B8\%D1\%82\%D0\%BD\%D1\%8B\%D0\%B5 $\% 20 \% \mathrm{D} 1 \% 80 \% \mathrm{D} 0 \% \mathrm{~B} 5 \% \mathrm{D} 0 \% \mathrm{~B} 9 \% \mathrm{D} 1 \% 82 \% \mathrm{D} 0 \% \mathrm{~B} 8 \% \mathrm{D} 0 \% \mathrm{BD} \% \mathrm{D} 0 \% \mathrm{~B} 3 \% \mathrm{D} 0 \% \mathrm{~B} 8 \% 20 \% \mathrm{D} 1 \% 81 \% \mathrm{D} 1 \% 82 \% \mathrm{D} 1$ $\% 80 \% \mathrm{D} 0 \% \mathrm{~B} 0 \% \mathrm{D} 0 \% \mathrm{BD} \% 20 \% \mathrm{D} 0 \% \mathrm{BC} \% \mathrm{D} 0 \% \mathrm{~B} 8 \% \mathrm{D} 1 \% 80 \% \mathrm{D} 0 \% \mathrm{~B} 0 \% 20 \% \mathrm{D} 0 \% \mathrm{~B} 0 \% \mathrm{D} 0 \% \mathrm{~B} 3 \% \mathrm{D} 0 \% \mathrm{~B} 5 \% \mathrm{D} 0 \% \mathrm{~B}$ D\%D1\%82\%D1\%81\%D1\%82\%D0\%B2\%20S\&P,\%20Fitch\%20\%D0\%B8,\%20\%20

"Expert RA": the trust management and collective investment market grew by 5.4\%. (2020). URL: https://raexpert.ru/researches/publications/banki_aug18_2020/

Fedulova D.V. (2010). The civil legal essence of trust management. Bulletin of Tomsk State University. №1. C. 113-116. URL: https://cyberleninka.ru/article/n/grazhdansko-pravovaya-suschnost-doveritelnogo-upravleniya/viewer

Kovalevich A.E. (2012). Trust management: essence and content. Bulletin of the Belarusian State Economic University. № 4. C. 73-79.

Labunska Sv., Petrova M., Prokopishyna O. (2017). Asset and cost management for innovation activity, "Economic Annals - XXI", Vol. 165, ISSUE 5-6, Pages: 13-18. DOI: https://doi.org/10.21003/ea.V165-03

Loistl O., Petrag R. (2003). Asset Management Standards. DOI:10.1057/9781403946058

Marinov, M. (2012). Researching variations in the market trend by using indicators for technical analysis. "Scientific research" Almanac, vol. 18, pp. 187-204

Mazajeva A.V. (2017). Trust: the experience of civil law countries. Journal of Foreign Law and Comparative Jurisprudence. №1. URL: https://cyberleninka.ru/article/n/doveritelnoe-upravlenie-i-trast-opyt-strankontinentalnogo-prava/viewer 
Milinov, V. (2012). On evolution and the new challenges facing bank marketing in the aftermath of the financial crisis. "Scientific research" Almanac, vol. 18, pp. 167-186

Petrova, M., Radukanov, S. (2021). Expenditures for innovations and foreign direct investments in Bulgaria - regional aspects, features and trends. SHS Web of Conf., 10th Annual International Conference "Schumpeterian Readings" (ICSR 2021), Virtual and Perm, Russia, April 7 and April 15-16, 2021. Volume 116, https://doi.org/10.1051/shsconf/202111600050

Preliminary results of the trust management market in the III quarter of 2020 . URL: https://raexpert.ru/researches/ua/du 3q_2020pre/

Preliminary results of the trust management market in the IV quarter of 2020. (2020). URL: https://raexpert.ru/researches/ua/du_4q_2020pre/

Private investors choose bonds, foreign exchange strategies and mutual funds. (2020). URL: https://raexpert.ru/researches/publications/vedomosti_aug18_2020/

Puchkina E.S., Rindina I.V., Morusova O.G. (2016) Otsenka i sovershenstvovanije dejatelnosti bankov v sphere doveritelnogo upravlenija sredstvami chastnih investorov. Finansi $i$ kredit. №15 (687). C. 2-19. URL: https://cyberleninka.ru/article/n/otsenka-i-sovershenstvovanie-deyatelnosti-bankov-v-sfere-doveritelnogoupravleniya-sredstvami-chastnyh-investorov

Radukanov, S. (2012). Trends in the development of profitability and risk profile of the banking sector in our country. "Scientific research" Almanac, vol. 18, pp.243-253

Second-tier stocks - what are they? Where to find and how to buy 2nd tier stocks? (2020). URL: https://internetboss.ru/akcii-vtorogo-eshelona/

Smirnov I. (2020). Trust. URL: https://myfin.by/wiki/term/doveritelnoe-upravlenie

The bond market in 2020: booming despite the crisis. (2020). URL: https://raexpert.ru/researches/ua/bond2020/

Vorotilov A. (2013). Subtlety of control. URL: https://forbes.kz/finances/markets/tonkost_upravleniya/

Woodhouse J. (2003). Asset Management: concepts \& practice. https://www.researchgate.net/publication/ 228905772_Asset_Management_concepts_practices

Woodhouse J. (2018). Value in Asset Management. Infrastructure Asset Management. 6(2):1-25. DOI:10.1680/jinam.17.00040

\section{About the author}

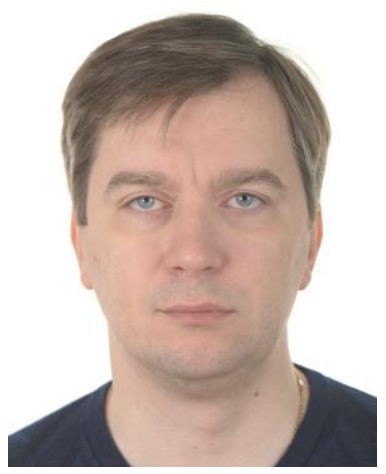

\section{Stanislav PERMINOV}

Current position: PhD Students, ISMA; Russia

University studies: London Business School - Corporate Finance Modular Programme - 2006-2007; Moscow Institute of Economics, Management and Law - Economist in Finances and Loans - 1997 - 1999; Moscow State Technical University in honor of N.E. Bauman - Mechanical Engineer/ Researcher with specialization in Machine Dynamics and Strength - 1988 1994

Scientific interest: trust management, banking management

ORCID ID: https://orcid.org/0000-0002-9353-8365

Copyright ( $\odot 2020$ by author(s) and ACCESS Publishing Press This work is licensed under the Creative Commons Attribution International License (CC BY) 


\title{
MARKETING MIX MODELING FOR PHARMACEUTICAL COMPANIES ON THE BASIS OF DATA SCIENCE TECHNOLOGIES
}

\author{
Galyna Chornous ${ }^{1}$, Yana Fareniuk ${ }^{2}$ \\ ${ }^{1,2}$ Taras Shevchenko National University of Kyiv, Kyiv, Ukraine \\ e-mails: ${ }^{1}$ chornous@univ.kiev.ua, ${ }^{2} y$ fareniuk@gmail.com
}

Received: 01 July 2021; Accepted: 20 August 2021; Online Published: 26 August 2021

\begin{abstract}
The article contains the results of Data Science technologies application (including machine learning and regression analysis) to modelling the results of marketing activities of key brand of one of the Ukrainian pharmaceutical companies on the basis of historical data for the period from 2015 to 2019 in weekly detail. The main goal of research is to estimate the influence of key elements of the marketing mix (penetration of pharmacy chains, price policy vs main competitors, advertising activity of the brand and its competitors in all communication channels (television, Digital, radio, outdoor advertising, press)) on company's sales, volume market share and value market share in relevant segment of drugs. Based on the results obtained, the article explains in detail the impact of penetration, price policy and media activity on the competitiveness of the enterprise and its position in the market. The influence of the price policy and penetration directly on sales (market share), as well as on other factors (including the effectiveness of the brand's advertising activity on television) is estimated and taken into account for development the effective marketing strategy. Based on the research, the article contains main recommendations for optimizing the marketing strategy to maximize the company's sales and increasing market share in monetary or physical terms. Data Science technologies become a tool for sales management, because it creates the ability to quantify the impact of each factor on sales, determine their optimal combination for achievement of business goals and strengthening the company's position in the market, effective marketing budgets distribution and scenario forecasting. Continuous model support allows to increase the return on each factor, improve return on investment and ensure the achievement of business goals in the most efficient way. Data Science forms the basis for finding effective marketing solutions and forming an effective business development strategy.
\end{abstract}

Keywords: marketing mix modelling, data science, machine learning, regression analysis, pharmaceutical company, Return on investment (ROI), strategy

JEL classification: $\mathrm{C} 5, \mathrm{M} 3, \mathrm{O} 1$

Citation:

Chornous, G., Fareniuk, Y. (2021). Marketing mix modeling for pharmaceutical companies on the basis of data science technologies. Access to science, business, innovation in digital economy, ACCESS Press, 2(3): $274-289$. https://doi.org/10.46656/access.2021.2.3(6)

\section{INTRODUCTION: MARKET CONTEXT AND BUSINESS TASKS}

The current business environment of enterprises is quite competitive and requires companies to focus on effective business activities with sufficient profitability. Establishing an effective marketing mix in accordance to its relationship with business results (fair and reasonable price, necessary penetration level and relevant media presence) is given considerable attention in modern marketing. Pricing is an important element of a modern marketing mix of any enterprise, where the main focus is on finding the optimal market price that will satisfy both the company and the consumer (Zhukov et al., 2014). Media activity is one of the key channels 
for attracting of new audience for a brand which helps sales increase and improving of companies' position on the market. High competition in the market and high inflation in the media create the need to find progressive solutions, and Data Science opens up many opportunities in this direction at all management level (operational and tactical tasks and strategic decisions). Own data approaches that combine Data Science technologies, marketing technologies and comprehensive expertise will be the most valuable resources for optimizing marketing investments and differentiating firms on the market.

The pharmaceutical business is one of the quickly growing in Ukraine. The sales volume of all categories of goods in the "pharmacy basket" amounted to UAH 74.3 billion ( 2.8 billion USD) in 9 months in 2019 and increased by $15.9 \%$ in hryvnia and $18.3 \%$ in dollar compared to the same period in 2018. In physical terms, sales amounted to 1.25 billion packages and dropped by $3.1 \%$.

The pharmaceutical market in Ukraine is developing mainly due to rising prices (high inflation component), as well as due to the redistribution of consumption towards more expensive drugs (substitution index), as evidenced by the dynamics of the drug market indicators in monetary terms.

At the same time, inflation in the pharmaceutical industry and in healthcare in general, according to the State Statistics Service of Ukraine is still lower than in the country in general and in other categories of goods and services.

The weighted average cost of 1 package for 9 months of 2019 amounted to UAH 58.7 and increased due to inflation by 19.6\% compared to the same period in 2018 (Kirsanov, 2019b). Under such conditions, rising prices are partially offset by increasing consumer incomes, as market development depends largely on the consumer and his level of well-being. In recent years, there has been an increase in both wages and incomes. The National Bank of Ukraine is constantly recording wage growth, but its growth rate is slowing down. According to the results of the second quarter of 2019, the State Statistics Service of Ukraine reports an increase in real incomes of the population by $7 \%$, and nominal - by $17 \%$.

The improvement of the economic situation in the country has positive influence on the development of the pharmaceutical industry: 2019 is characterized by double-digit growth in sales of "pharmacy basket" goods in hryvnia and dollar equivalent, although they slowed down compared to the previous year. According to the latest estimates and predictions of experts, the development of the pharmaceutical industry will continue, despite the impact of the COVID-19 crisis.

With the rapid development of the pharmaceutical market and solving the problems related to the economic crisis, in order to improve the management system of business competitiveness, the mechanism of managing the elements of the marketing mix is becoming increasingly important to improve business performance and maximize profits.

Pricing and media strategies in the marketing system occupy one of the key places (Korzh, 2018; De Toni et al.). They are an integral part of marketing strategies, and there is significant potential for optimization for companies that are deeply analyse the marketing data to find effective solutions and enhance their competitive advantage. 
To make informed business decisions about choosing an effective marketing strategy, it is advisable to develop it using a systematic approach that allows the company to succeed in the market. According to this, there is an urgent need to improve the marketing strategy and mechanisms for managing its elements, and Data Science technologies are the tools that open up significant opportunities in this area.

\section{MATERIALS AND METHODOLOGY}

A large number of articles have been written on this topic. Marketing mix modelling (MMM) is the most commonly used method, which consists of building a regression model based on historical data to present business metrics (sales or share of market) as a function of marketing and advertising variables, such as price index, product characteristics, media activity (number of advertising outputs, ratings, impressions) and other variables such as seasonality, macroeconomic factors, weather, level of competition in the market and so on.

The theoretical foundations and a wide range of issues related to the modelling of socio-economic processes are reflected in the works of such domestic and foreign scientists as Ansoff I., Kotler F., Porter M., Thompson A., Kizim M. (Kizim et al., 2009), Pushkar O., Ponomarenko V., Klebanova T. (Ponomarenko et al., 2020), Blagun I., Chernyak O., Khristianovsky V., Vitlinsky V. (Ponomarenko et al., 2013), Tarasevich V. (2010) and many others.

The greatest research of the theoretical and practical issues of marketing pricing policy was found in the works of Balabanova L., Osypenko S., Romanchyk T. (Osypenko et al., 2020), Slushaenko N. (2015), Myshko O. and Kaminska I. (Myshko et al., 2021), Noritsyna N. (2007), Farm A. (2020), which focused on the relationship between price and competitiveness. The importance of this aspect of marketing for any enterprise was showed by De Toni D., Milan G. (De Toni et al., 2017), Ryzhikov V., Pankov V. (Ryzhikov et al, 2004).

The researches of the application of machine learning technologies and Data Science for modelling the enterprises' marketing mix were conducted by such domestic and foreign scientists as Bazhenov Y., Burnet J., Bodnar L., Vinkovska A. (Vinkovska et al., 2019), Büschken J. (2007), Guz M., Lysenko Y., Lukyanets T., Bowman D. and Gatignon H. (Bowman et al., 2010), Pargelova A. (Pargelova et al., 2010), Rossiter J. (Rossiter et al., 2017), Romat E., Batra R. (Batra et al, 2016), Fryburger V., Sandage C. (Sandage et al, 1986) and others.

Data Science and mathematical modelling open up significant opportunities in the implementation of marketing activities of any company. Chan and Perry (2017) argue the importance for companies to work with different approaches to marketing modelling, as advertisers need to understand the effectiveness of their media and marketing spends in driving sales to optimize the distribution of marketing budgets.

The contribution of classic machine learning methods like regression analysis to marketing decisionmaking is quite important, but there are alternative methods. Dawes et al. (2018) research evidence-based methods that have been shown to be useful for forecasting. Jin et al. (2017), Zhang and Vaver (2017) recommend using Bayesian hierarchical modelling. 
According to research Chan and Perry (2017), the potential of marketing mix modelling may be limited by the lack of detailed and qualitative data. To solve this problem, they propose to develop better data and models, as well as test them, using simulations as the main instruments of improvement for marketing mix modelling.

Despite the scientific achievements of various scientists, many issues of finding ways to optimize marketing strategy remain unresolved. Elements of the marketing mix in the marketing system are well studied, but the optimization of the marketing mechanism and forecasting the results of marketing activities depending on marketing factors requires more detailed research. After all, an effective marketing strategy (including pricing policy and media strategy), as well as improving the mechanism of distribution of marketing budgets and effective implementation of marketing activities are determinants of sales growth of any enterprise (Zhukov et al., 2014). Adaptation of marketing strategy in highly competitive industries is one of the areas of daily work of every pharmaceutical campaign in Ukraine and in the world. Therefore, finding a solution to this issue based on data is extremely important.

The goal of the research is to modelling the impact of marketing mix elements on sales of key brand of one of the Ukrainian pharmaceutical companies based on Data Science and machine learning technologies (regression analysis), as well as the formation of recommendations for improving the efficiency of the marketing activities of companies in pharmaceutical business and optimizing the marketing results depending on the chosen marketing strategy of a particular product.

To achieve this goal were used economic and mathematical modelling (including on the basis of machine learning technologies like regression analysis) of the dependence of sales (market share in volume and in value) of certain drugs on the following factors: penetration of pharmacy networks (pharmacy coverage and drug availability for consumers), pricing policy (the index of the drug's price compared to brand's competitors), media activity of the brand and its competitors in all communication channels (television, Internet, radio, press and outdoor advertising), recommendations of doctors and pharmacists and others. Pharmaceutical companies have specific marketing mix (compared to Fast Moving Consumer Goods (FMCG) market) as include work with doctors and pharmacists and realisation of necessary penetration of pharmacy network.

Data on all variables for the period from 2015 to 2019 were collected in a weekly breakdown for all drugs in the relevant category (database was collected on the basis of data of the pharmaceutical company from Proxima Research, as well as the Industrial Television Committee and Nielsen Ukraine). Due to confidentiality, all data in the article will be indexed from 0 to 1.

For the constructed multiple regression models, which were estimated by the method of least squares, hypotheses about the adequacy of the models, the significance of the coefficients, the presence of heteroskedasticity and autocorrelation were tested.

Also, for the development of recommendations for optimal pricing policy, an approach based on machine learning technologies (coefficients from regression models and additional calculations) was developed to determine the optimal range of price index (price of drug compared to the average price of competitors) to maximize market share in packaging or market share in value depending on the company's goals. Determining 
the influence of media factors helps to formulate recommendations for media strategy of this drugs and as a result increase ROI (return on investment) of media investments.

\section{RESULTS AND DISCUSSION}

\subsection{Data Science as a relevant tool to find effective business solution}

The significant level of competition in the pharmaceutical industry, the growth in the price of advertising activity and the desire of manufacturers to constantly increase sales generates the need to find effective marketing solutions. To achieve these goals, it is necessary to actively use the data available on the market, using machine learning technologies and Data Mining approaches. Data Science is an extremely effective tool for improving the effectiveness of marketing activities of pharmaceutical companies, its optimization and greater validity.

The research of marketing activities of several pharmaceutical brands in Ukraine in one product category will show how on the basis of economic-mathematical modelling (regression analysis) and other Data Science technologies we can analyse what factors and to what extent affect the business results of the company (sales or market share in the relevant category). Understanding the influenced factors enables to calculate the elasticity of sales to each factor and as a result to distinguish the optimal range for each of them taking into account their marginal utility (for example, calculating price elasticity and finding the optimal value of the price index - the ratio of brand price and average price of competitors or determining the optimal level of media pressure in each communication channel). In addition, understanding the effectiveness of each communication channel make it possible to develop an effective media strategy and tactics for the brand.

Project was deploying in accordance with the most widely-used analytics model named "Cross-Industry Standard Process for Data Mining" (CRISP-DM) (Brown, 2015; Shearer, 2000). CRISP-DM describes the process through 6 stages: "Business Understanding, Data Understanding, Data Preparation, Modelling, Evaluation and Deployment" (Chernyak et al., 2014). In this project, the overall process was implemented through step-by-step analysis and modelling, as shown in Fig.1.

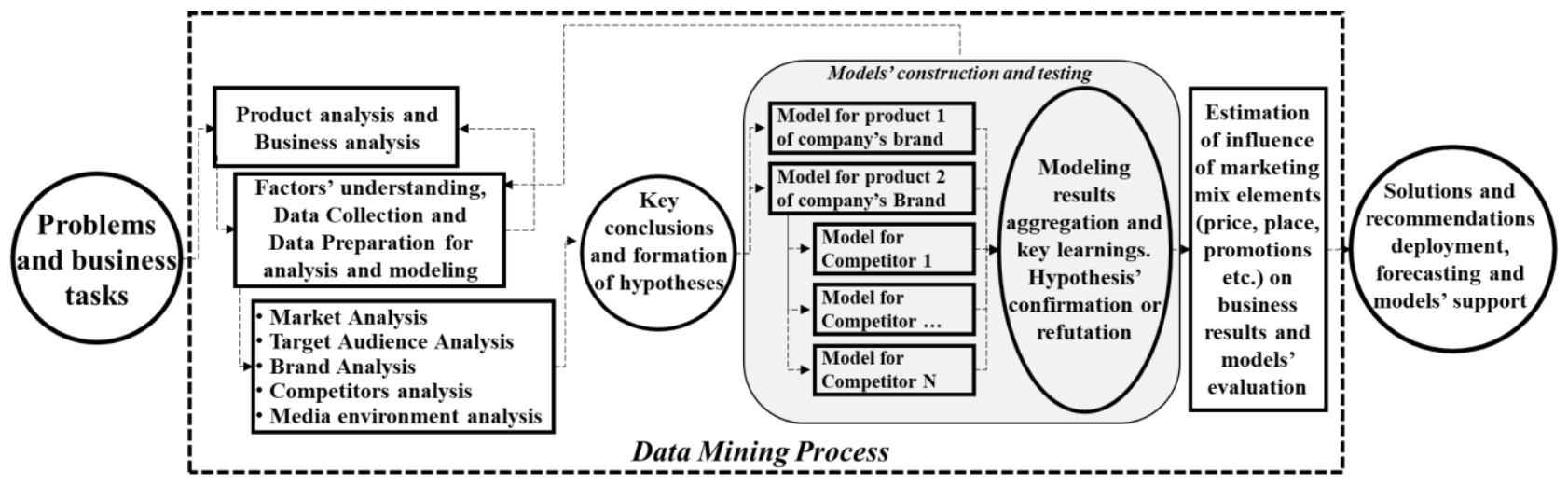

Fig. 1. Proposed concept of modelling marketing mix project realization

Source: Developed by the authors 
The process includes the ability to flexibly change the order of the stages, going back when the need arises. Data mining is cyclical in nature, as the process of finding solutions continues throughout the project and after the project has been deployed. The main knowledge, learnings and experience of the previous cycle can create new, deeper business issues that have a positive impact on future data mining processes (Chernyak et al., 2014).

At the first stage of working with a business task, it is necessary to study in detail the features of the brand and the category for which the analysis is implemented to determine all the factors that influence on the final performance of the business. In this study, we examine a brand that is a leader in the category, but is gradually losing its market position in favor of competitors who have active media support on television, as well as actively working with doctors and pharmacists.

In addition, a feature of this category is the availability for the consumer of two forms of the drug - drops or syrup (liquid form) and capsules or tablets (solid form), so in the future when using Data Science and machine learning to model volume market share (SOM - share of market) will consider a separate model for liquid and solid forms of drug (Fig. 2).

Economic and mathematical modelling of marketing mix on the basis of Data Science technologies enables to:

- determine the factors that influence on sales, as well as the extent of this impact;

- evaluate the elasticity of sales for each factor;

- forecast the target metrics depending on the planned level of each factor;

- make recommendations on the optimal / necessary level of each factor to achieve the business goals;

- compare the impact of factors for the company's brand and for competing brands in the case of model building for other brands also.

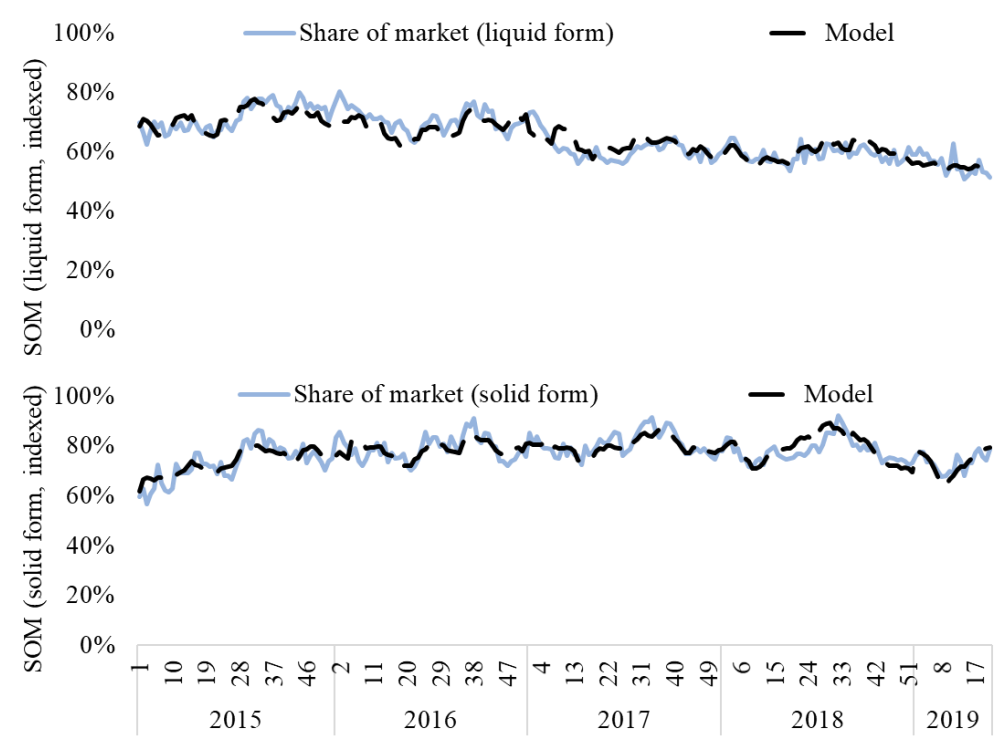

Fig. 2. Models for liquid and solid forms of the drug

Source: Authors' calculations based on data of the pharmaceutical company from Proxima Research, as well as the Industrial Television Committee and Nielsen Ukraine (data indexed due to confidentiality) 


\subsection{Marketing Mix Modelling results}

The key factors influencing the level of drug sales and its market share included the following:

- organic level (base line of sales - set of macroeconomic and rational marketing factors);

- penetration (distribution) - percentage of pharmacy stores in which the drug is available for consumers, the level of coverage of pharmacies;

- $\quad$ price policy - price index in comparison to brand's competitors (the ratio of the price of the drug and the average market price for similar products on the market);

- pharmacists' recommendations;

- doctors' recommendations;

- advertising activity of competitors in terms of communication channels, creative materials, video durations, etc.;

- media activity of brand in terms of communication channels, creative materials, video durations, etc.

The evaluation of influence of these factors on the basis of machine learning technologies (regression analysis) creates the basis for business optimization and finding effective marketing and media solutions and as a result development an effective strategy for the company's growth in the future.

The main criteria for model optimization are increasing of $\mathrm{R}^{2}$, its adequacy, absence of autocorrelation and heteroskedasticity and opportunities to estimate the efficiency of marketing mix elements with high level of significance.

The optimal model for each form of drug is multiple regression model and looks like this:

SOM $=$ Constant $+a_{1} *$ Penetration ${ }_{1}+a_{2} *$ Penetration $_{2}+a_{3} *$ Price_index $+a_{4} *$ Doctors + $+a_{5} *$ Pharmacists $+a_{6} *$ Adstock $\left(T V_{1}\right)+a_{7} * A d s t o c k\left(T V_{2}\right)+\ldots+a_{n} * \operatorname{Adstock}\left(T V_{n}\right)+b_{1} *$

$*$ Adstock $\left(T V_{-}\right.$Competitor $\left.{ }_{1}\right)+b_{2} * A d s t o c k\left(T V_{-}\right.$Competitor $\left._{2}\right)+\ldots+b_{m} * A d s t o c k\left(T V_{-}\right.$Competitor $\left.{ }_{m}\right)$, where (1)

- $\quad S O M$ - share of market in Volume;

- $\quad$ Penetration $_{1}$ and Penetration $_{2}$ - penetration level for SKU 1 and SKU 2 respectively;

- Doctors or Pharmacists - level of brand's recommendations by doctors and pharmacists;

- $T V_{l}$ or $T V_{2}$ or $T V_{n}$ - television activity of brand by different creative materials $\left(T V_{l}\right.$ is for creative 1 and $T V_{n}$ is for creative $n$ respectively);

- TV_Competitor or TV_Competitor $_{m}$ - TV activity of competitor 1 or competitor 2 respectively;

- Adstock is the instant, prolonged and lagged effect of advertising activity on consumer purchase behavior, which indicate influence of television activity during a time.

$$
\operatorname{Adstock}(T V) t=T V t+a * \operatorname{Adstock}(T V) t-1
$$

The built models are characterized by high quality indicators (coefficients of determination $\mathrm{R}^{2}$ are $78 \%$ and $70 \%$, respectively for model for liquid form and for model for solid form), and the average error RMSPE is less than $4 \%$, the models are adequate, all factors are significant, the both models haven't autocorrelation and 
heteroskedasticity), which confirms their practical application for optimization of marketing activities (Table $1)$.

Table 1. Technical Characteristics of One of the Models (for one of the Product Form)

\begin{tabular}{lcccc}
\hline \multicolumn{1}{c}{ Indicator } & Coefficient & $\begin{array}{c}\text { Stand. } \\
\text { Error }\end{array}$ & t-statistics & P-value \\
\hline Constant & 0,120 & 0,00 & 71,77 & 0,0000 \\
Penetration & 0,983 & 0,12 & 8,24 & 0,0000 \\
Price index & $-0,970$ & 0,09 & 11,02 & 0,0000 \\
Doctors & 0,561 & 0,41 & 1,37 & 0,0000 \\
Pharmacists & 0,396 & 0,11 & 3,57 & 0,0000 \\
TV & 1,085 & 0,18 & 6,03 & 0,0000 \\
Competitors & 0,988 & 0,14 & 7,23 & 0,0000 \\
Multiple $\mathrm{R}^{2}$ & 0,78 & & Adjusted $\mathrm{R}^{2}$ & 0,77 \\
F-statistics & 140,93 & & p-value & 0,0000 \\
\hline
\end{tabular}

Source: Own calculations based on data of the pharmaceutical company from Proxima Research, as well as the Industrial Television Committee and Nielsen Ukraine (data indexed due to confidentiality)

The base level of sales or share of market (constant in Table 1) is the level of company's sales that will accumulate in the short term with a minimum level of penetration level (level of presence in pharmacy stores), a minimum level of price index compared to competitors, minimal level of doctors' and pharmacists' recommendations and in conditions of lack of advertising activity of the brand for which prepared analytics, and competing brands, and includes a number of other qualitative characteristics.

The period of drug's presence on the market influenced the share of the base line impact on sales or share of market and it will range from the minimum level to most of the sales of the drug. So, if the drug is on the market in the last few years and we prepare analytics from the moment of its launch, the base line will be absent and vice versa - if the drug is on the market in the last 5 years or more, the share of the base line will be growth.

On the case of this brand, the base line generates a significant share of sales $-57 \%$, but this factor is stable in the short term (is a constant in the model), so the right work with other factors creates opportunities for the brand for future growth (Fig. 3).

In order to estimate the influence of each factor on sales, it is necessary to analyse in detail the dynamics of each of them, distinguish their impact through the construction of models, as well as compare all factors' parameters with indicators for competing brands on the market.

Factor 2 - penetration level. In general, the high level of penetration is an integral part of effective brand growth, because the presence on the shelf is a key marketing factor not only for pharmaceutical companies, but also for all FMCG brands. This brand is one of the main brands in the pharmaceutical market and in 2019 provided a high level of penetration for the main product form - up to $90 \%$, actively increasing it in previous years. Growth of penetration during the previous periods generated a significant additional growth in sales of brand and its position on the market.

Factor 3 and 4 - recommendations of doctors and pharmacists. Doctors and pharmacists are one of the main communication channels with the potential consumers, as they often make the final decision for purchase after 
a doctor's recommendation or pharmacist's advice. As a result, the proper level of work with these medical personnel are a necessary condition for the effective development of the brand and the company in the market in general. Of course, stimulation the level of doctors' and pharmacists' recommendations, even at a low level, provides a growth in the company's sales, and its strengthening improves the company's efficiency and its sales level. Thus, changes in work with doctors and pharmacists provided additional sales growth of our brand and generated X packages for the period 2015-2019.

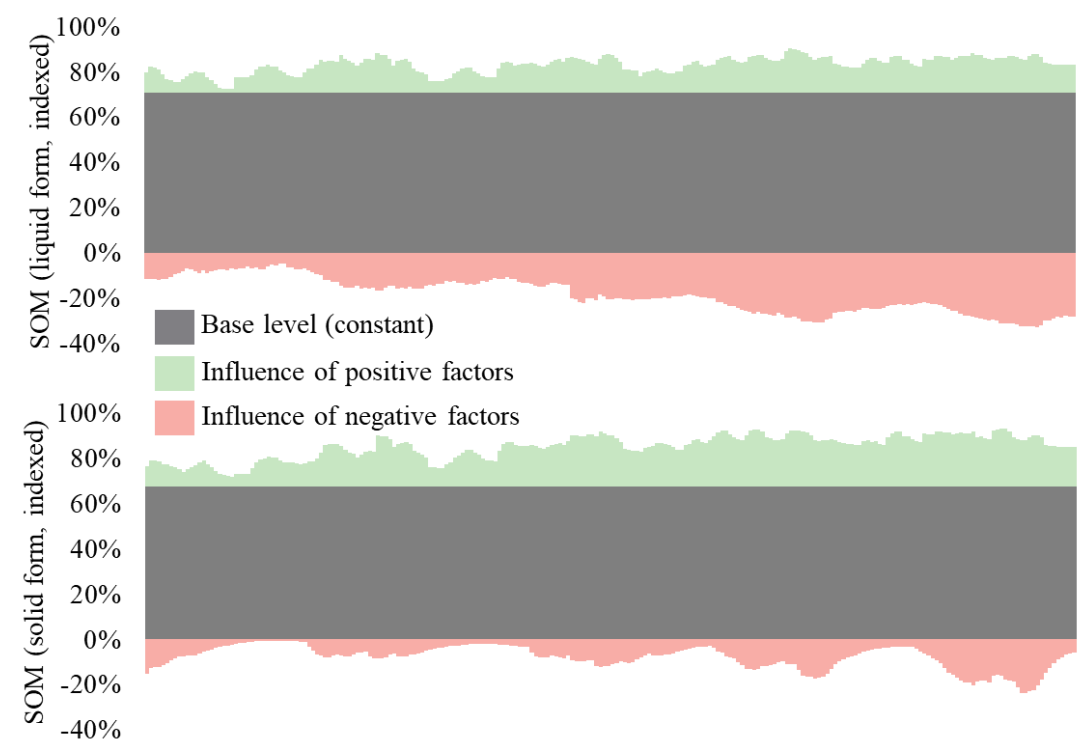

Fig. 3. Model decomposition by different group of factors (base line, positive factors, negative factors)

Source: Authors' calculations based on data of the pharmaceutical company from Proxima Research, as well as the Industrial Television Committee and Nielsen Ukraine (data indexed due to confidentiality)

Factor 5 - price policy. In the period 2015-2019, the company raised price for this brand faster than its competitors, which stimulated to an increase in the price index (the ratio of the price of the drug compared to average price on the market). The average price level of the drug is $5-25 \%$ higher than the competitors' price, depending on the products' segment, which have negative effects on the dynamics of sales in physical term.

Ukrainians are a nation that tends to save, so rising prices faster than competitors leads to switching to competing brands and losing brand's market share in physical term. As a result, changes in the pricing index in previous periods led to a loss of brand sales (Fig. 4).

However, if we analyse the pricing policy, a certain level of price growth might lead to a drop in sales in physical terms, but generate an additional level of revenue when the price increase compensates for the fall in sales in physical terms and vice versa - a significant growth in prices of drug might lead to a significant drop in sales in physical terms and the company's profit will be significantly reduced. As a result, there is potential for optimization depending on the price elasticity of sales and share of market in value and in volume.

Taking into account the business goals - to increase share of market in value (increase revenue) or increase share of market in volume (increase penetration of drug among target audience and consumers), recommendations for price policy will be radically different. 


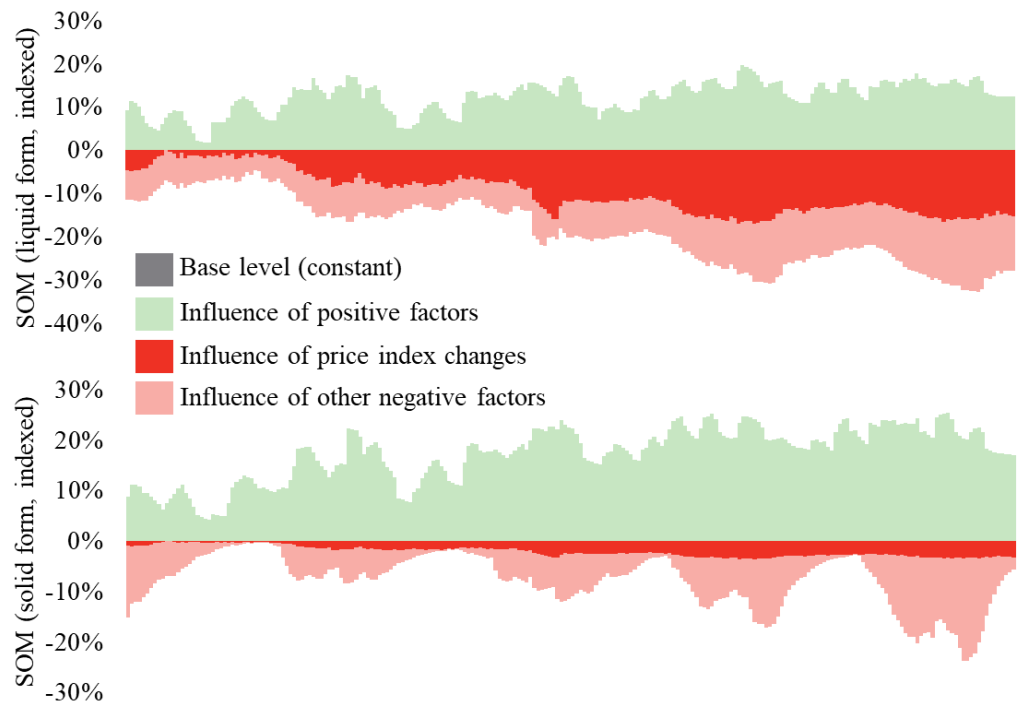

Fig. 4. The impact of price on market share in the dynamics of 2015-2019 (model decomposition)

Source: Authors' calculations based on data of the pharmaceutical company from Proxima Research, as well as the Industrial Television Committee and Nielsen Ukraine (data indexed due to confidentiality)

On the basis of the built econometric models for liquid and solid forms of the drug, we can estimate the curves of share of market in money and share of market in packages depending on the price index level, as the coefficients of models at the price index indicate how share of market will change with rising price index by 1 unit (the character of the connection is linear in the case of building a linear regression or non-linear in another conditions).

The share of market in value and the share of market in volume are linked by a price index. Due to the fact that the rate of change of share of market in physical terms does not coincide with the rate of change of the price index, there is a non-linear relationship between the price index and share of market in value, which leads to an optimization zone depending on business objectives.

On the case of our brand of drug, the optimal value of the price index to maximize share of market in money was from 1.0 to 1.4 (Fig. 5), which means that the drug should have parity prices to the market or be more expensive up to $+40 \%$ to average prices on the market to obtain the maximum level of profit. Depending on the business' goals, this methodology becomes a flexible and convenient tool for the price policy department, as it is possible to form a recommendation for price level to achieve the goals of both share of market in value and share of market in volume.

Factor 6 and 7 - advertising activity of the brand and its competitors. One of the main factors in increasing sales is the active promotion of brands through media channels, because advertising is the key way of communication between producers and their consumers.

The Ukrainian pharmaceutical market continues to develop actively, but it is highly competitive, and in the struggle for the consumer, companies are forced to actively promote their brands via advertising activity. 


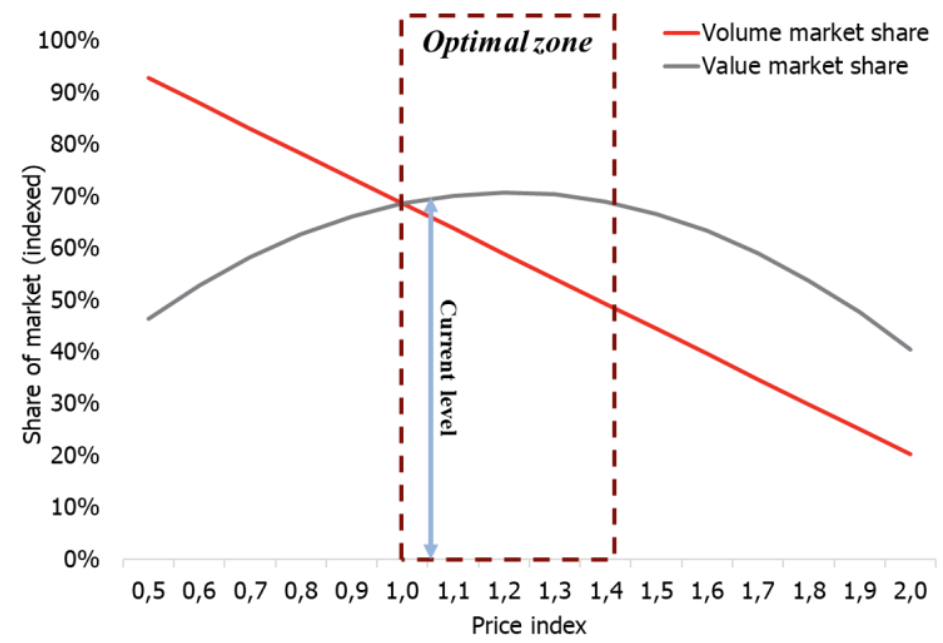

Fig. 5. Optimal level of price index in terms of growth of value market share

Source: Authors' calculations based on data of the pharmaceutical company from Proxima Research, as well as the Industrial

Television Committee and Nielsen Ukraine (data indexed due to confidentiality)

The main channel for the advertising activity of pharmaceutical manufacturers has long and stable been television (TV). All-Ukrainian Advertising Coalition (VRK), estimated that in 2019 the volume of the TV advertising market (direct advertising and sponsorship) increased by $24 \%$ and amounted to UAH 11.5 billion, which corresponds to about $47 \%$ of the total volume of advertising media market of Ukraine in 2019.

Pharmaceutical companies are one of the main advertisers on Ukrainian TV. The share of their investments in TV consistently occupies about $30 \%$ of the total advertising investment in this communication channel. They invested more than UAH 2.1 billion in their brand's advertising on TV in 9 months in 2019, increasing their media budgets by $28 \%$ compared to the same period in previous year. Investments in TV advertising by pharmaceutical companies show a steady increase, but the volume of activity by EqTRPs (weighted target rating points) has been dropping in recent years due to significant inflation.

The efficiency of investment in advertising is determined by the indicators of EqTRPs, which ultimately affect the company's sales as this indicator is relevant to advertising cost. Due to the increasing of advertising instruments' cost due to high inflation, among pharmaceutical companies created the significant preconditions for finding effective data-based solutions on the basis of in-depth analysis of all available data on the market using Data Science technologies to optimize marketing (including media) investments.

TV support generates the growth of the brand's share of market, but the TV activity of competitors has a significant negative impact. Realizing the significant negative influence of TV activity of competitors, it is important to control share of voice (SOV) on TV in the future and realize parity placement with competitors, because the more advertising activity a brand launches during the year, the higher sales level it stimulates. The loss of share of voice on TV is the main reason for the loss of the brand's position in the market for this brand.

It should be noted that the efficiency of TV activity differs during the year due to the seasonality of the category and price conditions of TV instruments, which necessitates a redistribution of TV activity during the year to get the maximum return on investment (ROI) and as a result increase sales level. In this category, sales 
are reduced in the summer, due to the specifics of the disease and, accordingly, treatment, but the prices for TV advertising in this period are also slightly lower. Autumn and spring - the main sales season, but the cost of advertising increases significantly during this period. As a result, the ratio of these indicators will determine the effectiveness of media activity and, as a consequence, the feasibility of its launch in each period of time. Given the results obtained for this brand, it is most appropriate to use TV advertising almost throughout the year, except for the period April-May, when lower advertising costs do not offset the decline in sales level and as a result the effectiveness of media activity declines significantly (Fig. 6).

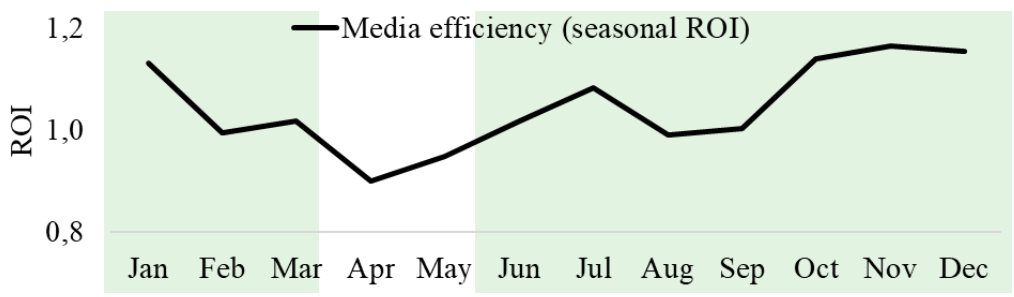

Fig. 6. Response from TV activity during a year

Source: Authors' calculations based on data of the pharmaceutical company from Proxima Research, as well as the Industrial Television Committee and Nielsen Ukraine (data indexed due to confidentiality)

The effectiveness of advertising activity depends on a large number of factors, both media (average weekly pressure, periods of activity, creative materials, videos' duration, etc.) and non-media (including penetration and price policy). To test these hypotheses, similar economic and mathematical models were constructed for other brands in this category. After that, the results of all models were aggregated and the following conclusions were proved:

- The hypothesis that more weekly pressure (more activity) provides higher efficiency of media presence and as a result a higher level of sales is generated due to advertising activity was refuted. Within this category, we identified brands that realized a presence on TV with high weekly weights (AWW average weekly weights), which did not provide a corresponding increase in business performance (the brand in this case overinvests). As a result, recommendations were formed regarding the optimal range of activity to obtain the maximum level of ROI - from 150 to 200 TRPs (target rating points) per week (Fig. 7).

- The influence of penetration on the effectiveness of advertising activity: the lower the penetration of pharmacies, the lower the efficiency of TV support, because the target audience, coming to the pharmacy stores can't buy the drug due to its absence. The product for which the analysis and modelling were prepared has a high penetration level (more than 90\%), which has a strong positive effect on the efficiency of TV activity.

- The influence of price index on effectiveness of media support is opposite, but also quite significant: the higher the price of the product, the fewer interested audience dare to buy, because the level of price in these conditions become a barrier for the consumer and as a result efficiency from TV activity reduce (Fig. 8). The brand for which the analysis was prepared is in the middle price group and has 
sufficient efficiency from TV activity. The optimal level of the price index to maximize sales of the brand is $1.0-1.4$ (Fig. 5).

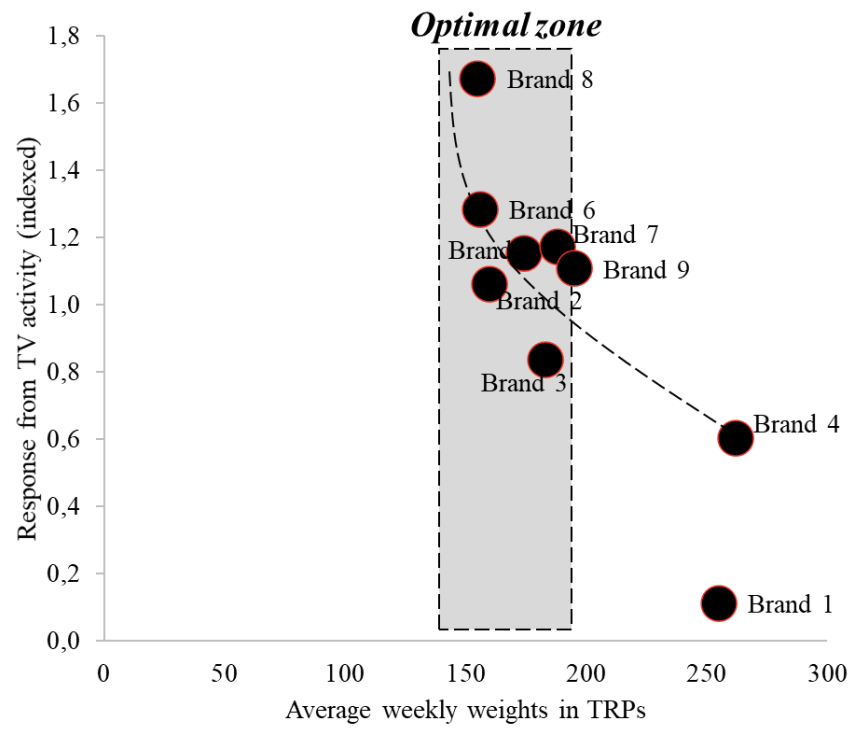

Fig. 7. The impact of average weekly weights on efficiency of media support and optimal range for media pressure Source: Authors' calculations based on data of the pharmaceutical company from Proxima Research, as well as the Industrial Television Committee and Nielsen Ukraine (data indexed due to confidentiality)

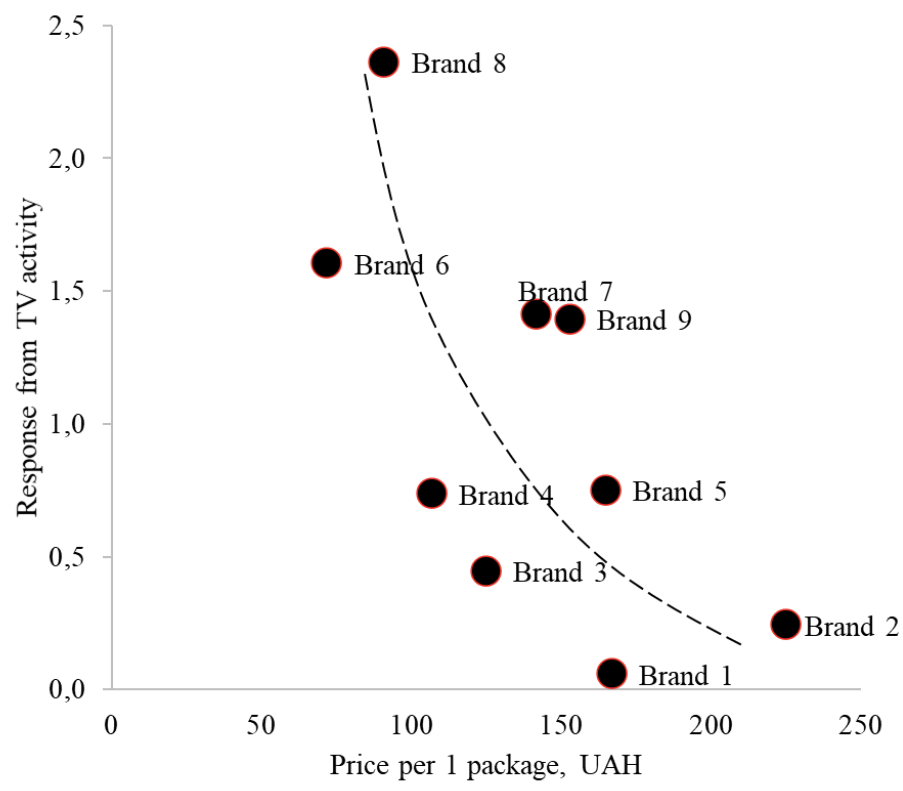

Fig. 8. The impact of price on efficiency of media support

Source: Authors' calculations based on data of the pharmaceutical company from Proxima Research, as well as the Industrial Television Committee and Nielsen Ukraine (data indexed due to confidentiality)

It is important to understand that these recommendations and conclusions can't be taken generally for all brands and companies on the market, as the final business results are a complicated combination of many factors and conditions that are formed at each time, which requires an individual approach and analysis in each situation. 


\section{CONCLUSION}

Thus, the economic and mathematical model enables to understand and estimate the contribution of each marketing factor in the brand's sales level and make it possible to form effective recommendations for each element of marketing mix. The econometric model in such conditions is a convenient and flexible tool for marketing management, because it make it possible to find the optimal combination of factors to achieve shortterm and long-term business goals through management of key KPIs (key performance indices). Regular model's support enables to maximize the influence of each factor, which ultimately make it possible to achieve the necessary business results by the minimum budget or higher business results by the current existing budget.

Thus, the modelling and ongoing process of data analysis becomes a convenient tool for making effective operational marketing decisions:

- estimation on a regular basis of the optimal price taking into account the dynamics of competitors' prices and monitoring its effect on sales;

- tracking the efficiency of the advertising campaign in all communication channels;

- forecasting of business results at different scenarios of activity in the communication with the potential consumers due to work with doctors and pharmacists;

- forecasting of business results for different combinations of marketing factors (realizing of scenario forecasting);

- calculation of optimal level of each factor taking into account the marginal efficiency of each of them;

- analysis of the influence of factors on brand sales, evaluation of winnings and losses.

Econometric model for this pharmaceutical brand helps to find following conclusions:

- TV activity is a main driver of sales growth, but efficiency is different by each month and influenced by price policy and distribution level;

- Optimal media pressure per week - 150-200 TRPs (target rating points);

- Competitors' activity has strong negative influence, so we need to control share of voice in communication channels (to have leading position by media pressure);

- Distribution generates a large share of sales, so we need to maintain current level of distribution (at least $90 \%)$;

- Optimal range of price index is 1.0-1.4 (price vs competitors).

The economic and mathematical model acquires the greatest value at the moment when it becomes a tool for business simulations and the opportunity of implementing scenario forecasting. In such case there is a possibility to assess and realize the various scenarios of business development, for example:

- What will happen if we increase TV support by X\% and increase the price by $\mathrm{Y} \%$ ?

- What will happen if we transfer the budget for work with doctors and pharmacists to TV activity? 
- What will happen if we drop prices by $\mathrm{X} \%$ and change the period of media presence from October to September?

Realization of Data Science projects have strong economic influence on business performance as help to increase return on marketing investment by more than $5 \%$ and plan future business results with average error less than $5 \%$.

\section{Conflict of interests}

The authors declare no conflict of interest.

\section{References}

Batra, R., Keller, K. (2016). Integrating marketing communications: New findings, new lessons, and new ideas. Journal of Marketing, 80(6), pp. 122-145. https://doi.org/10.1509/jm.15.0419.

Bowman, D., Gatignon, H. (2010). Market Response and Marketing Mix Models: Trends and Research Opportunities. Foundations and Trends® in Marketing, Vol. 4, No. 3, pp. 129-207. DOI: http://dx.doi.org/10.1561/1700000015.

Brown, M. S. (2015). What IT Needs To Know About The Data Mining Process. Forbes.

Büschken, J. (2007). Determinants of Brand Advertising Efficiency: Evidence from the German Car Market. Journal of Advertising, Vol. 36, No. 3, pp. 51-73. DOI: https://doi.org/10.2753/JOA0091-3367360304.

Chan, D., Perry, M. (2017). Challenges and Opportunities in Media Mix Modeling, Technical report, Google Inc, https://ai.google/research/pubs/pub45998 (accessed: August 2021).

Chernyak, O., Zaharchenko, P. (2014). Data mining: Textbook, Znannya, Kyiv (UA).

Dawes, J., Kennedy, R., Green, K. (2018). Forecasting advertising and media effects on sales: Econometrics and alternatives. International Journal of Market Research, Vol. 60, No. 6, pp. 611-620. DOI: https://doi.org/10.1177/1470785318782871.

De Toni, D., Milan, G., Saciloto, E., Larentis, F. (2017). Pricing strategies and levels and their impact on corporate profitability. Revista de Administração, Vol. 52 (2), p. 120-133. DOI: https://doi.org/10.1016/j.rausp.2016.12.004.

Farm, A. (2020). Pricing in practice in consumer markets. Journal of Post Keynesian Economics, Vol. 43:1, pp. 61-75. DOI: https://doi.org/10.1080/01603477.2019.1616562.

Jin, Y., Wang, Y., Sun, Y., Chan, D., Koehler, J. (2017). Bayesian Methods for Media Mix Modeling with Carryover and Shape Effects, Technical report, Google Inc. https://static.googleusercontent.com/media/ research.google.com/ru//pubs/archive/46001.pdf (accessed: August 2021).

Kirsanov, D. (2019). Advertising of pharmaceutical brands in various media based on the results of 9 months of 2019 Helicopter view. Pharmacy Online, No. 44 (1215), https://www.apteka.ua/article/521815 (accessed: August 2021).

Kirsanov, D. (2019b). Ukrainian pharmacy market for 9 months of 2019: Helicopter View. Pharmacy Online, No. 41 (1212), https://www.apteka.ua/article/519677 (accessed: August 2021).

Kizim, M., Geiman, O. (2009). Scenario modeling of development of social and economic systems: directions, features and mechanisms. Regional economics, №4, pp. 16-23. http://nbuv.gov.ua/UJRN/regek_2009_4_4 (accessed: August 2021).

Korzh, M. (2018). Price optimization modeling in international marketing. Foreign trade: economics, finance, law, №5, pp. 87-100.

Myshko, O., Kaminska, I. (2021). Formation of price policy of trade enterprises in modern conditions. Economy and society, (23). DOI: https://doi.org/10.32782/2524-0072/2021-23-25.

Noritsina, N. (2007). Marketing pricing as a factor of profitable activity of the enterprise. Marketing in Ukraine, №5, pp. $41-43$.

Osypenko, S., Romanchyk, T., Pisarevsky, S. (2020). Substantiating the Prices for Enterprise Products on the Basis of Optimization Models. Business Inform, №6, p. 145-151. https://doi.org/10.32983/2222-4459-2020-6-145-151. 
Pergelova, A., Prior, D., Rialp, J. (2010). Assessing advertising efficiency. Journal of Advertising, Vol. 39/3. DOI: https://doi.org/10.2753/JOA0091-3367390303.

Ponomarenko, V., Klebanova, T., Guryanova, L. (2020). System analysis and modeling of management. BratislavaKharkiv, HSEM - KhNUE im. S. Kuznets, 288 p.

Ponomarenko, V., Klebanova, T., Kizim, O. (2013). Models of Assessment and Analysis of Complex Socio-Economic Systems: Monograph. Kherson, Publishing House "Inzhek", 664 p.

Ryzhikov, V., Pankov V., Rovenska V., Pidgora Y. (2004). Business Economics: Textbook. Kyiv: Slovo Publishing House, $253 \mathrm{p}$.

Rossiter, J., Percy, L. (2017). Methodological Guidelines for Advertising Research. Journal of Advertising, 46 (1), pp. 71-82.

Sandage, C., Fryburger V. (1976). Advertising Theory and Practice. Ninth edition. Homewood, Illinois: Richard D. Irwin, Inc. Journal of Advertising, 5:1, 43, DOI: 10.1080/00913367.1976.10672626.

Shearer, C. (2000). The CRISP-DM model: the new blueprint for data mining. J Data Warehousing, 5:13-22.

Slushaenko, N., Apenko, O. (2015). Modern methods of pricing in the strategic activities planning of pharmaceutical companies in Ukraine. Bulletin of the Taras Shevchenko National University of Kyiv. Economy, Vol. 4, p. 58-63. DOI: http://dx.doi.org/10.17721/1728-2667.2015/169-4/10.

Tarasevich, V. M. (2010). Pricing policy of the enterprise. 3rd ed, Saint-Peterburg, 320 p.

Vinkovska, A., Kiv, A., Koycheva, T., Bodnar, L., Donchev, I. (2019). Information model of the economic efficiency of advertising. SHS Web Conf., 65, p. 1-6. DOI: https://doi.org/10.1051/shsconf/20196504022.

Website of Nielsen Ukraine, https://www.nielsen.com/ua/uk/.

Website of Proxima Research, https://proximaresearch.ua/en/.

Website of State Statistics Service of Ukraine, http://www.ukrstat.gov.ua/.

Website of Television Industry Committee, http://www.itk.ua/en/root/index/.

Website of VRK, https://vrk.org.ua/.

Zhang, S., Vaver, J. (2017). Introduction to the Aggregate Marketing System Simulator, Technical report, Google Inc, https://research.google/pubs/pub45996/ (accessed: August 2021).

Zhukov, S., Fedurtsa, V., Gromova, Y. (2014). Optimization of marketing price policy of industrial enterprises. Actual problems of economy: Scientific economic journal, №6, pp. 213-219.

\section{About the authors}

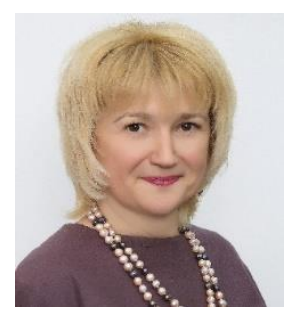

Galyna CHORNOUS, Doctor of Sciences (Economics), Professor of the Department of Economic Cybernetics, Taras Shevchenko National University of Kyiv, Kyiv, Ukraine. Research interests: Decision Support Systems, Economic Cybernetics, Intellectual Data Analysis, Data Science.

ORCID ID: https://orcid.org/0000-0003-4889-1247

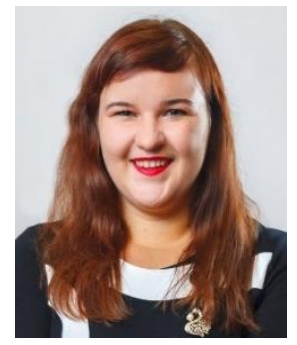

Yana FARENIUK, PhD Student (Economics) of the Department of Economic Cybernetics, Taras Shevchenko National University of Kyiv, Kyiv, Ukraine. The topic of $\mathrm{PhD}$ dissertation is «Modeling of marketing activities of enterprises using Data Science technologies». Research interests: economic and mathematical modeling, mathematical statistics, econometrics, Data Science and Machine Learning in marketing.

ORCID ID: http://orcid.org/0000-0001-6837-5042

Copyright (C 2020 by author(s) and ACCESS Publishing Press This work is licensed under the Creative Commons Attribution International License (CC BY) 


\title{
INSTITUTIONAL DYSFUNCTIONS AS A FACTOR OF CONVERGENT- DIVERGENT INSTITUTIONAL DEVELOPMENT OF POST-SOCIALIST COUNTRIES
}

\author{
Nadiia Grazhevska $^{1}$, Tetiana Gaidai ${ }^{2}$, Alla Mostepaniuk ${ }^{3}$, Andrii Zavazhenko ${ }^{4 *}$ \\ 1,2,3,4 Taras Shevchenko National University of Kyiv, Kyiv, Ukraine \\ e-mails: ${ }^{1}$ nadiia.hrazhevska@gmail.com, ${ }^{2}$ gaidai@univ.net.ua, ${ }^{3}$ a.mostepaniuk@gmail.com, \\ ${ }^{4}$ zavazhenko96@gmail.com
}

Received: 31 July 2021; $\quad$ Accepted: 20 August 2021; Online Published: 31 August 2021

\begin{abstract}
The article examines the causes, nature and consequences of institutional dysfunctions that arise in the process of market transformations of post-socialist economies, as well as how they affect the institutional development of these countries. A comparative analysis was conducted on the conceptual and methodological basis of modern economic transitology and new institutional economics using such statistical methods as comparison of averages, graphical, correlation analysis, and clustering. The results of the analysis revealed the convergent-divergent nature of the institutional dysfunctions impact on institutional development of post-socialist countries. In particular, the similarity of changes in averages of such development indicators was observed, which indicates the existence of a cluster (convergent-divergent) relationship between 19 analyzed post-socialist countries during the second decade of the XXI century. The convergence of institutional development trends is determined both by the general strategic orientation of systemic market reforms and by the geopolitical, territorial proximity of countries, their membership in regional associations. Clustering of countries through the use of Euclidean distance found that due to differences in institutional development rates of post-socialist economies over the past ten years, the number of clusters has increased, indicating the divergent institutional development of these countries. It is due to the degree of congruence of the prevailing informal institutional environment in countries with the implemented institutional modernizations, which creates various complicating, inhibitory and contradictory institutional dysfunctions or traps that should become an object of further institutional reform.
\end{abstract}

Keywords: market transformations of post-socialist countries, institutional changes, institutional dysfunctions, convergent-divergent institutional development.

JEL clasification: $B 41, B 52, C 38, D 02, E 02, O 43, O 57$

Citation: Grazhevska, N., Gaidai, T., Mostepaniuk, A., Zavazhenko, A. (2021). Institutional dysfunctions as a factor of convergent-divergent institutional development of post-socialist countries. Access to science, business, innovation in digital economy, ACCESS Press, 2(3): 290-308. https://doi.org/10.46656/access.2021.2.3(7)

\section{INTRODUCTION}

The general institutional orientation of development of post-socialist countries is determined by the joint strategy of systemic institutional changes in the direction of creating a modern developed and effective institutional structure of market economy, which would promote sustainable economic development, global competitiveness of national economies and social welfare. However, the similarity of the initial conditions at

\footnotetext{
${ }^{*}$ Corresponding author, Andrii Zavazhenko - zavazhenko96@gmail.com
} 
the beginning of transformation processes in post-socialist countries and the commonality of strategic goals did not lead to a general convergence of their institutional development and an achievement of the same socio-economic results. Particular countries (Latvia, Lithuania, Estonia, East Germany and others) have achieved sustainable and irreversible results of institutional reforms, which has had a positive impact on the pace and results of their economic development. In other countries, in particular the post-Soviet countries, the issue on forming rather than imitating a real and efficient market environment is still pressing.

At the same time, the experience of market reform in post-socialist countries has shown that institutional changes aimed at replacing inefficient weak institutions with new effective and strong ones, unfortunately, have not been fully implemented in a number of transformational economies. The divergence of institutional development of these countries was demonstrated by the fact that new market-entrepreneurial economic relations, formed in an imperfect institutional environment, acquired specific signs of quasi-market and took root as defective or deviant informal interactions associated with the shadow economy, corruption, evasion of tax and payments, other anomalies. The realization that persistent inefficient norms may emerge in the process of market transformation has drawn researchers' attention to the phenomenon of institutional dysfunctions and traps, as well as to studying the mechanisms of their emergence and overcoming.

These problems are especially relevant at the present stage of institutional modernization of post-socialist economies, the institutional environment of which is in a state of deep qualitative systemic transformations that have been going on since the early 1990s. Scientific understanding of causes of the emergence, rooting and reproduction of institutional dysfunctions and traps and accordingly developed required recommendations for the formation of effective institutional design of these economies have important theoretical and practical significance to ensure their sustainable economic development, improving the welfare of the population, increasing global competitiveness and full integration into the world economy.

Despite the available theoretical studies of institutional dysfunctions, currently, the uncertain aspects of the problem include the elucidation of preconditions, factors and cumulative consequences of institutional dysfunctions of market transformations of post-socialist economies in their complexity and variability, which cause convergent-divergent trajectories of institutional changes, differences in the institutional design of their economies and as a result, differences in economic growth and quality of socio-economic development. An in-depth theoretical study and practical solution to this problem will be important in overcoming the systemic institutional shortcomings that hinder the positive socio-economic dynamics of these countries and their further effective institutional modernization.

The purpose of the paper is to develop and test the hypothesis on the convergent-divergent institutional development of post-socialist countries due to the emergence and consolidation of institutional dysfunctions in the context of ongoing market transformations. The latter makes it possible to suggest practical recommendations for improving the priority areas of institutional reformation of these countries. 
The significance of the paper is in the implementation of a comparative analysis to study the specifics of institutional development within countries of the former socialist camp and identify the factors that lead convergent-divergent institutional changes in mentioned countries.

The conceptual and methodological basis of this paper includes scientific approaches developed within the framework of modern economic comparative studies, economic transitology and new institutional economics. The study was conducted using the comparative institutional analysis and following statistical methods: comparison of averages, graphical, correlation analysis and clustering.

\section{LITERATURE REVIEW}

The period of transition from a command-administrative centrally managed economy to a modern market economy in a number of countries in Eastern Europe and Asia over the past 30 years is of considerable interest to representatives of economic comparative studies, economic transitology and others. At the same time, the attention of many researchers is drawn to the problems of long-term stagnation of post-socialist economies due to the inefficiency of the institutional environment formed during the transition period.

As known, the conceptual and methodological foundations of the study of the institutional structure and dynamics of economic systems have been developed by leaders and representatives of modern institutional economic theory. However, in our opinion, the most prominent in this sense are the theoretical achievements of the leader of the institutional-evolutionary approach of the new institutional economics and the recipient of the Nobel Memorial Prize in Economic Sciences - D. North. In particular, D. North developed the theory of institutional change, had made a significant contribution to the categorical definition of the concept of "institution" as "humanly devised constraints that structure political, economic and social interactions"; introduced a division of institutions into informal and formal and their structuring; substantiated the methodological distinction between institutions (norms and rules of the game) and organizations (players) that function and interact under conditions of institutional constraints (North 2000).

Additionally, D. North introduced the concept of "lock-in effect", caused by the ability of the institutional matrix to self-support and self-recovery. According to the researcher, this is due to the dependence of organizations on institutional constraints in which they were formed (North 2000, p. 23). Answering the question "Why are there relatively inefficient economies and what prevents them from adopting the institutions of efficient economies?", the scientist relies on the fundamental assumption that "history matters", because the historical path of a particular society largely determines the further trajectory of economic development and at the same time limits a variety of available alternatives. Thus, according to the scientist, "the sustainability of poorly functioning economies and the centuries-lasting divergent model of development have the same origin" (North 2000, p. 120). In this context, the undoubted scientific interest is carried out to the definition of divergent vectors of institutional historical development of socio-economic systems, according to D. North, based on the typology of institutional orders by the criterion of the dominant way of access to basic economic and political resources - "natural state" or "limited access orders", that are 
rent-seeking by their nature, and the alternative - "open access orders", that are competitive. The formation of the latter is a strategic goal of the institutional transformation of post-socialist countries (North, Wallis, Weingast 2009; North, Wallis, Webb, Weingast 2013).

In the context of the problem under study, the works of the famous Icelandic institutionalist T. Eggertsson on the existence of imperfect institutions within the institutional environment of individual countries, that provoke their economic backwardness, should be emphasised. Based on a systematic analysis of the preconditions and factors of formation, long-term preservation and reproduction of institutional dysfunctions, which was conducted through empirical studies of institutional changes in many countries (from Africa to Iceland), the scientist substantiated the possibilities and limits of institutional reforming of emerging economies (Eggertsson 2005).

The category of "institutional trap" was introduced into scientific use by the Russian economist V. Polterovich, who defined it as a stable inefficient, self-sustaining norm (Polterovich 1999, p. 11). The researcher offered a detailed explanation of this phenomenon, theoretically described the universal mechanisms of both formation and counteraction to institutional traps, which are the main obstacle to the successful implementation of market reforming of economy (Polterovich 2004, p. 8). The inclusion of the concept of "institutional trap" in the respectable scientific publication "The New Palgrave Dictionary of Economics" in 2007 demonstrated its entry into the broad international scientific context (Polterovich 2007, pp. 1-16). Further institutional research has proven the demand for and analytical ability of this term, which is due to the fact that it is both a rigorous scientific concept and an eloquent metaphor. Existing publications have shown that in the transition to specific model constructions, the concept of institutional trap acquires mathematical rigor and applied operationality (Balatsky, 2020).

In the last 30 years, economic and sociological institutional research has revealed the presence of socalled institutional isomorphism that is seen through differences in the implementation of institutional changes. At the same time, studies of systemic institutional transformations in post-socialist countries, which began in the 1990s and continue to this day, showed that the sources and factors of isomorphic changes can also cause divergent changes or divergences of economic development trajectories (Skott 1999). Thus, the divergence of institutional changes as an ontological and theoretical phenomenon was studied by $\mathrm{K}$. Herrmann-Pillath (Herrmann-Pillath 2006, 2009). The theoretical problem of determining the conditions under which institutional changes push economies towards homogenization or divergence was raised (Beckert, 2010), additionally, common general patterns or convergent factors and growing differences or socalled signs of divergence of their development were identified (Nell, Signorelli 2015).

The outstanding scientific significance and practical importance are noted in the study on institutional content, specifics of implementation, problems and contradictions of economic reforms in general context of formation, functioning and development of emerging markets of transitive economies (Hartwell 2015). In this context its worth mentioning a comparative study conducted by the British scientist S. Hartwell on the 
causes of divergence of implementation and economic results of transformation processes in Poland and Ukraine, based on the analysis of differences between political and economic institutions (Hartwell, 2015).

However, further scientific development requires the identification and specification of causal factors of insufficient social and economic effectiveness of institutional transformation of post-socialist countries, without which it is impossible to effectively correct its further strategy and tactics. Against this background, the research problem of convergent-divergent variability of institutional changes, in particular the impact of institutional dysfunctions, on the course of economic development of post-socialist countries becomes vital.

\subsection{Theoretical Background}

One of the prominent manifestations of institutional anomalies in the market reform can be identified as institutional traps - stable, self-sustaining, inefficient institutions that have a destructive effect on the interactions between economic entities within and outside the economic system. It should be noted, that institutional dysfunction is a more general phenomenon, that is associated with deviations and distortions, which emerge within any institutional environment (Börzel, 2016; Vashkiv, 2014). Although institutional changes can somehow reduce negative effects of institutional traps, they will not be able to fully flatten or overcome them due to the hysteresis effect. The point is that even after the complete elimination of causes of institutional traps, latter do not disappear immediately and entirely due to the heterogeneity, asynchrony and complexity of institutional change.

At the same time, the issue of determining the preconditions and factors leading to the formation of institutional dysfunctions in transformational economies is debatable. Regarding the main factors, modern researchers single out the lack of a clearly defined and well-founded long-term strategy for institutional change; unsystematic "mechanical" borrowing of elements of transformation models; imperfection and inefficiency of state regulation of the economy; making socio-economic decisions under the pressure of influence groups; transfer of transitional rent to private individuals; forcing formal institutional transformations without proper and balanced consideration of real informal restrictions; underestimation or even ignoring the complementarity of elements of the institutional environment; lack of proper preliminary assessment of the congruence degree of formal and informal institutions; lack of experience and developed algorithms for overcoming institutional inaccuracies and dysfunctions caused by them, etc. It is worth mentioning that one of the main reasons for emergence of institutional traps in transformational economies, which are undergoing radical institutional changes of the revolutionary type, is considered to be the predominance of informal institutions over formal ones.

With regard to post-socialist countries, it is about forming and consolidating of following institutional dysfunctions: sustainable shadowing of the economy; tax evasion; economic and political corruption; poor specification and insufficient level of institutional support for the protection of property rights, raiding; tolerance of corruption and other violations of the rule of law at the level of public consciousness; low intensity of competition, administrative barriers; bureaucratization and high status rent; low level of 
economic freedom; the predominance of rent-seeking model of economic behaviour over entrepreneurial; insufficient innovation and investment activity of entrepreneurship; underdevelopment of small business; high transaction costs in the economy; brain drain and capital outflow; low institutional efficiency of power, "appropriation" of the state by pressure groups or special interests, imitation of market reforms; low economic and social return of transformation and modernization; the famous "poverty trap": low incomes $\rightarrow$ low savings $\rightarrow$ low levels of investment $\rightarrow$ low levels of innovation $\rightarrow$ low productivity $\rightarrow$ low production efficiency $\rightarrow$ low primary and secondary incomes; low investment in human capital and low efficiency of the state socio-economic policy: healthcare, social protection, education, science and communal services etc.

As for the mechanism of institutional traps setting, it can be formalized as follows: the effect of coordination is manifested through the mass introduction of ineffective informal norms $\rightarrow$ it provokes the emergence of new norms due to the effect of learning $\rightarrow$ ineffective norms continue to be combined with other elements of the institutional environment or even with existing institutional traps as a result of the intensification of the combination effect $\rightarrow$ the lobbying effect associated with the selfish behaviour of certain stakeholders, formed by them resists any attempt to eliminate institutional anomalies $\rightarrow$ after a certain period of time, due to the effect of cultural inertia, society no longer sees alternatives to institutional dysfunction $\rightarrow$ hence the effect of hysteresis appears, according to which the institutional trap is fixed and reproduced in further reform.

It is important to note that the exit problem of transition economies from institutional traps is also debatable. According to many researchers, this solution is usually not associated with the complete removal of the institutional trap, but rather minimizes the level of its destructive impact on the institutional environment, because according to the hysteresis effect even after eradicating the causes of the institutional trap, its complete elimination is impossible (Polterovich, 1999, p. 12). For example, such an institutional trap as corruption is found in almost every economy, but some countries feel almost no negative impact of it, while others suffer significant economic and social losses from it.

An analysis of the theory and practice of systemic market transformations in post-socialist economies shows that overcoming of institutional traps involves processes of institutional change that can be implemented in two ways. Firstly - evolutionary way, which does not require active actions on the part of economic actors, because inefficient institution and all associated negative effects disappear due to cyclical processes or the gradual emergence and rooting of new more progressive values of society in the process of generational change. This mechanism of institutional change is inherent in the evolutionary-genetic formation and development of the institutional system. The determining factor is the lower level of costs associated with the adaptation of the new institution, compared with the costs of operating the old inefficient norm.

Secondly, institutional changes can be revolutionized, involving a complete revision and replacement of ineffective norms as a result of radical institutional reforms based on the reproduction or borrowing (importation) of desired institutional patterns. In the case of transitive post-socialist economies, it is about 
rapid intensive or radical institutional changes, which are usually implemented through institutional innovations following the patterns of economically developed countries.

However, this version of institutional change is much more complex and objectively more controversial. First, it does not imitate, but changes the previous trajectory of development. Second, it involves the complex interaction of old informal institutions, bearing the hallmarks of past economic experience, with the newly created formal institutional framework. Third, this version of institutional change emphasizes the role of the state, because it fixes many crucial functions, namely: authorizing the choice of the optimal institutional model; organizational and legal support and implementation of this process; tracking its effectiveness; making the necessary adjustments and eliminating the negative consequences. It is about a rather fast centralized breaking of "old" institutions by the state or on its behalf by separate groups with simultaneous disappearing of relevant institutional traps (Vashkiv ,2014, p. 122-123). Thus, the evolutionary scenario of overcoming the institutional trap assumes passive long-term counteraction through the gradual institutional development, while the revolutionary scenario is based on the active application of institutional reforms by stakeholders in order to transform the existing institutional environment.

The complexity and contradiction of the process of so-called revolutionary institutional change are embodied in a wide range of new theoretical problems: institutional risks, institutional dysfunctions and traps, institutional adaptation, institutional trade-offs, the market for institutional innovation and borrowing, rational selection of the most effective institutional borrowing and others. This determines the orientation of researchers to find more organic (non-mechanical) ways of institutional design. In view of this, scholars do not raise the issue of borrowing (importing) institutions, but of their cultivation on their own ethno-national and socio-cultural grounds.

As the experience of practical implementation of post-socialist market transformations of the last three decades shows, the task of adapting the new institutional framework to national-historical and socioeconomic features of the national economic system is extremely difficult. The effectiveness of institutional reform is determined by the degree of correspondence or congruence of the existing and prevailing in the country informal institutional environment with the implemented institutional innovations.

Mentioned above is the most important and complex aspect that should be considered in more detail. The fact is that the institutional structure of the transitive economy is formed by a set of old (inherited from previous stages of historical development) and new (produced at the result of institutional reforms) formal and informal institutions. The latter are traditions, established customs, unwritten codes of conduct, religious cults, moral and ethical norms, economic ethics, cultural heritage, mentality, etc. According to J. Hodgson, they define a social organization, "which through tradition, custom ... forms long-term routine patterns of behaviour" (Hodgson, 2003, p. 37). In this context, routine means stability, inertia, immobility in historical time, the constant reproducibility of elements of the institutional environment. It is important to mention that in particular informal institutions provide these qualities to the institutional environment, ensuring the genetic continuity of the historical and national-cultural development of social communities. 
It is clear that the mutual congruence of the informal institutional environment, that left after the command-and-control system and the newly created formal institutions is rather low. The mentioned above had led to the comparative complexity and contradiction of institutional innovation in post-socialist countries. The problem is exacerbated by the more conservative nature of informal restrictions, such as customs or norms of behaviour that cannot be changed immediately. As noted by T. Veblen, "the usual way of thinking of people ... tends to prolong its own existence indefinitely" (Veblen, 1984, p. 202).

Thus, it is important for the transitive economy to what extent the new institutional framework is compatible with existing informal institutions. Different variants of their interaction are possible: first, convergence of old and new institutional norms, which determines the positive evolutionary convergence of post-socialist economies, caused by the capacity of new imported institutions; secondly, the partial institutional incompatibility of old and new institutional norms, which results in the negative evolutionary convergence of post-socialist economies based on the establishment of inefficient and incapable institutions; third, divergence - that is, differences, incompatibilities of institutional development trajectories of former socialist countries. Since, unfortunately, the manifestations of such divergence are observed in a number of post-socialist countries, they should be the subject of further institutional research.

The contradiction of the consequences of market transformation in these countries is fundamentally rooted in the incongruence of the informal institutional background and borrowed or imported formal market institutions. A significant complicating and inhibiting factor in this regard is the interaction of new markettype institutional formations with the traditions, customs, norms of economic ethics, features of economic mentality, which were formed in the command-administrative system.

Manifestation of contradictory interaction of formal and informal institutions is the emergence of signs of "intermediate" type of market economy on the ruins of the command-administrative system - the one that has formal market attributes (institutional imitation), but does not really function according to market laws and principles (lack of competition as the main regulator of market processes, equal access to the industry and economic resources, full openness of market information, equal distancing from government structures, true business motivation, etc.). Institutional defects appear in the dominance of regional and sectoral oligarchic groups, excessive concentration of power and property; merging financial-industrial with state-bureaucratic elites. These phenomena and ways to overcome them should be the subject of careful and impartial study in positive and normative economic theory.

Defective institutional structure does not allow to use the advantages and incentives inherent in the market system, as it is characterized by the strong government regulation, dependence of the state on elite groups, their competition for privileges in the form of subsidies and other benefits, etc. Such an economy, while retaining the characteristics of both market and command, is neither one nor the other, and its economic efficiency is much lower compared to market or planned economic systems. Therefore, the consistent weakening and eventual elimination of the existing negative signs will contribute to the creation of conditions for effective economic development. 


\section{RESEARCH METHOLOGY AND RESULTS}

To achieve the goal of the theoretical study, a hypothesis was developed on the existence of a divergent impact of institutional dysfunctions on the dynamics of economic development of post-socialist countries. In order to prove or reject the hypothesis, it was decided to apply a comparative analysis of the indicators of the institutional environment quality of 19 post-socialist countries.

The following indicators were selected for comparative analysis:

- Index of Economic Freedom (IoEF) as an indicator of control over economic activity in accordance with the established institutional constraints, published by the Wall Street Journal and the Heritage Foundation. This figure varies from 0 to 100 . The zero value corresponds to despotism, and 100 - to countries with free economies. In the context of the study, the low value of this indicator is evidence of institutional dysfunctions, such as low intensity of competition, administrative barriers, the predominance of a rentseeking model of economic behaviour over entrepreneurial etc.;

- Fragile States Index (FSI) as an indicator of institutional efficiency of the government and security in the country according to the data provided by the Fund for Peace. This indicator varies from 0 to 120 . Accordingly, the zero value is typical for very stable states, and 120 - for very anxious. In the context of the analysis, the high value of this indicator proves the existence of such institutional dysfunctions as low institutional efficiency of the government, "appropriation" of the state by pressure groups or special interests etc.;

- Property Rights Index (PRI) as an indicator of institutional support for the protection of property rights of economic entities according to the data of the Property Rights Alliance. This indicator varies from 0 to 10. A value of zero describes the lack of institutional support for the protection of property rights, and $10-$ indicates proper institutional support. In the context of this paper, the low value of this indicator demonstrates insufficient specification and protection of property rights of economic entities, the spread of raiding;

- Corruption Perceptions Index (CPI) as an indicator that comprehensively characterizes both the informal institutional environment, which determines the level of tolerance of society to corruption, and the state's anti-corruption policy and its effectiveness according to the Transparency International. This indicator varies from 0 to 100. Therefore, the zero value is typical for highly corrupted countries, and 100 - for countries where it is absent. In the context of the analysis, the low value of this indicator is evidence of persistent and rooted economic and political corruption.

The selected institutional indicators, on the one hand, characterize the quality of the institutional environment formed in the transformational economies of post-socialist countries. Therefore, they can be projections of the presence or absence of significant institutional dysfunctions in the studied economies. On the other hand, these indicators are important in the context of defining the determinants of the institutional changes trajectories in the economies of these countries, as well as drivers of their economic development. 
In order to provide a significant contribution to the current scientific literature and obtain practically important results, time interval: 2010 and 2019 was chosen for the study. The authors' choice of this time interval can be supported by the following reasons and considerations. First, the institutional environments of post-socialist countries underwent through significant restructuring during the 1990s, and during the first decade of the new millennium they were generally formed on the basis of their own immanent and endogenous trajectories of institutional development, which in turn was accompanied by further active deployment of convergent-divergent processes. Secondly, the choice of 2010 and 2019 to characterize the institutional development of these countries is due to the fact that in 2010 national economies began to stabilize their functioning after the global financial crisis, and 2019 is the last year of stable development before the global Covid-19 pandemic and the following global Covid-19 crisis of the world economy. The latter is a specific exogenous factor that has negatively affected the economic development of the world, the impact of which should be eliminated in the proposed study.

Thus, it is about the adequacy and reality of the obtained results, that describe the institutional factors of economic development of 19 analysed post-socialist countries during the second decade of the XXI century (table 1).

Table 1. Statistical Sample of Analyzed Indicators

\begin{tabular}{|c|c|c|c|c|c|c|c|c|}
\hline \multirow{2}{*}{ Country } & \multicolumn{4}{|c|}{$\mathbf{2 0 1 0}$} & \multicolumn{4}{|c|}{$\mathbf{2 0 1 9}$} \\
\cline { 2 - 9 } & IoEF & FSI & PRI & CPI & IoEF & FSI & PRI & CPI \\
\hline Albania & 66 & 66,1 & 3,799 & 33 & 66,9 & 58,8 & 4,546 & 35 \\
\hline Armenia & 69,2 & 72,3 & 3,839 & 26 & 70,6 & 64,2 & 4,812 & 42 \\
\hline Azerbaijan & 58,8 & 81,9 & 3,983 & 24 & 69,3 & 71,3 & 5,12 & 30 \\
\hline Bulgaria & 62,3 & 59 & 5,239 & 36 & 70,2 & 49,2 & 5,569 & 43 \\
\hline Croatia & 59,2 & 57,3 & 4,901 & 41 & 62,2 & 46,1 & 5,168 & 47 \\
\hline Czech Republic & 69,8 & 42,4 & 6,231 & 46 & 74,8 & 35,7 & 7,029 & 56 \\
\hline Estonia & 74,7 & 49,3 & 6,665 & 65 & 77,7 & 38,5 & 7,173 & 74 \\
\hline Georgia & 70,4 & 86,4 & 3,75 & 38 & 77,1 & 71,2 & 5,247 & 56 \\
\hline Hungary & 66,1 & 48,7 & 6,461 & 47 & 66,4 & 47,6 & 6,218 & 44 \\
\hline Kazakhstan & 61,3 & 70,2 & 4,311 & 29 & 69,6 & 59,8 & 4,855 & 34 \\
\hline Latvia & 66,2 & 54,2 & 5,448 & 43 & 71,9 & 42,3 & 5,936 & 56 \\
\hline Lithuania & 70,3 & 45,3 & 6,165 & 50 & 76,7 & 36,5 & 6,46 & 60 \\
\hline Moldova & 53,7 & 81,2 & 3,841 & 25 & 62 & 66 & 4,221 & 32 \\
\hline Poland & 64,2 & 46,8 & 5,549 & 53 & 69,1 & 41 & 5,996 & 58 \\
\hline Romania & 63,2 & 59,8 & 5,378 & 37 & 69,7 & 46,7 & 6,028 & 44 \\
\hline Russian Federation & 50,3 & 77,7 & 4,299 & 21 & 61 & 72,6 & 4,989 & 28 \\
\hline Slovak Republic & 69,7 & 47,1 & 6,373 & 43 & 66,8 & 38,2 & 6,386 & 50 \\
\hline Slovenia & 64,7 & 35,5 & 5,579 & 64 & 67,8 & 25,8 & 6,102 & 60 \\
\hline Ukraine & 46,4 & 69 & 4,149 & 24 & 54,9 & 69 & 4,432 & 30 \\
\hline
\end{tabular}

Source: Corruption Perceptions Index Data, Fragile State Index Data, Index of Economic Freedom Data, International Property

$$
\text { Rights Index Data }
$$

It should be noted that the selected indicators are calculated in index values. In this case, 3 out of 4 indicators are stimulants, meaning that with a quantitative increase their result improves, and for the Fragile States Index - on the contrary, the result progresses with a decrease in its value, so it is a destimulant. This necessitates the standardization of data (table 2). 
Table 2. Standardized Data

\begin{tabular}{|c|c|c|c|c|c|c|c|c|}
\hline \multirow{2}{*}{ Country } & \multicolumn{9}{|c|}{$\mathbf{2 0 1 0}$} & \multicolumn{4}{c|}{$\mathbf{2 0 1 9}$} \\
\cline { 2 - 9 } & IoEF & FSI & PRI & CPI & IoEF & FSI & PRI & CPI \\
\hline Albania & 1,039 & 0,916 & 0,752 & 0,842 & 0,974 & 0,878 & 0,813 & 0,757 \\
\hline Armenia & 1,09 & 0,837 & 0,76 & 0,663 & 1,028 & 0,804 & 0,860 & 0,908 \\
\hline Azerbaijan & 0,926 & 0,739 & 0,789 & 0,612 & 1,009 & 0,724 & 0,915 & 0,648 \\
\hline Bulgaria & 0,981 & 1,026 & 1,037 & 0,918 & 1,022 & 1,049 & 0,996 & 0,929 \\
\hline Croatia & 0,932 & 1,056 & 0,97 & 1,046 & 0,906 & 1,119 & 0,924 & 1,016 \\
\hline Czech Republic & 1,099 & 1,428 & 1,234 & 1,173 & 1,089 & 1,446 & 1,257 & 1,210 \\
\hline Estonia & 1,176 & 1,228 & 1,32 & 1,658 & 1,132 & 1,340 & 1,282 & 1,600 \\
\hline Georgia & 1,109 & 0,701 & 0,742 & 0,969 & 1,123 & 0,725 & 0,938 & 1,210 \\
\hline Hungary & 1,041 & 1,243 & 1,279 & 1,199 & 0,967 & 1,084 & 1,112 & 0,951 \\
\hline Kazakhstan & 0,965 & 0,862 & 0,854 & 0,74 & 1,014 & 0,863 & 0,868 & 0,735 \\
\hline Latvia & 1,043 & 1,117 & 1,079 & 1,097 & 1,047 & 1,220 & 1,061 & 1,210 \\
\hline Lithuania & 1,107 & 1,336 & 1,221 & 1,275 & 1,117 & 1,414 & 1,155 & 1,297 \\
\hline Moldova & 0,846 & 0,746 & 0,761 & 0,638 & 0,903 & 0,782 & 0,755 & 0,692 \\
\hline Poland & 1,011 & 1,294 & 1,099 & 1,352 & 1,006 & 1,259 & 1,072 & 1,254 \\
\hline Romania & 0,995 & 1,012 & 1,065 & 0,944 & 1,015 & 1,105 & 1,078 & 0,951 \\
\hline Russian Federation & 0,792 & 0,779 & 0,851 & 0,536 & 0,888 & 0,711 & 0,892 & 0,605 \\
\hline Slovak Republic & 1,098 & 1,285 & 1,262 & 1,097 & 0,973 & 1,351 & 1,142 & 1,081 \\
\hline Slovenia & 1,019 & 1,705 & 1,105 & 1,632 & 0,987 & 2,000 & 1,091 & 1,297 \\
\hline Ukraine & 0,731 & 0,877 & 0,821 & 0,612 & 0,799 & 0,748 & 0,792 & 0,648 \\
\hline Source: authors' calculation based on data from table 1 & & \\
\hline
\end{tabular}

To illustrate the obtained results, the average value of standardized indicators of countries for each year were calculated separately and compared, which will help to identify positive or negative dynamics of these indicators. Thus, fig. 1 demonstrates that Moldova, the Russian Federation, and Ukraine have a low quality of institutional development among the post-socialist countries over the analysed period due to the existence of significant institutional dysfunctions. At the same time, countries that have achieved relatively higher results of post-socialist transformations (Estonia and Slovenia) demonstrate a higher quality of institutional development. The maximum rate among the analysed countries exceeds the minimum almost twice, which indicates the presence of divergent signs of institutional development of the analysed countries.

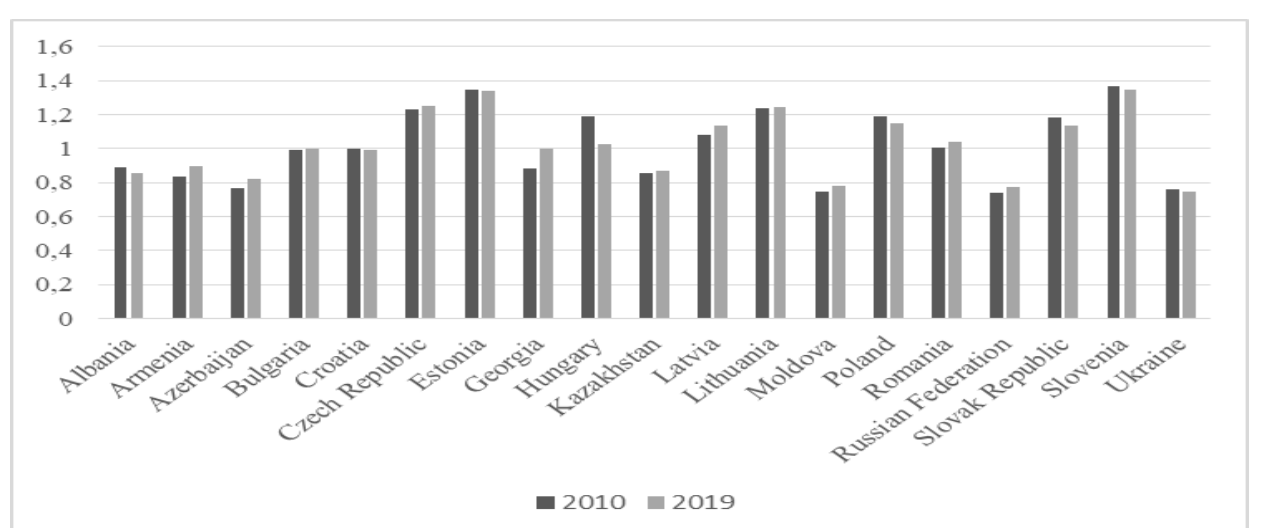

Fig. 1. Average Indicators of Institutional Development of the Analysed Post-Socialist Countries Source: authors' calculation based on data from table 2 
For a more thorough understanding of the divergence dynamics in the institutional development of the former socialist economies, that were seen over the past 30 years and evidently manifested over the past 10 years, it is necessary to analyse the dynamics of the average standardized level of institutional development for individual countries (Fig. 2).

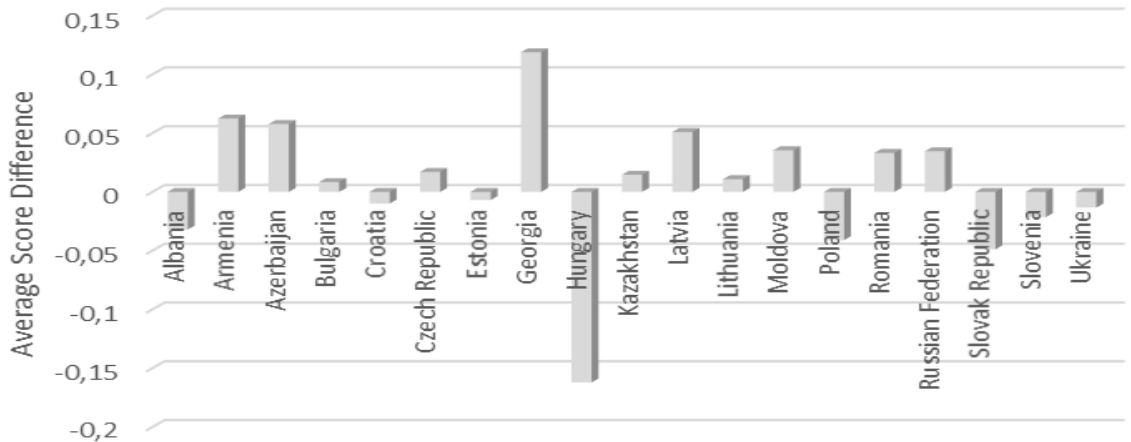

Fig. 2. Dynamics of Average Standardized Indicators of Institutional Development of the Analysed Countries Source: authors' compilation based on previous calculations

Fig. 2 shows that Georgia has achieved the greatest positive dynamics of institutional development among post-socialist countries with an average score of higher than 0.1 for each indicator. The lowest negative indicator of such development belongs to Hungary, which reduced its results by an average of 0.17 . In general, the average fluctuations of these indicators in most of the studied countries do not exceed 0.05 .

The obtained results are presented in fig. 3. It is clearly noticeable the tendency to group or cluster divergence of the results, meaning that countries are grouped by similarity of institutional development results. This necessitates further in-depth structured cluster analysis and identify groups of countries with similar institutional characteristics for each year separately in order to compare the dynamics and hence the vectors of convergent-divergent institutional development of national economies.

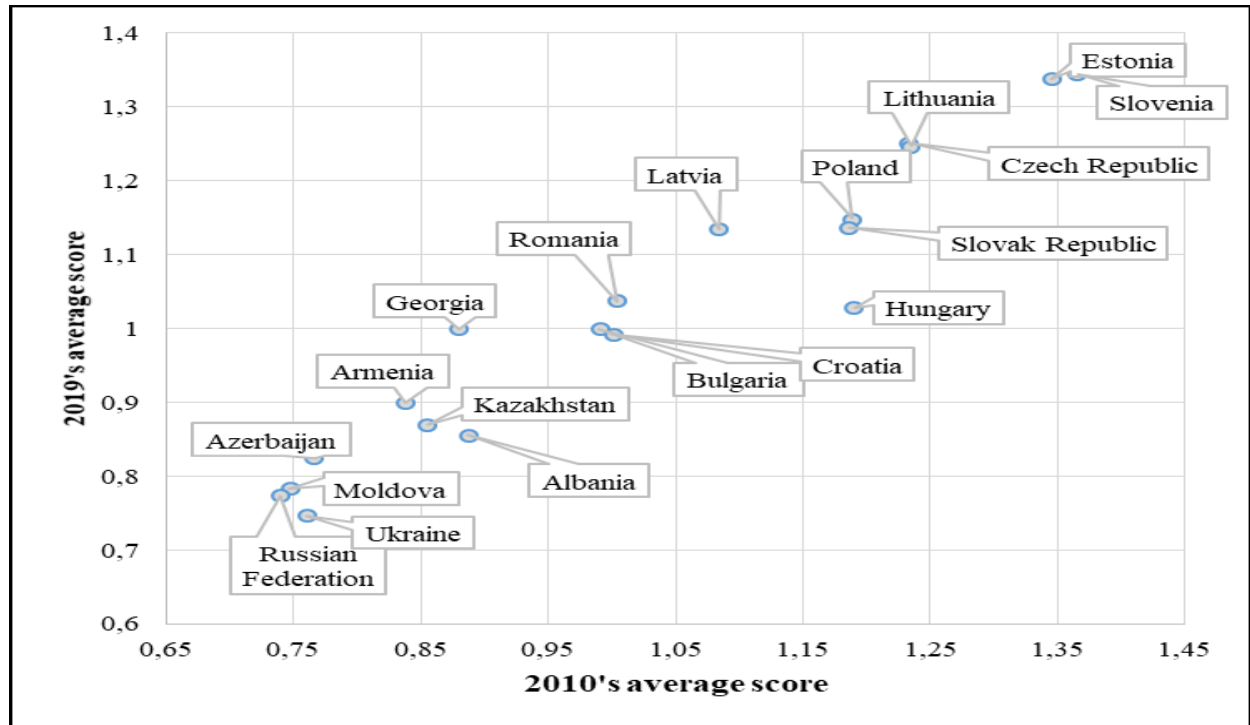

Fig. 3. Scatter Plot of Convergent-Divergent Institutional Development of the Analysed Countries Source: authors' compilation based on previous calculations 
Cluster analysis was performed using Euclidean distance and building on this basis dendrograms for each year separately in order to further compare the results. According to the obtained results of clustering, which are shown in fig. 4 and fig. 5, countries were ranked by the quality of institutional development.

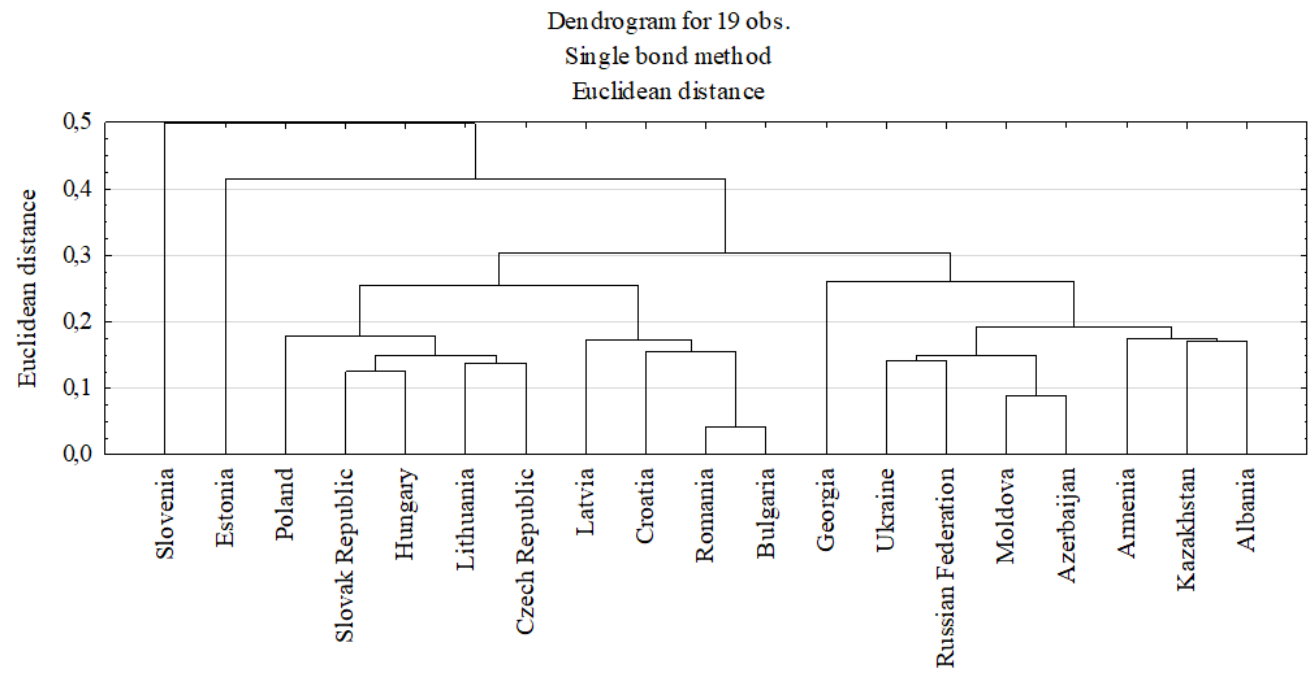

Fig. 4. Dendrogram of Institutional Development of the Analysed Post-Socialist Countries for 2010 Source: authors' compilation based on previous calculations

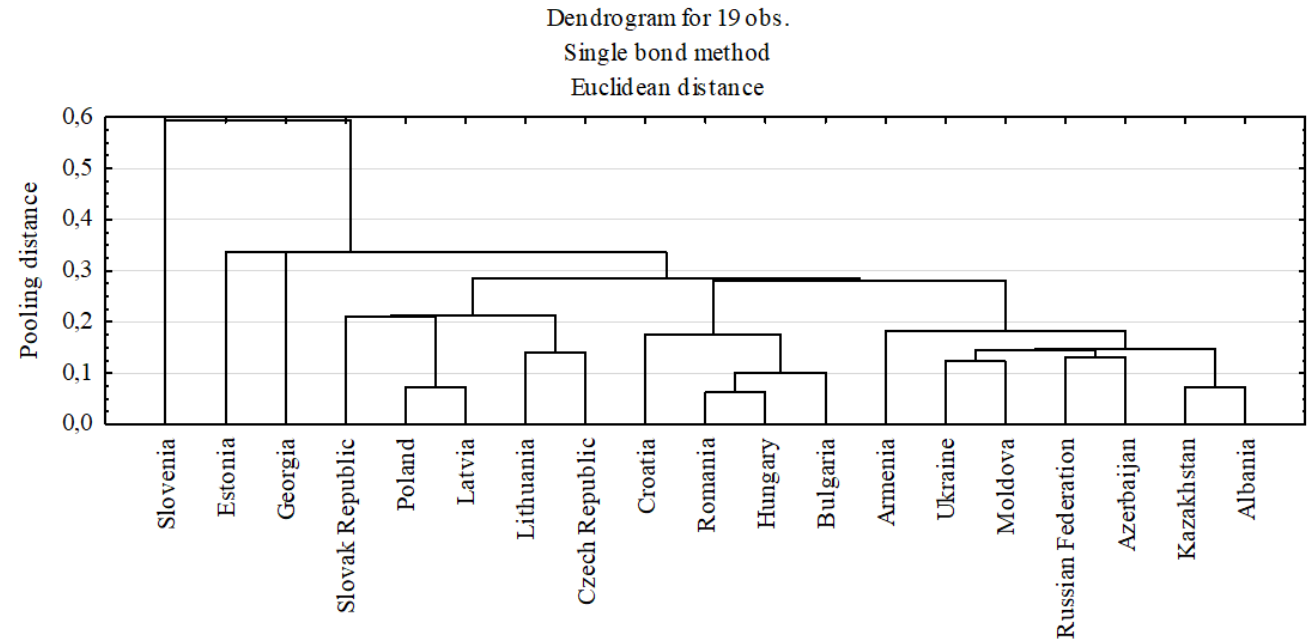

Fig. 5. Dendrogram of Institutional Development of the Analysed Post-Socialist Countries for 2019 Source: authors' compilation based on previous calculations

It should be noted that the line of demarcation between the countries along which the institutional clustering was carried out was drawn at the level of 0.19 for 2010 and 0.16 for 2019, respectively. As a result, it was found that in 2010 there were 4 clusters of post-socialist countries in terms of institutional development of economies, while in 2019 their number increased to 6. However, several sample countries show abnormally high results, which does not allow to include them in existing clusters or merge into one. 
The obtained results are shown in table 3.

Table 3. The Results of Clustering of the Analyzed Countries by the Quality of Institutional Development

\begin{tabular}{|c|c|c|c|}
\hline \multicolumn{2}{|c|}{$\mathbf{2 0 1 0}$} & \multicolumn{2}{|c|}{$\mathbf{2 0 1 9}$} \\
\hline $1^{\text {st }}$ cluster & $\begin{array}{c}\text { Albania, Armenia, } \\
\text { Kazakhstan }\end{array}$ & $1^{\text {st }}$ cluster & Albania, Kazakhstan \\
\hline $2^{\text {nd }}$ cluster & $\begin{array}{c}\text { Azerbaijan, Moldova, } \\
\text { Russian Federation, Ukraine }\end{array}$ & $2^{\text {nd }}$ cluster & $\begin{array}{c}\text { Russian Federation, } \\
\text { Azerbaijan }\end{array}$ \\
\hline $\begin{array}{c}\text { Transition } \\
\text { from } 2^{\text {nd }} \text { to } \\
3^{\text {rd }} \text { cluster }\end{array}$ & Georgia & $3^{\text {rd }}$ cluster & Ukraine, Moldova \\
\hline \multirow{2}{*}{$3^{\text {rd }}$ cluster } & $\begin{array}{c}\text { Bulgaria, Romania, Croatia, } \\
\text { Latvia }\end{array}$ & $\begin{array}{c}\text { Transition from } \\
3^{\text {rd }} \text { to } 4^{\text {th }} \text { cluster }\end{array}$ & Armenia \\
\hline \multirow{2}{*}{$4^{\text {th }}$ cluster } & $\begin{array}{c}\text { Czech Republic, Lithuania, } \\
\text { Hungary, Slovakia, Poland }\end{array}$ & $4^{\text {th }}$ cluster & $\begin{array}{c}\text { Bulgaria, Hungary, } \\
\text { Romania }\end{array}$ \\
\hline \multirow{2}{*}{ Others } & Estonia, Slovenia & $\begin{array}{c}\text { Transition from } \\
4^{\text {th }} \text { to } 5^{\text {th }} \text { cluster }\end{array}$ & Croatia \\
\cline { 3 - 4 } & & $5^{\text {th }}$ cluster & Lithuania, Czech Republic \\
\cline { 3 - 4 } & & $6^{\text {th }}$ cluster & Latvia, Poland \\
\cline { 3 - 4 } & & Others & $\begin{array}{c}\text { Estonia, Slovenia, } \\
\text { Slovakia, Georgia }\end{array}$ \\
\hline
\end{tabular}

Source: authors' compilation

According to the obtained results, over the analysed ten-year period, 13 countries changed the cluster and, accordingly, their number increased in terms of the quality of institutional development, which indicates a significant institutional divergence. Moreover, the results indicate the influence of the geopolitical factor on the formation of clusters. It is manifested in the fact that, firstly, in each cluster there is a territorial connection between countries, the only exception is the first cluster, but among its representatives there are also neighbouring countries. Secondly, if to analyse the existing clusters in more detail, it turns out that none of the European Union (EU) countries groups into the cluster with non-EU countries, which indicates the impact of this association on the institutional development of its members. To deepen the understanding of the reasons for transitions between clusters, a factor analysis was performed, which is detailed in Table $4 .{ }^{*}$

Table 4. Analysis of Institutional Factors of Countries Transitions Between Clusters

\begin{tabular}{|c|c|c|c|c|c|c|}
\hline \multirow{2}{*}{ Country } & \multicolumn{2}{|c|}{ Transition } & \multicolumn{4}{c|}{ Factor's dynamic } \\
\cline { 2 - 7 } & From & To & $\begin{array}{c}\text { Economic } \\
\text { Freedom }\end{array}$ & $\begin{array}{c}\text { Fragile } \\
\text { State }\end{array}$ & $\begin{array}{c}\text { Property } \\
\text { Rights }\end{array}$ & $\begin{array}{c}\text { Corruption } \\
\text { Perceptions }\end{array}$ \\
\hline Albania & 1 & - & $\mathbf{- 0 , 0 6 5}$ & $-0,038$ & $\mathbf{0 , 0 6 0}$ & $\mathbf{- 0 , 1 3 1}$ \\
\hline Armenia & 1 & $3 / 4$ & $\mathbf{- 0 , 0 6 2}$ & $-0,033$ & $\mathbf{0 , 1 0 0}$ & $\mathbf{0 , 2 0 8}$ \\
\hline Azerbaijan & 2 & - & $\mathbf{0 , 0 8 3}$ & $-0,015$ & $\mathbf{0 , 1 2 7}$ & 0,003 \\
\hline Bulgaria & 3 & 4 & 0,041 & 0,023 & $-0,042$ & $-0,039$ \\
\hline Croatia & 3 & $4 / 5$ & $-0,026$ & $\mathbf{0 , 0 6 3}$ & $-0,047$ & $\mathbf{- 0 , 0 8 7}$ \\
\hline Czech Republic & 4 & 5 & $-0,010$ & 0,018 & 0,023 & $-0,027$ \\
\hline Estonia & Others & - & $-0,045$ & $\mathbf{0 , 1 1 2}$ & $-0,037$ & $\mathbf{- 0 , 1 4 9}$ \\
\hline Georgia & $1 / 2$ & Others & 0,014 & 0,024 & $\mathbf{0 , 1 9 5}$ & $\mathbf{0 , 1 8 8}$ \\
\hline Hungary & 4 & 3 & $\mathbf{- 0 , 0 7 4}$ & $\mathbf{- 0 , 1 5 9}$ & $\mathbf{- 0 , 1 6 8}$ & $\mathbf{- 0 , 3 1 3}$ \\
\hline Kazakhstan & 1 & - & 0,048 & 0,001 & 0,014 & $-0,045$ \\
\hline
\end{tabular}

\footnotetext{
* Countries that have changed their cluster are highlighted in grey in the table. Standardized indicators, which have changed by more than 0.05 from the weighted average assessment each year, are in bold, and they will be taken into account to distinguish groups of indicators of institutional development of post-socialist countries.
} 


\begin{tabular}{|c|c|c|c|c|c|c|}
\hline Latvia & 3 & 6 & 0,005 & $\mathbf{0 , 1 0 3}$ & $-0,018$ & $\mathbf{0 , 1 1 4}$ \\
\hline Lithuania & 4 & 5 & 0,010 & $\mathbf{0 , 0 7 7}$ & $\mathbf{- 0 , 0 6 6}$ & $-0,048$ \\
\hline Moldova & 2 & 3 & $\mathbf{0 , 0 5 7}$ & 0,036 & $-0,006$ & 0,019 \\
\hline Poland & 4 & 6 & $-0,005$ & $-0,035$ & $-0,027$ & $\mathbf{- 0 , 1 7 2}$ \\
\hline Romania & 3 & 4 & 0,020 & $\mathbf{0 , 0 9 3}$ & 0,013 & $-0,044$ \\
\hline Russia & 2 & - & $\mathbf{0 , 0 9 6}$ & $\mathbf{- 0 , 0 6 8}$ & 0,041 & 0,040 \\
\hline Slovak Republic & 4 & Others & $\mathbf{- 0 , 1 2 5}$ & $\mathbf{0 , 0 6 6}$ & $\mathbf{- 0 , 1 2 0}$ & $\mathbf{- 0 , 0 7 6}$ \\
\hline Slovenia & Others & - & $-0,032$ & $\mathbf{0 , 2 9 5}$ & $-0,014$ & $\mathbf{- 0 , 4 2 5}$ \\
\hline Ukraine & 2 & 3 & $\mathbf{0 , 0 6 9}$ & $\mathbf{- 0 , 1 2 9}$ & $-0,029$ & 0,003 \\
\hline
\end{tabular}

Source: authors' compilation based on previous calculations

Analysing the obtained results, the following groups of institutional indicators were distinguished according to their change (table 5):

- those that influenced the transition of countries between clusters;

- those that have changed significantly in general.

Table 5. Groups of Indicators of Institutional Development in Post-Socialist Countries

\begin{tabular}{|c|c|c|c|c|c|c|c|c|}
\hline Indicator & \multicolumn{2}{|c|}{$\begin{array}{c}\text { Economic } \\
\text { Freedom }\end{array}$} & \multicolumn{2}{|c|}{ Fragile State } & \multicolumn{2}{c|}{$\begin{array}{c}\text { Property } \\
\text { Rights }\end{array}$} & \multicolumn{2}{c|}{$\begin{array}{c}\text { Corruption } \\
\text { Perceptions }\end{array}$} \\
\hline Influenced the transition between clusters & 5 & $38 \%$ & 7 & $54 \%$ & 5 & $38 \%$ & 7 & $54 \%$ \\
\hline In general, they changed by more than 0.05 & 8 & $42 \%$ & 10 & $53 \%$ & 7 & $37 \%$ & 10 & $53 \%$ \\
\hline
\end{tabular}

Source: authors' compilation based on previous calculations

Table 5 shows that the most powerful factor in the institutional development of post-socialist countries is the fight against corruption, as the main cumulative dysfunction of the institutional environment, and the provision of stable public policies, which showed similar results (both indices affected more than half of the transitions between clusters and in general changed significantly in 53\% of cases). At the same time, ensuring transparent conditions of doing business and improving mechanisms for protecting the property rights of economic entities also play an important role in the institutional development of these countries, as both of these indicators affected one in three sample countries that made the transition between clusters.

It is important to take into account that the achievement of sustainable and irreversible results of institutional market reform in the analysed countries has had a positive impact on the pace and results of their economic development. It is well-known fact that countries with the highest quality of institutional development also had higher GDP per capita.

\section{CONCLUSIONS}

Thus, a comparative analysis of the institutional development of post-socialist countries and the impact of institutional dysfunctions on the convergent-divergent nature of the latter allows us to draw the following conclusions:

1) as a result of a comparative analysis of the institutional development of 19 post-socialist countries during the second decade of the XXI century, a similarity of changes in the average levels of such development was revealed, which may indicate a cluster (convergent-divergent) relationship between the analysed countries; 
2) in order to confirm this assumption, countries were clustered using the Euclidean distance and it was found that due to different rates of institutional development of post-socialist countries the number of clusters increased over the past 10 years, from 4 to 6 , which indicates the differentiation and the divergent institutional development of these countries. However, several countries (Slovenia and Estonia in 2010 and Slovakia and Georgia, which joined them in 2019) showed abnormal results that did not allow them to be included in existing clusters, or combined into one;

3) additionally, the obtained results confirmed the existence of divergent institutional processes, as 13 analysed countries changed their cluster. At the same time, there is a general positive dynamic of institutional development of these post-socialist countries;

4) the highest quality of institutional development was demonstrated by Georgia. According to the results of clustering, Armenia and Croatia were in the transitional position between formed clusters in 2019, because their results exceed the indicators of the cluster in which they were included in 2010, but do not yet allow them to be assigned to the next cluster. However, Hungary, the only one of the analysed countries, has moved to a group of countries with a lower quality of the institutional environment;

5) during the analysed period, among the institutional development indicators of 19 post-socialist countries, the corruption perception index and the fragile states index often varied significantly, which are clear projections of institutional dysfunctions in these countries. Additionally, within the studied indicators, the index of economic freedom and the property rights index had the least impact on the quality of institutional development.

Given the above, it is possible to state the convergent-divergent nature of the institutional development of post-socialist countries. Convergent trends of such development are determined by: (1) the general direction of market reforms and a common strategy for post-socialist systemic change; (2) geopolitical factors related to the territorial proximity of countries and their membership in regional associations. In addition, the divergence of the institutional development of post-socialist countries is due to the degree of congruence of the existing and prevailing informal institutional environment in the country with the implemented institutional innovations, which is reflected in various institutional dysfunctions.

Under these circumstances, the institutional environments of these countries form their own unique trajectories of development, reflecting complex and contradictory convergent-divergent processes, when accumulated elements of the system form a unique integrity that varies from country to country and from cluster to cluster. It can be assumed that the preservation of the identified trends will lead to a further division of countries into a larger number of unique clusters, which necessitates the implementation of further research within this issue. Taking into account the correlation between the institutional and economic development of post-socialist countries that have carried out systemic market transformations, it is strategically important to focus reform efforts on overcoming institutional dysfunctions and improving the quality of their institutional environment. 


\section{Conflict of interests}

The authors declare no conflict of interest.

\section{REFERENCES}

Balatsky, E.V. (2020), "Institutional Trap: Both a Productive Concept and a Fine Metaphor", Journal of Institutional Studies, 12(3), pp. 24-41. https://www.doi.org/10.17835/2076-6297.2020.12.3.024-041

Beckert, J. (2010), "Institutional Isomorphism Revisited: Convergence and Divergence in Institutional Change", Sociological Theory, Volume 28, Issue 2. Pp. 150-166. https://doi.org/10.1111/j.1467-9558.2010.01369.x

Börzel, T. A., and Risse, T. (2016), "Dysfunctional state institutions, trust, and governance in areas of limited statehood", Regulation \& Governance, 10: 149- 160. https://doi.org/10.1111/rego.12100.

Corruption Perceptions Index Data. https://www.transparency.org/en/cpi\# (accessed 01.08.2021)

Eggertsson, T. (2005), "Imperfect institutions: possibilities and limits of reform", The University of Michigan Press, Michigan. 274 p. https://doi.org/10.3998/mpub.91126

Fragile State Index Data. URL: https://fragilestatesindex.org/data/ (accessed 01.08.2021)

Hartwell, Ch.A. (2015), “Institutional Reform: Irresistible Forces and Immovable Objects” in J. Hölscher \& H. Tomann (eds) Palgrave Dictionary of Emerging Markets and Transition Economics. Palgrave Macmillan UK. 589 p. pp. 153-169. https://doi.org/10.1007/978-1-137-37138-6_9

Hartwell, C. (2016). “Two Roads Diverge: The Transition Experience of Poland and Ukraine”, Cambridge University Press, Cambridge https://doi.org/10.1017/CBO9781316282373

Herrmann-Pillath, C. (2006), "The Divergence of Institutional Change as a Style-Theoretic Phenomenon", SSRN Electronic Journal, pp. 1-24. https://doi.org/10.2139/ssrn.948151

Herrmann-Pillath, C. (2009), “Time, Style and Institutions: An Evolutionary Approach to Institutional Diversity” in: Heinz Rieter, Joachim Zweynert (Ed.) Economic Styles in the Process of EU Eastern Enlargement, pp. 13-54. https://doi.org/10.5771/9783845217758-13

Hodgson, J. (2003), "Economic Theory and Institutions: A Manifesto for a Modern Institutional Economics", translation from English, Moscow: Delo, 464 p.

Index of Economic Freedom Data. https://www.heritage.org/index/explore (accessed 02.08.2021)

International Property Rights Index Data. https://internationalpropertyrightsindex.org/countries (accessed 02.08.2021)

Nell, G., Signorelli, M. (2015), “Convergence and Divergence” in J. Hölscher \& H. Tomann (eds) Palgrave Dictionary of Emerging Markets and Transition Economics. Palgrave Macmillan UK. 589 p. Pp. $437-457$. https://doi.org/10.1007/978-1-137-37138-6_23

North, D. C. (1991), “Institutions, “The Journal of Economic Perspectives”, 5:1, pp. 97-112. https://doi.org/10.1257/jep.5.1.97

North, D. C. (2000), “Institutions, Institutional Change and Economic Performance”, translation from English, Kyiv: Osnovy, $140 \mathrm{p}$.

North, D.C., Wallis, J.J., Weingast, B.R. (2009), "Violence and Social Orders: A Conceptual Framework for Interpreting Recorded Human History". Cambridge University Press, Cambridge. 308 p.

North, D.C., Wallis, J.J., Webb, S.B., Weingast, B.R. (eds.) (2013) "In the Shadow of Violence: Politics, Economics, and the Problems of Development”. Cambridge University Press, Cambridge. 378 p.

Polterovich, V.M. (1999), "Institutional traps and economic reforms", Ekonomika i matematicheskiye metody, Volume 35 (2), pp. 1-37.

Polterovich, V.M. (2004), “Institutional traps: is there a way out?”, Obshchestvennyye nauki i sovremennost, Issue 3, pp. 5-16.

Polterovich V. (2008), "Institutional Trap", In: Palgrave Macmillan (eds) The New Palgrave Dictionary of Economics. Palgrave Macmillan, London. https://doi.org/10.1057/978-1-349-95121-5_2717-1 
Skott, P. (1999), "Economic divergence and institutional change: some observations on the convergence literature", Journal of Economic Behavior \& Organization, Volume 39, Issue 3. pp. 235-247. https://doi.org/10.1016/S01672681(99)00034-7

Vashkiv, O.P. (2014), "Ways and obstacles to getting out of institutional traps", Rehionalna ekonomika ta problemy munitsypalnoho rozvytku: zb. mat. mizhnar. nauk.-prakt. konf. u 2-kh ch., Kyiv: Kyyivskyy ekonomichnyy naukovyy tsentr, Chapter. 2. pp. 122-124.

Veblen, T.B. (1984), "The theory of the leisure class. An economic study of institutions", translation from English, 4th Ed., Moscow: LIBROKOM, 365 p.

\title{
About the authors
}

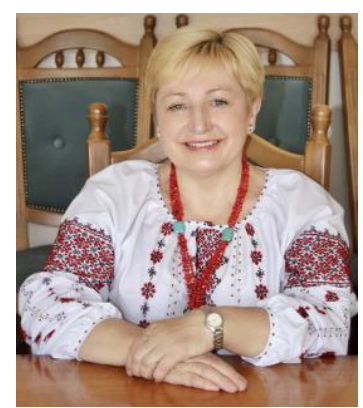

\section{Nadiia GRAZHEVSKA,}

Professor, Doctor of Economics, Department of Economic Theory, Macro- and Microeconomics, Taras Shevchenko National University of Kyiv, Kyiv, Ukraine. Research interests: theory of economic systems, economic transitology, evolutionary economics, economic comparative studies, theory of economic globalization, theory of institutional change, theory of social choice, new political economy.

ORCID ID: https://orcid.org/0000-0003-2549-8055

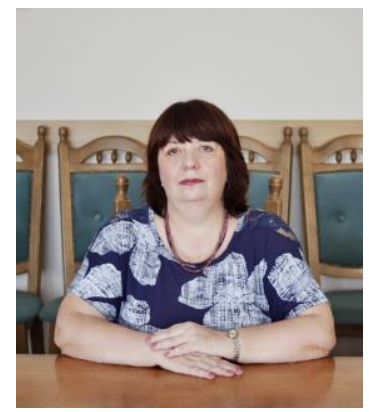

\section{Tetiana GAIDAI,}

Professor, Doctor of Economics, Department of Economic Theory, Macro- and Microeconomics, Taras Shevchenko National University of Kyiv, Kyiv, Ukraine. Research interests: philosophical and methodological problems of economics, history of economic theory, institutional economic theory.

ORCID ID: https://orcid.org/0000-0002-7413-3936

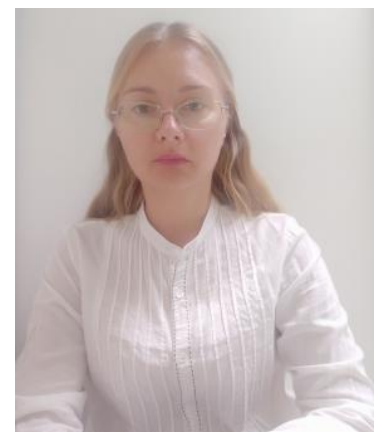

\begin{abstract}
Alla MOSTEPANIUK,
PhD (Economics), Department of Economic Theory, Macro- and Microeconomics, Taras Shevchenko National University of Kyiv, Kyiv, Ukraine. Research interests: transformation of economic systems, welfare of the population, corporate social responsibility.
\end{abstract}

ORCID ID: https://orcid.org/0000-0001-5327-2534 


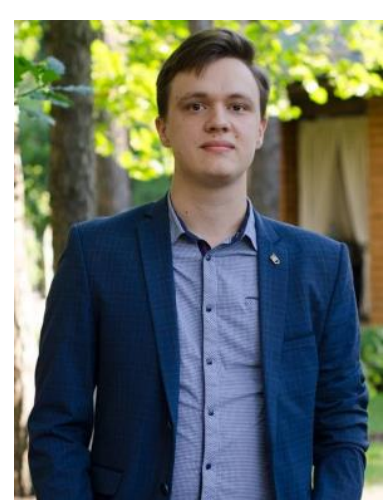

\section{Andrii ZAVAZHENKO,}

Postgraduate Student, Department of Economic Theory, Macro- and Microeconomics, Taras Shevchenko National University of Kyiv, Kyiv, Ukraine. Research interests: theory of institutional change, theory of economic systems, evolutionary economics, theory of economic globalization.

ORCID ID: https://orcid.org/0000-0002-3345-1671

Copyright ( 2020 by author(s) and ACCESS Publishing Press This work is licensed under the Creative Commons Attribution International License (CC BY) 


\title{
WHAT IS INDEPENDENCE AND HOW TO USE IT?
}

\author{
Prof. h. c. mult. Doctor h. c. mult. Fil. Dr. Jan-Urban Sandal
}

Executive Director and Owner of Fil. Dr. Jan-U. Sandal Institute

Excellence in Science and Education

Professor Chair Chernivtsi Schumpeter Centre for Economic Research, Yuriy Fedkovych Chernivtsi National

University, Chernivtsi, Ukraine

Patron of Harvard University Archives, USA

Honorary Professor Chernihiv Polytechnic National University, Chernihiv, Ukraine

Honorary Senior Fellow Science Technology and Training OMEGA Institute, Hanoi, Vietnam

Doctor Honoris Causa Alytaus Kolegija University of Applied Sciences, Alytus, Lithuania

e-mail: jan-u.sandal@janusandal.no

Received: 13 September 2021; $\quad$ Accepted: 13 September 2021; $\quad$ Published: 21 September 2021

JEL classification: A12, H11, O31

Citation: Sandal, Jan-U. (2021). What is independence and how to use it?. Access to science, business, innovation in digital economy, ACCESS Press, 2(3): 309-310. https://doi.org/10.46656/access.2021.2.3(8)

\section{Speech}

September 10, 2021

09.30 - 12.00 PLENNARY SESSION

Taras Shevchenko National University of Kyiv, Kyiv, Ukraine

International Scientific and Practical Conference

\section{“30 YEARS OF INDEPENDENCE OF UKRAINE: ACHIEVEMENTS, CHALLENGES AND PROSPECTS"}

Acting Director of the Educational and Scientific Institute of Public Administration and Civil Service of

Taras Shevchenko National University of Kyiv, Ms. Larysa Komakha has the honor to invite

Professor, Doctor of Philosophy Jan-Urban Sandal to speak at the Plenary Session of the Conference

Dear

Volodymyr Bugrov, Rector of Taras Shevchenko National University of Kyiv, Candidate of Philosophy, Professor, recipient of award for excellence in education of Ukraine, Honored Worker of Education of Ukraine, Larysa Komakha, Acting Director of the Educational and Scientific Institute of Public Administration and Civil Service of Taras Shevchenko National University of Kyiv, Doctor of Philosophy, Professor, 
Members of the main table,

Representatives of the Parliament, Verkhovna Rada of Ukraine,

Distinguished Guests,

Ladies and Gentlemen,

Today we gather in the name of science to celebrate 30 years of independence for Ukraine. Our task is to understand, on a deeper level, three decades of independence in Ukraine, the development of national parliamentarism and the challenges the nation will inevitably face on the way forward.

What is independence and how to use it is my question. The relevance and significance of the question has the quality of capturing the attention of everyone these days. Does independence mean that the president and the parliament are independent of the people? Alternatively, is it the other way around that the people now and in the future can live a good life based on democratic values and independently? Institutional arrangements that are intended to govern based on the will of the people to achieve the common good, do not necessarily or automatically reflect democratic values and way of living or individual conduct of life. Inclusive rule that constitute collecting wealth from the many to gain the few is only one of the dangers of electoral democratic superstructures as a basic and central political belief. Too often people`s trust and hope for a better world and a better life have been stopped and crushed because of political propaganda, the rule based on horrifying ideologies and religious lies. In every democracy, the dignity of the political actors depends on the acceptance of the common person. This fact contrasts with the situation regarding the entrepreneur, the creator of civilization throughout history dating back to the Neolithic Revolution as well as International Independent Science, which is the locomotive for democracy building around the world today. One should not forget that parliamentarism and political independence are the fruits of economic growth, a process that began almost three centuries ago. So how can we use independence? The method is obvious to everyone: Lay down your weapons; take up the sword, the word is the sword, but only when it represents the truth, International Independent Science is the truth, free from political propaganda, corruption and fraud, terrible ideologies and religious lies, and promotes a better life for all and peace on earth.

Rector, Acting Director, Members of the main table, Representatives of the Parliament Verkhovna Rada of Ukraine, Distinguished Guests, Ladies and Gentlemen:

Thank you very much for the attention.

Prof. h. c. mult. Doctor h. c. mult. Fil. Dr. Jan-Urban Sandal

Executive Director and Owner of Fil. Dr. Jan-U. Sandal Institute

ORCID ID 0000-0001-8072-0822 


\section{GUIDELINES FOR AUTHORS}

The submission template must be used in a mandatory manner. This journal register in the submission metadata the ORCID iD from authors.

There is no charge of any amount, either in the submission or publication of articles. Editorial team don't receive any fee. In order to maintain this collaborative activity free of charge, we place the target 120 days from the time between the reception and the publication of the articles. For this we adopted the system of continuous flow of publishing with closing of the editions in the months of May, September and January.

\section{Contribution to definition of authorship}

The recognition of authorship is based on a substantial contribution, related to the following aspects: (i) designing and delineating the study, analysis and interpretation of the data; (ii) writing or critical review relevant to the intellectual content of the manuscript; (iii) final approval of the version to be published; and (iv) responsibility for all aspects of the work, including ensuring its accuracy and integrity. All those designated as authors must meet the four criteria for authorship, and all those who meet the four criteria should be identified as authors.

At the submission checklist, is required that everyone's participation in the preparation of the manuscript and publicly assume responsibility for its content. At the end of the text of the manuscript, a paragraph should be included with the information on the contribution of each author to its elaboration.

Throughout the text, the international system of units (IS) should be used to indicate measures. The article should have the following structure:
a) Introduction;
b) Materials and Methods;
c) Results and Discussion;
d) Conclusion or Final Considerations;
e) References.

Other sections and subsections are accepted, such as the Bibliographic Review, however, the above sections are mandatory. The availability of a template for submission aims to standardize the submission format text of the journal, reducing the publishing period, and making possible the scheduled periodicity. The list of references should be presented at the end of the text, in a specific section. Do not use footnotes!

\section{General requirements for submission formatting}

The language of the article: English.

The article should be prepared and submitted of the journal in word processing program Microsoft Office Word 2003, in ".doc" format, with tables and figures included in the body of the text.

Section headings should be set in bold.

\section{METADATA}

- the author's name, surname (it is obligatory to give the author's name and surname in English according to passport data or any other IDs);

- the author's information (place of work or study, city);

- the title of the article;

- the abstract;

- $\quad$ key words (should not duplicate words from the title of the article); 
- JEL Classification;

- e-mail;

- Identifier ORCID;

- references.

\section{REQUIREMENTS FOR THE TEXT FORMATTING}

Requirements for the structure of the article (elements with text highlighting):

- general problem statement and its connection with main scientific and practical tasks (Introduction);

- analysis of recent researches and publications, which contain background for solution of the given problem and which the author relies on (Analysis of recent researches and publications);

- highlighting of previously unsettled problem constituent that is a part of the main problem, which the article is dedicated to (Previously unsettled problem constituent);

- formulation of the purpose of the article (Main purpose of the article);

- presentation of the main research material with full argumentation of received scientific results (Results and discussions);

- conclusions of the given research and perspectives for further researches in the given direction (Conclusions and further researches directions);

- References;

\section{Requirements for the article formatting:}

- the length of the article is from 10 to 15 pages (8000 words including spaces, but excluding an abstract and references);

- page format - A4 format ( $210 \times 297 \mathrm{~mm})$ page;

- page guidelines: top $-25 \mathrm{~mm}$, bottom $-25 \mathrm{~mm}$, left and right $-20 \mathrm{~mm}$.

- Alignment Justify, Line Spacing Single, Paragraph Before 0 pt, After 0 pt, Indentation Right/Left 0 pt.

- Do not use the numbering of pages.

- the article font guidelines: font size - 11-point, font type - Times New Roman, 1,5 line spacing.

\section{Requirements for formatting of the article structural elements:}

- JEL Classification (without paragraph indent, semi-bold, centered-alignment): font size - 10-point, font type - Times New Roman;

- the author's name and surname (one line space, without paragraph indent, semi-bold, centered-alignment): font size - 12-point, font type - Times New Roman;

- job of author (without paragraph indent, in italics, centered-alignment): font size - 10point, font type - Times New Roman, line spacing - 1,5;

- e-mail (without paragraph indent, in italics, centered-alignment): font size - 10-point, font type - Times New Roman;

- the title of the article (one line space, capital letters, without paragraph indent, semibold, centered-alignment): font size - 14-point, font type - Times New Roman, line spacing - 1 ;

- the abstract and key words (one line space, in italics, justified-alignment): font size 10-point, font type - Times New Roman, line spacing - 1, paragraph indent $-1 \mathrm{~cm}$;

- the text of the article (one line space, justified-alignment): font size - 11-point, font type - Times New Roman, line spacing - 1,5;

\footnotetext{
${ }^{*}$ Exceptionally, a smaller volume is allowed for doctoral students, but at least 8 pages
} 
- references: font size - 10-point, font type - Times New Roman, line spacing - 1; Paragraph spacing: before $5 \mathrm{pt}$, after $5 \mathrm{pt}$;

- identifier ORCID - end of paper (in about the authors), without paragraph indent, leftalignment: font size - 10-point, font type - Times New Roman;

- Author Photo - end of paper (JPG/JPEG format with resolution not less than $300 \mathrm{dpi}$ )

Requirements for formatting the abstract and the author's resume in English (Abstract):

Abstract should be not less than 250 words (not less than 2500 characters), arranged in one column 10 pt, font type - Times New Roman; line spacing - 1 .

Background of the research should be explained in few sentences.

Objectives: Objectives of the paper should be clearly stated in 1-2 sentences. Methods/Approach: Methods used in the paper should be explained in 1-2 sentences. Results: Results of the research should be presented in 1-2 sentences.

Conclusions: Main conclusions should be debriefed in 1-2 sentences.

\section{Requirements for formatting the references (References):}

- REFERENCES are formatting according to international bibliographical standard APA-2010 style in accordance with the specimen and requirements set on the website of the Journal.

- References should include not less than 20 sources, covering important previous works realised in the given area of interest on an international scale. References covered by major citation databases are preferred (Scopus, Web of Science).

- The reference be listed alphabetically and names of all authors should be given. Do NOT use "et al." in the list of references!

- The titles of Cirilic periodicals (journals, collections and others) are given by transliteration, and they are given in parenthesis in English;

- with obligatory citations in the text of the article, which are given in brackets in the text (alphabetically) and they appear in an order of citation or reference;

- references for the personal author's works or articles (self-citation) should not exceed more than $10 \%$ from the general number of sources.

\section{Requirements for drawing tables, pictures and formulas:}

- tables should have a serial number and a title in the middle (Table 1. Title): font size 10, interline spacing - 1, font type - Times New Roman;

- text in table: font size - 9, font type - Time New Roman; interline spacing - 1;

- pictures/ drawings must have a serial number and a name in the middle (Figure 1. Title): font size - 10, interline interval - 1, font type - Times New Roman;

- drawings are made in graphic editors, compatible with Word in the format JPG with a resolution of not less than $300 \mathrm{dpi}$;

- mathematical formulas are provided using the built-in Microsoft Equation formula editor;

- Equations and formulas are arranged in the center of the line, the number of the formula (in round brackets, on the right-hand side of the page, separated by blank lines): font size - 10, interline spacing - 1, font type - Times New Roman.

\section{Final provisions}

At the end of data on affiliation of authors of the manuscript author must specify his/her ORCID ID number (for each of the authors ORCID personal number needed) to allow the readers of this article refer to authors' publications in other journals. 


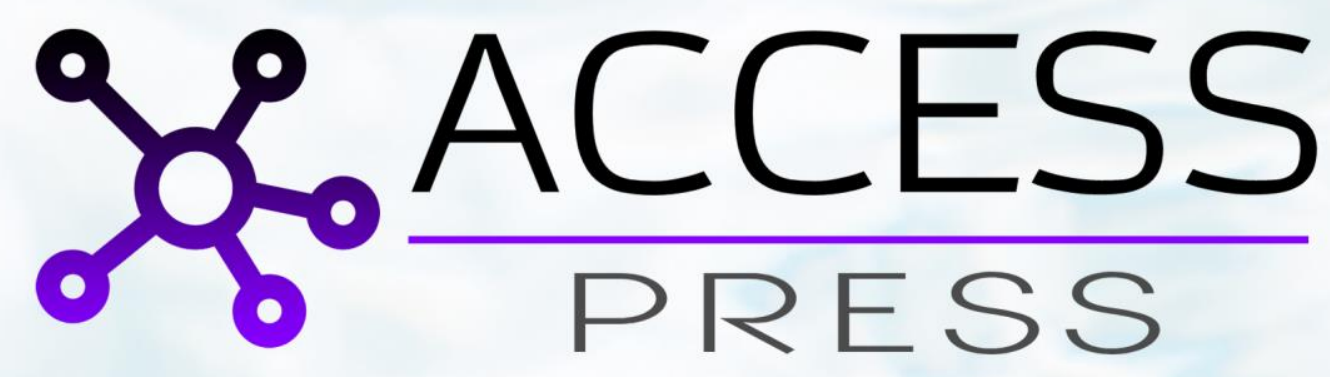

https://access-bg.org

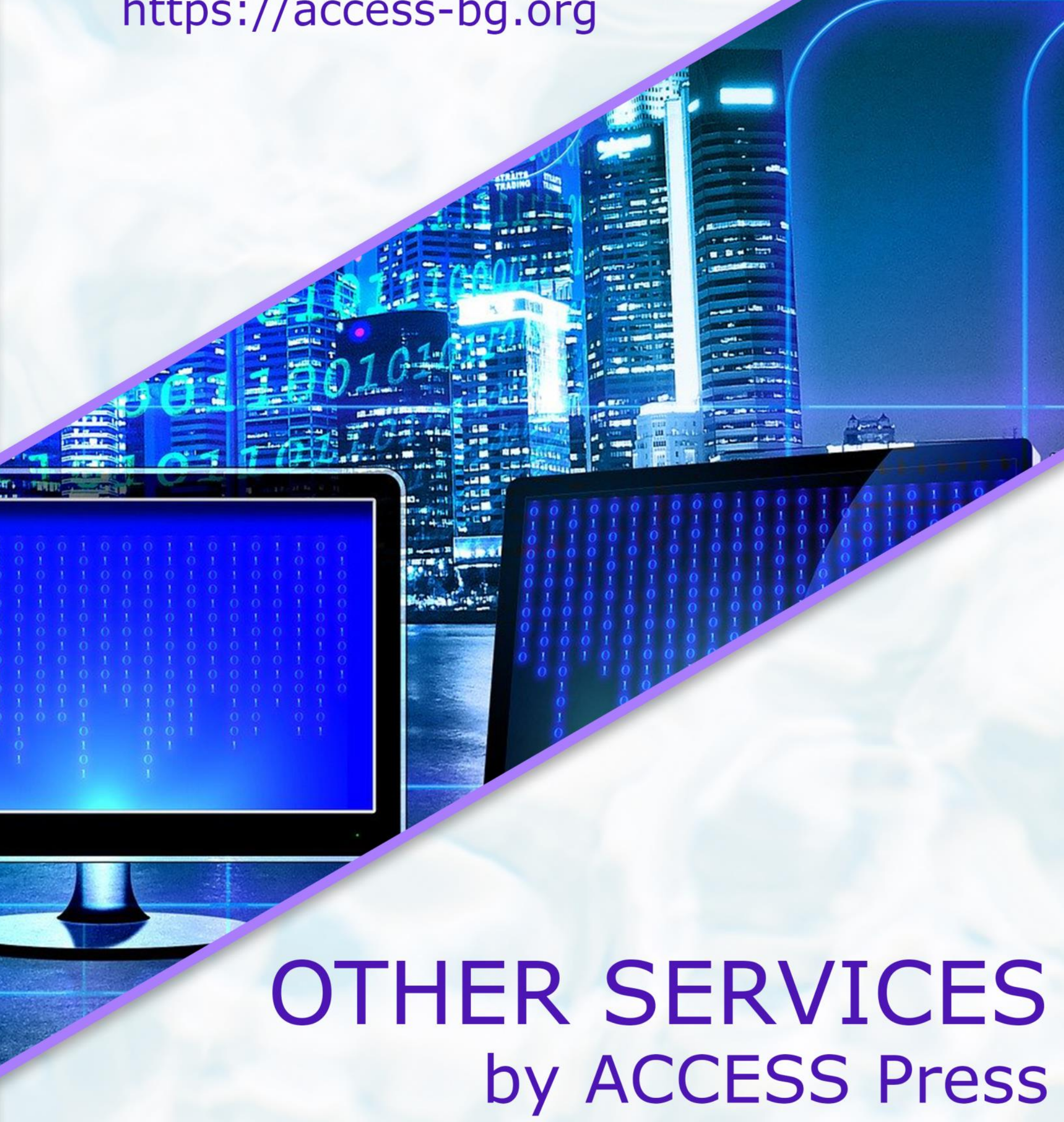




\section{E-BOOKS PUBLISHING}

ACCESS Press aims to meet public needs acting in the areas of education, life-long learning,

training, scientific research, organizing of scientific, cultural and other events.

ACCESS Press has a team with well-established experts with extensive experience in wide range of academic fields of journals, collections and books. In the Reviewer board members are scientists and experts from the countries of Europe, Russia, CIS. This provides an international expert evaluation of

the incoming scientific materials.

\section{Additional services}

ACCESS Press publishes conference abstracts and proceedings, scientific works, yearbooks, monographs, collective monograph series, journals and other literature resources, and management of scientific data sets.

Our team prepares and publishes monographs, scientific and reference literature, PhD and doctoral thesis and dissertations, conference proceedings, monographs in all languages.

We check the text for uniqueness / plagiarism as well as, if necessary, we edit and format the publication.

Publication of various academic and educational literatures enables us to develop and offer our authors european publications with foreign output data with international number ISBN/ ISSN.

We carry out the assessment of all the received articles and books quickly and we can offer optimum terms of cooperation.

When visiting Our E-books section website, you can read electronic books free of charge.

\section{SERVICES}

- Uniqueness verification (plagiarism)

- Article proofreading and editing

- Editing and formatting

- APA style

- Profile registration in ORCID, PUBLONS, Google Scholar, ResearchGate

- Increase of H-index/Work with indexing

- Assign DOIs

- Advertising

\section{Additional services}

- Positioning in a format for e-books (epub, etc.)

- DOI (Digital Object Identifier) assignation. DOI facilitates the process of search, citing and localization of scientific work.

- Inclusion of your monograph into RSCI database Elibrary.ru

- Publication with all metadata - annotation, key words, list of cited references, which will significantly increase author's rating 


\section{WHAT WE PUBLISH}

The wide range of services, we provide, allows us to guarantee a scientist a successful publication indexed in the largest scientific databases.

If you have a ready-made text of a monograph or other scientific publication and you want to publish it, you can take the opportunity of receiving the most qualitative result for the given price.

Your proposal will be evaluated by the Editor(s) and/or an external reviewer who is an expert in the fields covered. If accepted, the final manuscript also needs the approval from the Editor(s) before it is published, to ensure the quality of each book. The cost of services is calculated individually, and there is a fee for the provision of correct editing of materials for promotion in scientific journals, including consulting. The final cost of services varies according to the volume of work and urgency.

Order the service by contacting us on the website or e-mail.

\section{Advertising services}

You can contact the Editor-in-Chief for more detailed information about the financial terms of the advertising in the journal.

We invite scientists, researchers and practitioners to cooperate!

\section{Why electronic format?}

You have the foreign publication in the shortest terms, minimum term is 1 day. You have full legal rights on the intellectual property even if it is an electronic version

You receive the electronic version of your book that has absolutely the same legal properties as a printed version. The electronic version already has all necessary requisites: Bulgarian ISBN and all output data according to the international standards

Moreover, of course, the important parameter is the cost. We offer services of the European quality at the price almost coinciding with the prices in many other countries. Therefore, an electronic format of publication is an excellent option for the favorable and quick publication 


\section{PROCEEDINGS AND CONFERENCES}

ACCESS Press publishes proceedings in all major disciplines. We offer conference, symposium and workshop organizers a unique service which is not only fast and personalized, but also ensures maximum visibility for their conference and workshop proceedings.

All proceedings on the ACCESS Press platform are open access and hence freely accessible for all to read.

Where applicable, we take care that these proceedings are submitted to relevant indexation databases.

ACCESS Press adheres to the ethical frameworks and guidelines of the Committee on Publication Ethics (COPE), including the COPE Core Practices and the Principles of Transparency and Best

Practice in Scholarly Publishing

\section{Included in ACCESS Press proceedings service package}

Creation of a full-fledged web site dedicated to your conference with its own URL, including search engine, table of contents, conference details, etc.

Professional hosting service, guaranteeing 24-hour access and fast response times

Comprehensive similarity checking and plagiarism detection for all articles to be published in a proceedings

Personalized, high-quality assistance for preparing your conference and proceedings

Provision of clear instructions for authors and editors, as well as style sheets, for Word

Fast and high-quality communication with a dedicated Access Press staff member in either English,or Russian

Articles can be of any length with no restrictions on the use of colours and the possibility to add multi-media elements

Fast publication of your proceedings in less than 2 weeks

Registration of an ISBN for your proceedings publication

Inclusion in major search engines, such as Google and Google Scholar

Registration of a unique online reference (DOI) for all articles at CrossRef

Submission to relevant indexation databases 


\section{ONLINE PLATFORM FOR ELECTRONIC JOURNALS}

As ACCESS Press understands the importance of core principles of scholarly communication, the editors of journals strive to organise peer review process within 20 days, and publishing house puts effort in publishing articles usually within 2-4 weeks after acceptance.

All journals on the ACCESS Press platform follow the highest international standards on publishing ethics as described in the ethical frameworks and guidelines of the Committee on Publication Ethics (COPE). ACCESS Press is a strong advocate of integrity in science and adheres

to these guidelines in full. Moreover, we are a strong supporter of the principles of openness, transparency and reproducibility in research and an organizational signatory of the Transparency and Openness Promotion (TOP) guidelines issued by the Center for Open Science.

- Publications are reckoned by the Higher Attestation Commission as a publication in a foreign publishing house.

- European publication with foreign output data with international number ISSN.

- Prompt e-mailing of a journal's electronic version to authors.

- Every journal gets its own space on the web, and still present in the search results for the whole platform.

- Journals are published in open access mode on the publishing house site access-bg.org

We follow strict guidelines for authors and our eminent editorial board members are also dedicated to build a framework that is based on the ethics and virtues of publication. Access Press safeguards that each article is peer-reviewed and goes through a strict screening process before being published.

Detailed information about each journal can be found in their homepages.

ACCESS publishes academic journals that belong to universities, research institutes, academies of sciences, learned societies and other organizations. We can publish them both in the Open Access and in traditional (paid access) models.

We currently publish journals in the English language, but content in other languages will be considered.

We have a special offer for universities and other organizations to publish their English language journals, books and other publications. 
ACCESS Press has a special offer for universities and other organizations that are seeking a partner to publish all or some of their English language journals, books and other publications. This applies to new publications and to previously published books and previous journal volumes. We publish monographs, textbooks, edited volumes, and other categories.

The university can decide if a given journal or book is published using the Open Access or paid access model. All books and journal articles bear both the university and ACCESS logos.

ACCESS Press will design, produce and manage the website of this publishing house. The role of the university is to select and channel books and book proposals for this publishing cooperation, as well as to promote this publishing opportunity to its faculty.

The university can decide which package of services applies to each journal and book. Such packages are described in the pages for journals and books. If the value of the contract exceeds an agreed amount, the university can enjoy discounts up to $60 \%$ on standard fees.

Please contact us to discuss the terms of the ACCESS Publishing House offer.

Recently, the interest of the scientific community in the scientometric indicators impact factor, IF and impact rank, SJR, which reflect the level of citation of articles published in various journals, is increased. Inclusion of scientific journals in global indexed systems for citations Scopus and Web of Science requires the editors and publishers to meet the selection criteria, strictly established by these systems, which generally meet the international standards for the issuance of scientific periodicals. As one of the 13 criteria for selection of journals in Scopus is online accessibility - accessibility to the journal site with a mandatory English version and the quality of the journal site, the ACCESS team has created a platform for periodic electronic publications.

Each university needs objective data for assessment of the science, for making decision for further development.

Main problems of the quantity assessment of publications are an insufficient number of journals in Scopus and Web of Science. 


\section{Main features of ACCESS Journal Platform}

- Each journal has a dedicated website, which by request can have a custom design

- Journal websites have a dedicated subdomain myjournalname.access-bg.org, but by request the journal can use a dedicated domain myjournalname.com and still use the ACCESS platform

- Each journal website has informational sections - description of the journal subject, editorial board, review policy, open access policy

- Each journal website has a contact page to contact the journal team

- Each journal has an archive with all the issues and their articles

- Each journal website has a search functionality only in the context of the journal, results from the rest of the platform are not included

- By request each journal structure can be customized

- Journal websites are built in English, but by request they can be customized to be multi-language

- The main platform website has links to each journal website

- The main platform search and browse functionalities include all issues and articles from the journal websites, linking to them

- The main platform and each journal website is with responsive design and mobile-friendly

\section{Administration}

- Each journal administrator has access to a control panel to administrate their content and upload new issues

- The control panel is user-friendly and with responsive design, working equally well on all kinds of mobile and desktop devices

- Administrators can add, edit, remove issues

- Administrators can add, edit, remove articles

- Administrators can manage most of their site content 


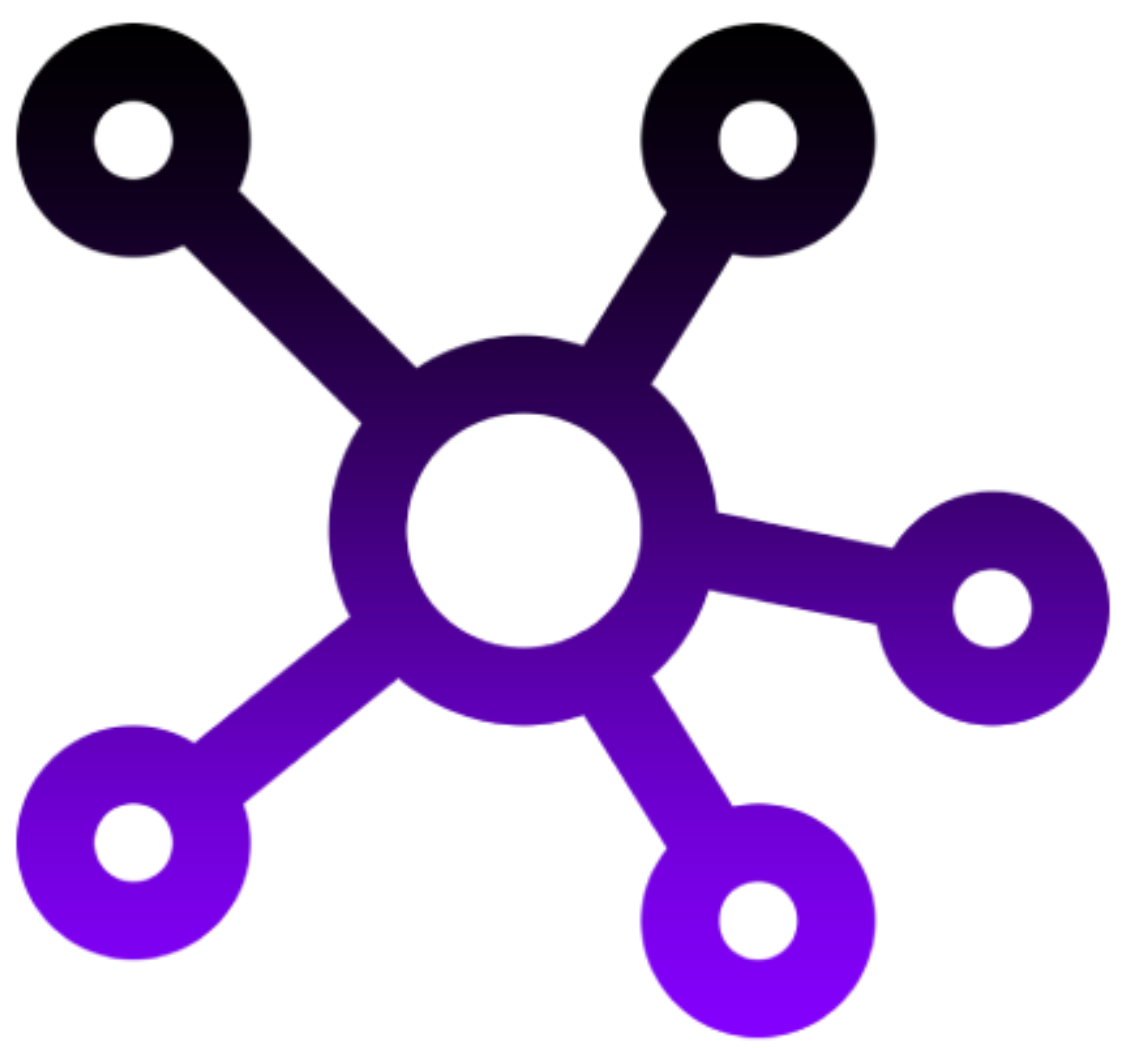

ACCESS JOURNAL

2021

Website: https://access-bg.org/

Email: office@access-bg.org; editors@access-bg.org

Phone: Bulgaria + 359 (0) 886-842-129 